\title{
WHAT IS THE INFLUENCE OF SELF-IMAGE AND PERCEIVED PARENTING ROLE EXPECTATIONS ON ADOLESCENT FATHERS' PERCEIVED ROLE PERFORMANCE?
}

\author{
BY \\ MERLE B. JONES
}

\author{
A Thesis \\ Submitted to the Faculty of Graduate Studies \\ in partial fulfilment of the requirements \\ for the Degree of
}

\section{MASTER OF NURSING}

\author{
Faculty of Nursing \\ University of Manitoba \\ Winnipeg, Manitoba
}


National Library of Canada

Acquisitions and Bibliographic Services

395 Wellington Street Ottawa ON K1A ONA Canada
Bibliothèque nationale du Canada

\section{Acquisitions et} services bibliographiques

395, ne Wellington Ottawa ON KIA ON4

Canada
The author has granted a nonexclusive licence allowing the National Library of Canada to reproduce, loan, distribute or sell copies of this thesis in microform, paper or electronic formats.

The author retains ownership of the copyright in this thesis. Neither the thesis nor substantial extracts from it may be printed or otherwise reproduced without the author's permission.
L'auteur a accordé une licence non exclusive permettant à la Bibliothèque nationale du Canada de reproduire, prêter, distribuer ou vendre des copies de cette thèse sous la forme de microfiche/film, de reproduction sur papier ou sur format électronique.

L'auteur conserve la propriété du droit d'auteur qui protège cette thèse. $\mathrm{Ni}$ la thèse ni des extraits substantiels de celle-ci ne doivent être imprimés ou autrement reproduits sans son autorisation.

\section{Canadầ}


THE UNIVERSITY OF MANITOBA

\section{FACULTY OF GRADUATE STUDIES

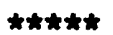

COPYRIGHT PERMISSION PAGE

What is the influence of self-image and perceived parenting role expectations on adolescent fathers' perceived role performance?

\section{BY}

Merle B. Jones

A Thesis/Practicum submitted to the Faculty of Graduate Studies of The University of Manitoba in partial fulfilment of the requirements of the degree

of

Master of Nursing

MERLE B. JONESO1999

Permission has been granted to the Library of The University of Manitoba to lend or sell copies of this thesis/practicum, to the National Library of Canada to microfilm this thesis and to lend or sell copies of the film, and to Dissertations Abstracts International to publish an abstract of this thesis/practicum.

The author reserves other publication rights, and neither this thesis/practicum nor ertensive extracts from it may be printed or otherwise reproduced without the author's written permission. 


\begin{abstract}
"Adolescent pregnancy is one of the most pressing, persistent, and poignant problems facing society" (Yoos, 1987, p. 247). Manitoba's teen pregnancy rates are among the highest in Canada. Yet, little is known about adolescent fathers and their parenting involvement. The purpose of this descriptive correlational study was to explore variables which may influence teen fathers' participation in parenting. A convenience sample of 30 adolescent fathers, whose partners were attending an Adolescent Prenatal Clinic, completed two questionnaires: Offer Self-Image - Revised, and Perceived Parenting Role Performance. Guided by family role theory, four hypotheses were examined utilizing a quantitative research method. Data analysis revealed that $30 \%$ of these respondents had a low to very low self-image. Pearson's correlation coefficient, which facilitated hypotheses testing, failed to validate a relationship between teen fathers' perceived role performance and self-image, and perceived parenting role expectations. Nevertheless, a moderate negative correlation was noted between teen fathers' self-image and their perceived parenting role expectations ( $\mathrm{r}$ $=-\cdot 35, \mathrm{p}<-05$ ). These findings contradict the philosophy of family role theory. Results of this study indicated that teen fathers want to be involved in parenting. However, unrealistic expectations and the inability to combine the developmental tasks of adolescence with the responsibilities of fatherhood increase their vulnerability to parenting failure.
\end{abstract}




\section{ACKNOWLEDGEMENTS}

To my exceptional sister, Allison, for her unwavering faith in my abilities and encouragement.

To Laurie, for his enduring patience.

Sincere thanks to my friends for their guidance, understanding and encouragement.

My sincere gratitude to Beryl, for giving so much of her time, and for patiently wading through each revision.

Special thanks to Tina Vieira who lived through this project almost as long as I have.

Sincere thanks to my thesis committee members for their guidance and encouragement.

This research was partially funded by:

The Health Sciences Centre Foundation 


\section{Table of Contents}

Abstract

Page

Acknowledgements $\quad$ v

Chapter I: Statement of the problem 1

Historical perspective 1

Developmental Aspects Related to Parenting 3

Lack of Research 4

State of Knowledge $\quad 7$

Interest and Issues $\quad 8$

Purpose of Study 10

Chapter Summary and Thesis Organization 11

Chapter II: Conceptual Framework 13

Introduction and Rationale 13

Definition of Terms $\quad 13$

Family Role Structure $\quad 16$

Patemal Role Development $\quad 17$

Operationalization of Concepts 20

Chapter Summary 21

Chapter III: Review of the Literature 22

Introduction $\quad 22$

Factors Influencing Self-Image 23

Psychosocial Development 23

Family $\quad 25$

Peers $\quad 27$

Section Summary 28

Self-Image $\quad 29$

Section Summary 33

Impact of Adolescent Development on Fatherhood 33

Section Summary $\quad 35$

Premature Fatherhood: Psychosocial Issues 35 
Social Variables of Adolescent Fatherhood 36

Psychosocial Variables of Adolescent Fatherhood 38

Locus of Control and Adolescent Fatherhood $\quad 39$

Psychosocial Consequences of Teen Fatherhood 42

Parental and Partner Influence 43

Partners/Teen Mothers' Influence on Teen Fathers 45

Section Summary 47

Adolescent Fathers' Role Performance 47

Impact of Adolescent Father's Involvement with Mother and baby 53

Effects of Teen Father's Involvement in Parenting:

Baby

Chapter Summary and Significance of Study $\quad 57$

Chapter IV: Methodology 60

Sample 61

Setting 63

Conduct of the Study 64

Institutional Access and Subject Recruitment $\quad 64$

Instrumentation/Questionnaires 67

Offer Self-Image Questionnaire Revised (OSIQ -R) 67

Reliability and Validity $\quad 70$

Questionnaire:

Perceived Role Expectations of Self and Others, and Perceived Role Performance 71

Demographic Data Sheet 73

Ethical Considerations $\quad 74$

Limitations and Strengths $\quad 76$

Chapter Summary 77

$\begin{array}{lll}\text { Chapter V: } & \text { Results } & 78\end{array}$

Sample Characteristics $\quad 78$

Miscellaneous: Abuse $\quad 81$

Parental Living Arrangements $\quad 81$

Self-Image $\quad 82$

Perceived Role Performance:

Adolescent Fathers/Partners 83

Perceived Expectations:

Fathers/Partners $\quad 84$

Perceived Expectations of Fathers/Partners:

Parents 
Hypotheses $\quad 86$

Chapter Summary $\quad 88$

Chapter VI: Discussion 89

Characteristics of Adolescent Fathers/Partners $\quad 89$

Employment Status $\quad 92$

Support 93

Adolescent Father: Abuse $\quad 93$

Self-Image $\quad 94$

Perceived Role Expectations and Role Performance 96

Perceived Role Expectations of Parents and

Partners/Teen Mothers 98

Hypotheses $\quad 99$

Implications for Role Theory $\quad 102$

Strengths and Limitations $\quad 103$

Implications for Practice $\quad 104$

Implications for Research $\quad 106$

Summary 108

$\begin{array}{ll}\text { References: } & 109\end{array}$

Appendices:

A. Request for permission to purchase OSIQ-R:

Self-Image Questionnaire

B. Letter of permission to use Questionnaire:

Role Performance and Expectations $\quad 132$

C. Demographic Data 143

D. Explanation of Study $\quad 148$

E. Consent Form 158

F. Unit Managers Approach for Participation

in Study

162

G. Ethical Approval 165

H. Institutional Access Approval $\quad 167$ 


\section{TABLES}

Table 1: $\quad$ Ethnic background of sample $\quad 79$

Table 2: $\quad$ Age distribution of subjects $\quad 79$

Table 3: $\quad$ Educational level of subjects $\quad 80$

Table 4: Employment status of sample $\quad 80$

Table 5: $\quad$ Subjects' living arrangements $\quad 81$

Table 6: $\quad$ Marital status of subjects' parents $\quad 82$

Table 7: $\quad$ Self-image scores' of subjects 83

Table 8: $\quad$ Self-image score summary 83

Table 9: Role performance/expectations: summary scores $\quad 85$

Table 10: Perceived role expectations of parents': summary of t-values $\quad 86$

Table 11: Pearson's correlation coefficient:

Hypotheses 1 - 4 


\section{FIGURES}

Figure I: Development of role behaviour 16

Figure II: Development of role behaviour for

male adolescents faced with unplanned/

unwanted pregnancy

Figure III: Operationalization of concepts 


\section{CHAPTER I}

\section{Statement Of The Problem}

"Adolescent pregnancy is one of the most pressing, persistent, and poignant problems facing society today" (Yoos, 1987, p. 247). The immediate and long term consequences of teenage pregnancy jeopardize the future well-being of not only the mother and her child, but also the father (Barth, Claycomb \& Loomis, 1987). It is almost impossible to obtain figures on the number of pregnancies involving male adolescents since all mothers do not identify the biological father (Barret \& Robinson, 1985). Berland (1987), estimates that each year in Canada, 40,000 adolescent males become fathers.

Despite the large number of adolescent fathers, and the negative consequences of premature fatherhood, the father's role has been virtually ignored. According to Christmon (1990), the father's role in teenage pregnancy has traditionally been discredited. Although this is slowly changing, investigators have highlighted the omission of the adolescent father by referring to him as 'the forgotten half' (Barret \& Robinson, 1986; Leashore, 1979). To understand teenage pregnancy in its entirety, greater attention must be focused on adolescent fathers (Redmond, 1985).

\section{Historical Perspective: Adolescent Fathers}

It is known that teens, due to the nature of their development, seldom possess the maturity to understand the long-term repercussions of unprotected intercourse and premature parenting (Spivak \& Weitzman, 1987). According to Sarrel (1967), teenage pregnancy begins a cycle consisting of failure to complete education, dependence on a 
social welfare system, inability to create a stable family life, and continues with subsequent pregnancies. Much of the ongoing and increased attention on adolescent fathers has been associared with three factors. The first factor to gain attention is often disregarded, but vitally important, namely involving males in any program to combat adolescent pregnancy and its repercussions. Sometimes "...it is forgotten that it takes two to create a human" (Haskins, 1984, p. 160).

The second factor, the parental rights of unwed fathers, has received much attention. The proliferation of court cases by unwed fathers in the United States has served to increase public awareness of these young fathers' plight (Christmon, 1987). The plight young fathers face, includes lack of involvement and/or consultation when future care or custody of their children is being considered. This was illustrated in two landmark cases during the 1960 's. Both cases went all the way to the United States Supreme Court, which ruled in favour of the unwed fathers' parental right to be heard (Leashore, 1979; Pannor \& Evans, 1975). Thus, the tone was set for inclusion of all fathers, including adolescent fathers, when the decisions are being made concerning custody of children.

Finally, the extraordinary interest of social scientists and other related disciplines in fatherhood has consequently promoted interest in adolescent fathers. Recent investigations have focused on assessing the problems of adolescent pregnancy and the relationship between adolescent fathers and their children. These investigations are dispelling some of the doctrine and conventional wisdom which guided and defined health care of pregnant adolescents. Additionally, in the face of the changing fatherhood 
role, men are being urged to play a more active role in their childrens' lives. Fathers are becoming more involved during pregnancy by accompanying their partners to prenatal clinics and childbirth classes. According to Fein (1978), “... increasing numbers of men have begun to reach out for more sustaining relationships with children in their lives" (p. 122).

\section{Developmental Aspects Related to Parenting: Adolescent Fathers}

Adolescence has long been described as a period of transition between childhood and adulthood in which developmental tasks, whether successfully or unsuccessfully completed, result in social and personal change (Taucher, 1991). In his search for independence and individuality, the adolescent male experiences a high level of stress and instability which are compounded by the responsibilities and psychosocial consequences of premature fatherhood (Castiglia, 1990). The term "premature fatherhood" is frequently used by researchers since it denotes adolescents' immaturity and unreadiness to become fathers. Premature fatherhood may impede the male adolescent's search for independence, and culminate in abandonment of future goals. As a result, he may be forced to remain in a dependent role due to lack of emotional, social, and financial resources (Auvenshine \& Enriquez, 1985; Smith, 1984; Taucher 1991). However, other investigators have found that precocious fatherhood is not correlated with helplessness, but is related to the perception of lack of opportunities which the adolescent male held prior to the fatherhood crisis (Hanson, Morrison, \& Ginsburg, 1989). 
Nurse researchers have given a great deal of attention to the development of the fatherhood role. However most of their efforts have focused on mature, married, financially secure males who were experiencing a planned, wanted pregnancy (Bowen \& Miller, 1980; Cronenwett \& Kunst-Wilson, 1981; May, 1978 \& 1982). Results of studies on paternal involvement show that the fathers' own self-esteem increased, in addition to facilitating greater father-infant bonding (Cronenwett $\&$ Newark, 1974; Klein, Grist, Nicholson \& Stanley, 1981; Palkovitz, 1982). The effect of adolescent fathers' involvement and emotional support during pregnancy as well as with childcare activities has been shown to result in greater maternal role satisfaction (Berland, 1987; Elsters, Lamb \& Kimmerly, 1989). Ongoing involvement of adolescent fathers has contributed to the emotional, psychological, and intellectual growth and development, not only of their children, but also of the enhancement of the adolescent fathers' own self-esteem (Connolly, 1978; Elster, Lamb \& Kimmerly, 1989; Henderson, 1980; Parke, 1979; Sander \& Rosen, 1989).

\section{Lack of Research: Adolescent Fathers}

Despite the positive effects of adolescent fathers' involvement in the pregnancy and childcare activities, health and allied service providers continue to undermine and/or ignore the teen fathers' presence (Rivara, 1981). Although the negative stereotype of adolescent fathers has been refuted (Castiglia, 1991), these fathers continue to be portrayed as uncaring, pleasure-seeking, and irresponsible (Robinson, 1988; Taucher, 1991). This results in the exclusion, and alienation of teen fathers from counselling and 
Adolescent fathers: perceived role performance 5 teaching which would greatly benefit them, according to Robinson (1988), and Taucher (1991).

Researchers have acknowledged the gap and lack of empirical information surrounding adolescent fathers and have conducted studies which claim to correct the disparity. Robinson and Barret (1982), conducted a critical analysis of published studies related to adolescent fathers and outlined "... at least five methodological shortcomings which cloud empirical investigations" (p. 596). These 'shortcomings' include:

1. Omission of adolescent fathers from investigations related to teen pregnancy.

2. Conclusions based on inferred information.

3. Data collected through maternal contact only.

4. Post hoc and retrospective data analysis which do not reflect contemporary psychosocial changes.

5. Unrepresentative sampling (Robinson \& Barret, 1982;

Robinson, 1987 \& 1988).

While numerous researchers have investigated various aspects of teenage pregnancy, few have looked at this issue from the adolescent fathers' perspective. The term "father involvement" is vague and poorly defined (May, 1982). This shortcoming is actually reflected in the literature surrounding adolescent pregnancy which questions or denies the male partner's involvement. Meyers (1994), reviewed 71 published articles which claimed to be seeking determinants and solutions to resolve teenage pregnancy. 
The near exclusion of males as study subjects was found. Thirty-three articles focused on a single sex - only one of these was on males. The rest ( 38 articles), either did not differentiate between the sexes, or provided minimal data on sex differences. This exclusion of males demonstrates the gender bias which reinforces the idea that teen pregnancy is a female issue, and that solutions lie in dealing with that population. Furthermore, the omission of males reinforces the negative stereotypical image that professionals and lay people have towards adolescent fathers and their parenting roles. Agencies do not routinely involve adolescent fathers, even when they accompany their partners to every prenatal visit. Vaz, Smolen and Miller (1983) reported that only 19 percent of adolescent male partners were seen by a health professional to discuss concerns related to the pregnancy, and even less (nine percent) received contraceptive counselling. Despite the evidence showing adolescent fathers have tremendous potential for involvement with parenting responsibilities, they remain "shadowy figures" (Berland, 1987). Although a more realistic picture of adolescent fathers is beginning to emerge (Christmon, 1987), most of the studies related to adolescent fathers are actually descriptions of these fathers' involvement with the mother over time (Barth, Claycomb \& Loomis, 1988).

The major obstacle facing investigators who wish to pursue research with teenage fathers is that subjects are reluctant and suspicious about coming forward (Barret \& Robinson, 1986; Taucher, 1991). Adolescents may believe that their privacy is being invaded by the investigator. This was illustrated by Berland (1987), who reported that 
subjects declined participation because they "... didn't want people prying in their lives" (p. 256). Access to agencies or institutions and the expectant mother's reluctance to disclose the biological father's name or his denial of paternity have also been cited by these authors as factors which contribute to the limited scope of previous investigations. What is really known about adolescent fathers and their involvement with their children? State of Knowledge: Adolescent Fathers

Contrary to the widely held belief that adolescent relationships are transient affairs, several studies have shown the exact opposite (Cady \& Schurman, 1991; Dallas \& Chen, 1998; Redmond, 1985; Robinson \& Barret, 1982; Ryan \& Sweeney, 1980; Sherline \& Davidson, 1978; Taucher, 1991). Others have agreed, but argue that the adolescent father's commitment to the relationship declines over time (Barth, et al., 1988; Furstenberg \& Talvite, 1980). This is not surprising, since the potential positive effects of adolescent father involvement have not been consistently promoted. Despite evidence to the contrary, healthcare and allied workers who are involved with adolescent fathers continue to propagate the negative stereotype image of teen fathers (Platt, 1968). According to Caparulo and London (1981), these fathers are "adolescents first, fathers second." This is supported by Berland (1987), who observed "... the children's welfare proved to be secondary in importance for the young fathers to their own personal development" (p. 256). 


\section{Interest and Issues: Adolescent Fathers}

Questions and concerns about the male adolescent partner often arouse the interest of health care and allied professionals. As a nurse who has had past clinical contact with a large number of pregnant teens and their partners in a prenatal clinic situated in a large tertiary care hospital and presently employed in a maternal/child area, I have observed this first hand. Care providers want to know who the father is? Is he still involved? If so, how supportive is he? How old is he? Is he in school or employed? Answers to these questions and numerous others are sought from the expectant mother, while her male partner, even when present, is left in the waiting room. Even though these young men appear eager and enthusiastic to learn and participate in all aspects of their partners' care, healthcare staff barely acknowledge their presence.

Healthcare professionals and other service providers tend to rely on the expectant mother's interpretation of her partner's behaviour. Direct service providers often take a condescending or punitive attitude towards the male adolescent partner, and therefore, fail to aggressively seek out the male partner's involvement. Although the Adolescent Prenatal Clinic provides care for pregnant adolescents, the clinic does not define how this care is extended to include the male partner involved in the pregnancy. Adolescent fathers who attend such clinics often feel unwelcome and uncomfortable. It is not uncommon for some to feel that they have been too harshly judged (Taucher, 1991). As a result their interest in accompanying their partners to the prenatal clinic wanes over time. When adolescent mothers are asked about their partners' whereabouts, they often reply "he doesn't want to come" or "Oh, he won't come." Healthcare and allied 
professionals accepted these responses and believed that their perceptions of the adolescent male partner were correct.

Interest in this study also stems from the persistently high rates of teen pregnancy in Manitoba. Although estimates of teen fathers in this Province is unknown, Berland (1985) estimates 40,000 adolescents become fathers each year in Canada. Morris (1991), reported that there were approximately 2,750 teenage mothers raising their children in Manitoba. This trend is increasing, since more teenagers who opt to continue with the pregnancy are choosing to parent their children. According to Grant (1993), only five to seven percent of North American teens give up their babies for adoption. This has important implications for Manitoba, since the fertility rate among adolescents age 15 to 19 years old is 42.5 per 1,000 women, while the National rate is only 24.5 per 1,000 women (Statistics Canada, Health Reports, 1997). Pregnancy rates have remained virtually unchanged in Manitoba since 1993. Furthermore, the number of pregnancies terminating in abortion among women aged $15-19$ years was $45 \%$ in 1994 (Statistics Canada, Health Reports, 1997).

Pregnancy rates for adolescents age 15-19 were declining until the mid to late 1980's. However, since 1987 the Manitoba teen pregnancy rate has been steadily increasing and was reported to be 61.5 per 1,000 women, age 15-19 years old in 1995 (Statistics Canada, 1997). This increase in teen pregnancy, which is mirrored nationally, is even more alarming in light of the lower teen population. In Alberta, the cost of 
providing social services for single, adolescent families was estimated to be $\$ 22$ million per year. This has grave economic implications for Manitoba where the teen pregnancy rate is even higher (Health and Welfare Canada, 1990).

Further interest in adolescent fathers has been sparked by recent reports of child abuse. Many of these males suspected or charged with physical abuse are adolescents. In almost every case, the mother of the physically abused child is also an adolescent, while the perpetrator/or suspected perpetrator is her male partner. Of interest is that these children were being cared for by these fathers/partners at the time of the alleged abuse. Almost all studies related to teen parents report that adolescents are emotionally and intellectually unprepared for parenthood (Barret \& Robinson, 1986). Lack of child development knowledge frequently leads to impatience which precedes child abuse (de Lissovoy, 1973). These children are at increased risk for abuse due to their teen parents' inappropriate and unrealistic expectations (Field et al., 1980). Furthermore, Kinard and Klerman (1980), reported that adolescent parents are more likely than adult parents to use physical punishment to discipline their children. Therefore, nurses and allied care providers need to increase their sensitivity to the characteristics and needs of adolescent fathers.

\section{Purpose of Study: Adolescent Fathers}

Research findings do not support the myth of non-involvement of adolescent fathers in parenting. Nevertheless, care providers need to be better informed about the correlates of parenting involvement by teen fathers. Greater understanding will enable 
health care providers to assist adolescent fathers in their transition to parenthood. It is anticipated that findings from this study will add to the further understanding of some of the variables which are thought to influence adolescent fathers' parenting behaviour. These variables are: role expectations of self and others (parents and partners), perceived role performance and self-image. These variables will be tested in the following study the hypotheses:

1. Perceived parenting role performance of the adolescent father/partner is positively related to his self-image.

2. Perceived parenting role performance of the adolescent father/partner is positively related to his own parenting expectations.

3. Perceived parenting role performance of the adolescent father/partner is positively related to his perceptions of his parents expectations.

4. Perceived parenting role performance of the adolescent father/partner is positively related to his perceptions of his partner's expectations.

Additionally, this investigation will provide knowledge and insights related to adolescent fathers, a population about which very little is known - especially from a Canadian perspective.

\section{Chapter Summary and Thesis Organization}

This chapter provided an introduction to the problems and issues related to the study of adolescent fathers. The conceptual framework guiding this study is explained in chapter two. A discussion of the relevant literature will follow in chapter three. The methods and procedures followed in this study are presented in chapter four. Results of 
methods and procedures followed in this study are presented in chapter four. Results of data analysis will be contained in chapter five. Discussion and conclusions will be presented in chapter six. 


\section{CHAPTER II}

\section{Conceptual Framework}

\section{Introduction and Rationale}

Family role theory (Friedman, 1992), provided the conceptual framework which guided this study. Meleis (1985), postulates that a theoretical framework provides a mechanism through which the investigator can organize observations to focus on the enquiry and communicate the findings and/or outcome. According to Friedman, family role theory emphasizes the integral part of specific roles that members play in the structure and organization of each family. Family role theory is therefore appropriate for examining male adolescents' parenting, since it considers both the individual and the social system within which that individual exists (Field \& Radin, 1983, p. 6). Furthermore, family role theory (Figure I) provided a perspective to explain how the adolescent father's behaviour was influenced and/or affected by external factors, such as, societal expectations and the perceived expectations of his parents and partner, and internal factors such as, his self-image and abilities, as well as his own role expectations.

\section{Definition of Terms}

The following definitions will explain various elements of the conceptual framework:

- Role: a "homogeneous set of behaviours which are normatively defined and expected of an occupant of a given social position" (Nye, 1976, p. 7). A role, therefore guides the behaviour associated with a position. 
An individual's behaviour is linked to the social structure through the role he occupies.

- Position: "a person's location within a social system" (Friedman, 1992, p. 159). Positions exist in a social structure with or without occupants.

However, when an individual assumes a position, he has also assumed a role. For example, adolescent father is a position. Therefore, when a young man/youth becomes an adolescent father, he assumes a role, and as a resuit people will expect certain behaviour from him. Position, therefore, is an unoccupied recognized role - in other words, positions do not have occupants, but roles do.

- Role behaviour/performance: “... what a person actually does within a position in response to role expectations" (Friedman, 1992, p. 159), in this case the adolescent father's role.

Role expectations: these are the idealized attitudes and behaviours of any occupant of a social position within society or the family (Biddle, 1979, Friedman, 1992, Sarbin \& Allen, 1968). Role expectations bridge the gap between the social structure and role behaviour. In the case of the adolescent father - he learns the correct/appropriate behaviour associated with his parenting role through role expectations. Therefore, role expectations influence the behaviour of the performer by inducing conformity. The 
impressions we form from others, and the qualities we attribute to them also influence our behaviour (Atkinson, R.C., Atkinson, R. L. \& Hilgard, 1983). For example, adolescent fathers' behaviour may be influenced by expectations of their parents and/or partners. Teen fathers are more likely to accept the fatherhood role if they perceive that it is the expectation of their parents and/or partners'. Additionally, the perception teen fathers have of themselves will influence role acceptance and, ultimately role performance, since personality, attitudes, capacities, needs and motives influence behaviour, according to Atkinson R.C., Atkinson, R. L. and Hilgard, (1983).

- Self-Image "...is the sum total of the perceptions, thoughts, and feelings that individuals have of themselves" (Offer, Ostrov \& Howard, 1981, p. 24). According to Garett (1982), perceptions, thoughts, and feelings/beliefs are formed relative to the evaluations we receive from others. Subjective perceptions are more important than reality in influencing behaviour (Comer et al., 1987). Self-image influences both the individual's perception of the world and his behaviour (Atkinson, et al., 1983 p. 400). People, therefore, behave in a manner consistent with their self-image according to Atkinson et al. 
Figure I illustrates the process involved in the development of role behaviour

\section{Family Role Structure}

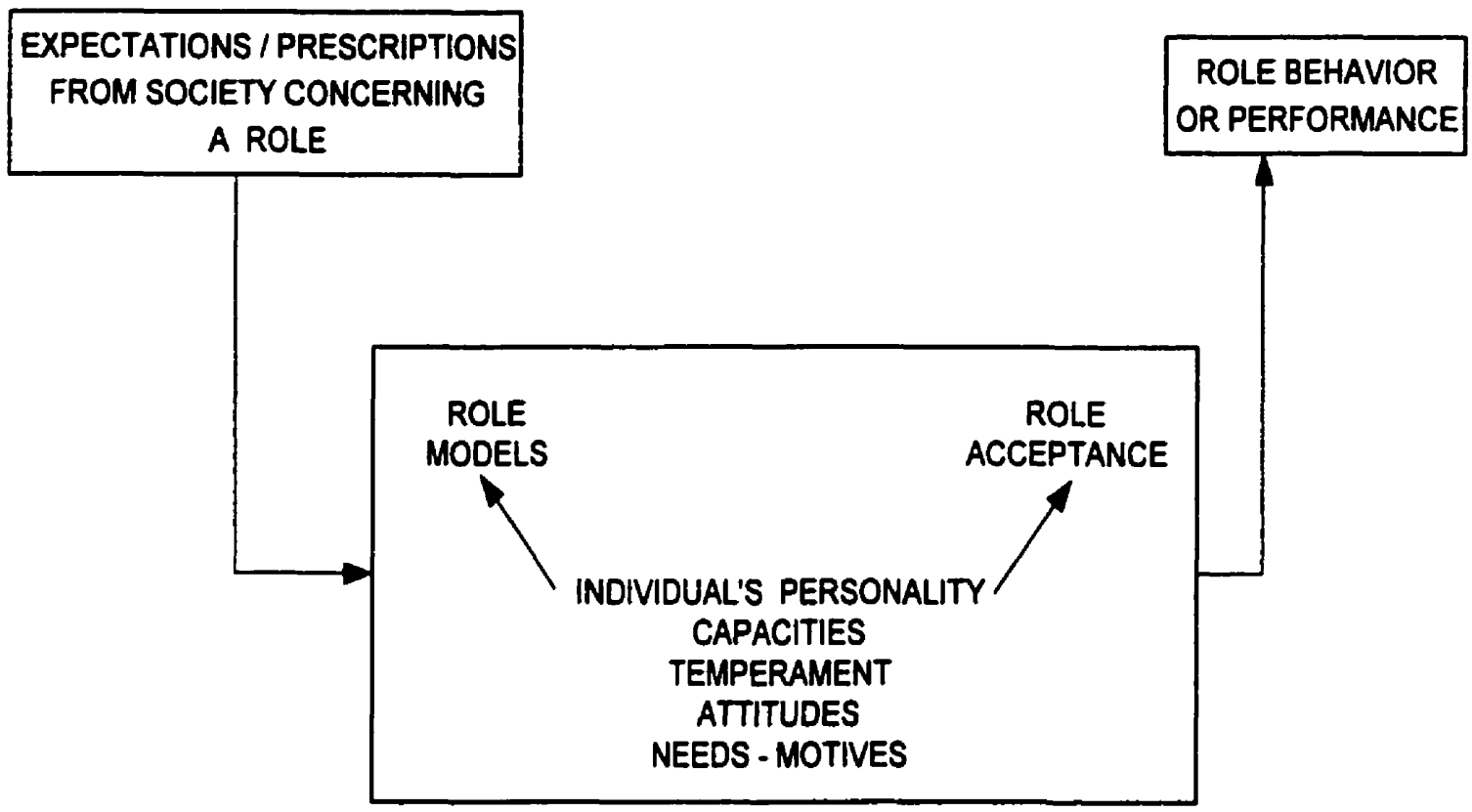

Figure 1

DEVELOPMENT OF ROLE BEHAVIOR

(Friedman, 1992, p 159)

Friedman's schematic model is adapted and modified to illustrate the process by which male adolescents develop parenting behaviour. The schematic model presented in Figure II demonstrates the societal expectations and perceptions of "self" which are precursors for role performance. 


\section{Paternal Role Development}

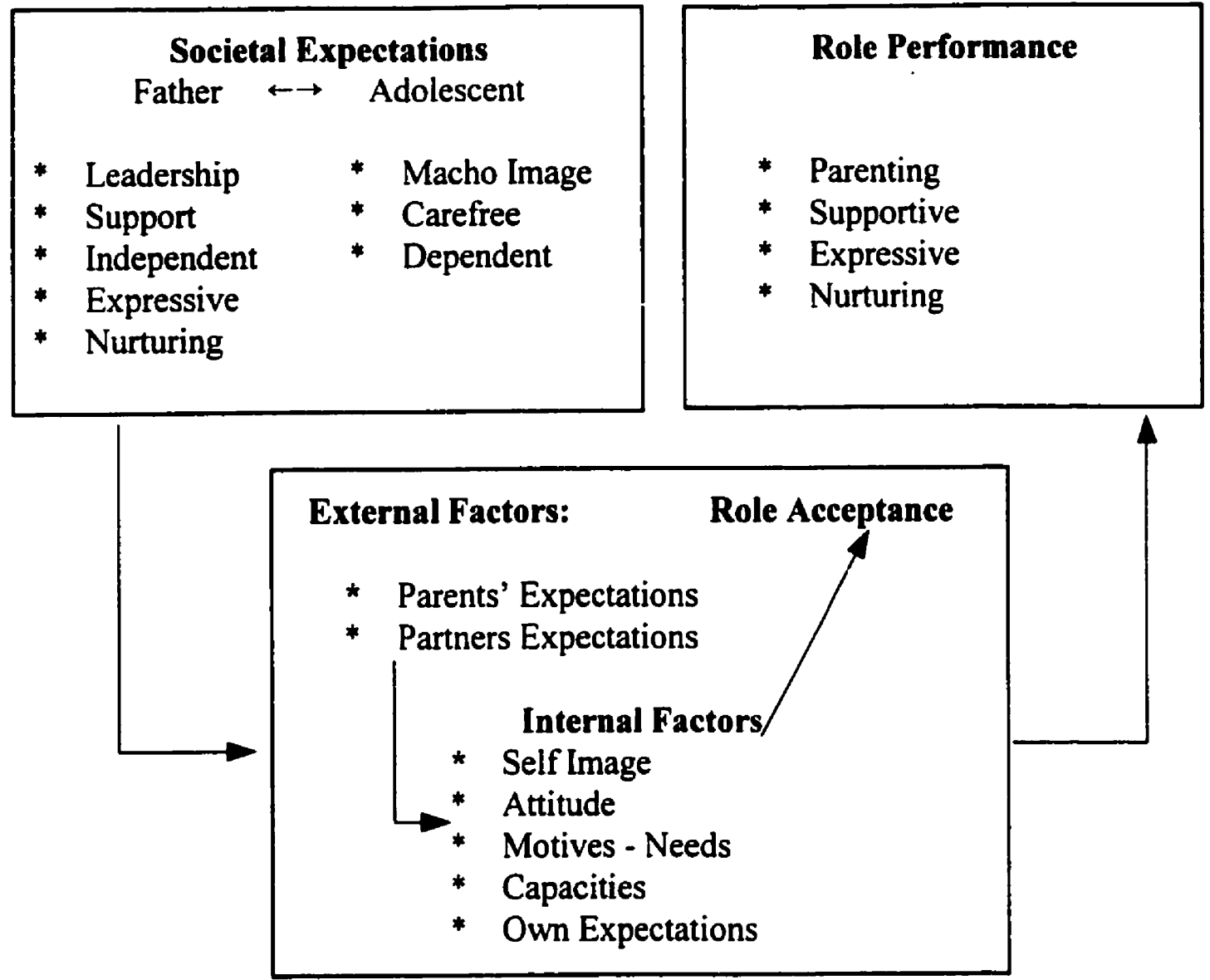

Figure II

Development of role behaviour for male adolescents faced with unplanned/unwanted pregnancy (Adapted from Friedman, 1992).

Society has prescribed role expectations for fathers, as well as for adolescent males.

The duties/responsibilities of fatherhood which are dictated by society hold greater importance than those associated with adolescence. Therefore, when adolescents become fathers they are expected to assume the responsibilities society dictates for the fatherhood role and abandon those of adolescence, since the two roles are incongruent. The top, left 
box in Figure II illustrates the dichotomy of the role expectations a young man faces when he becomes an adolescent father. While the male adolescent is unlikely to be married and economically secure, societal expectations are that the male is mature, married, and able to provide economic support for his partner/wife and child. According to Rotundo (1985), “...men function as providers and disciplinarians for their children" (p. 15). This is typical of the traditional role of fathers which outline clear expectations. Friedman (1992), believes that roles are enacted based on expectations, that is, what a person should do to meet his own or someone else's expectations. However, due to an adolescent's immaturity, he may require support and guidance to achieve his parenting role, in the face of competing expectations between fatherhood and adolescence.

Several factors, both external and internal may also contribute to the development of role behaviour/performance. These are illustrated in the middle box of Figure II. According to Friedman, the family forms the base unit of society and has significant influence on the development of its members. Futhermore, this author stresses the mediation role that family plays between the basic societal expectations and obligations, which it modifies to fit the needs and interest of the family and/or individual, so that parental values and perceptions do have an impact on children. Cervara (1991), and Robins and Lyn (1973), reported that informal expectations may influence role performance and contribute to the development of a different set of expectations from mainstream society. They go on to say that adult, unwed fathers, through direct and indirect ways transmit attitudes to their sons which contribute to generational recidivism in illegitimacy. 
Another external source which has been found to have a strong influence on the adolescent fathers' role development and subsequent behaviour is his partner. Several investigators have reported that adolescent fathers' perceptions of paternal involvement is influenced by their partners' expectations (Cervera, 1991; Elsters and Lamb, 1989; Furstenburg \& Talvite, 1980). Role expectations from external sources, namely, society, parents and partners have an impact on the male adolescents own conceptions.

The role performer, in this case the adolescent father, brings his own ideas about his rights and duties, as well as his appraisal (which may or may not be accurate) of how others with whom he interacts define his rights and obligations (Sarbin \& Allen, 1968). According to Biddle (1979), most of us hold expectations of ourselves and those with whom we interact frequently. Field and Radin (1982) describe expectations of self as role conceptions. These authors contend that a person's conceptions are influenced by his characteristics, for example, personality attributes (self-image), capacities, attitudes, needs and motives (Figure II). According to Felson (1985), there is a strong correlation between self perception and the way a person thinks others perceive him. Similar findings were reported by Shrauger and Schoeneman (1979). Gecas and Schwabe (1986), reported that a son's self-image was strongly influenced by his perceptions of his parents' behaviour, especially by his father's perceived behaviour.

Role expectations and role conception merge and collectively influence role acceptance, which determines role behaviour/performance. According to Friedman (1992), role performance and role behaviour, in this case adolescent father's parental role, actually illustrates what a person does within a given position in response to role 
expectations and role conceptions (p. 159).

Gibbs (1972), provided the foundation for the integration of these concepts into an operational framework (See Figure III). The schematic model (Figure III), defines the

\section{Operationalization Of Concepts}

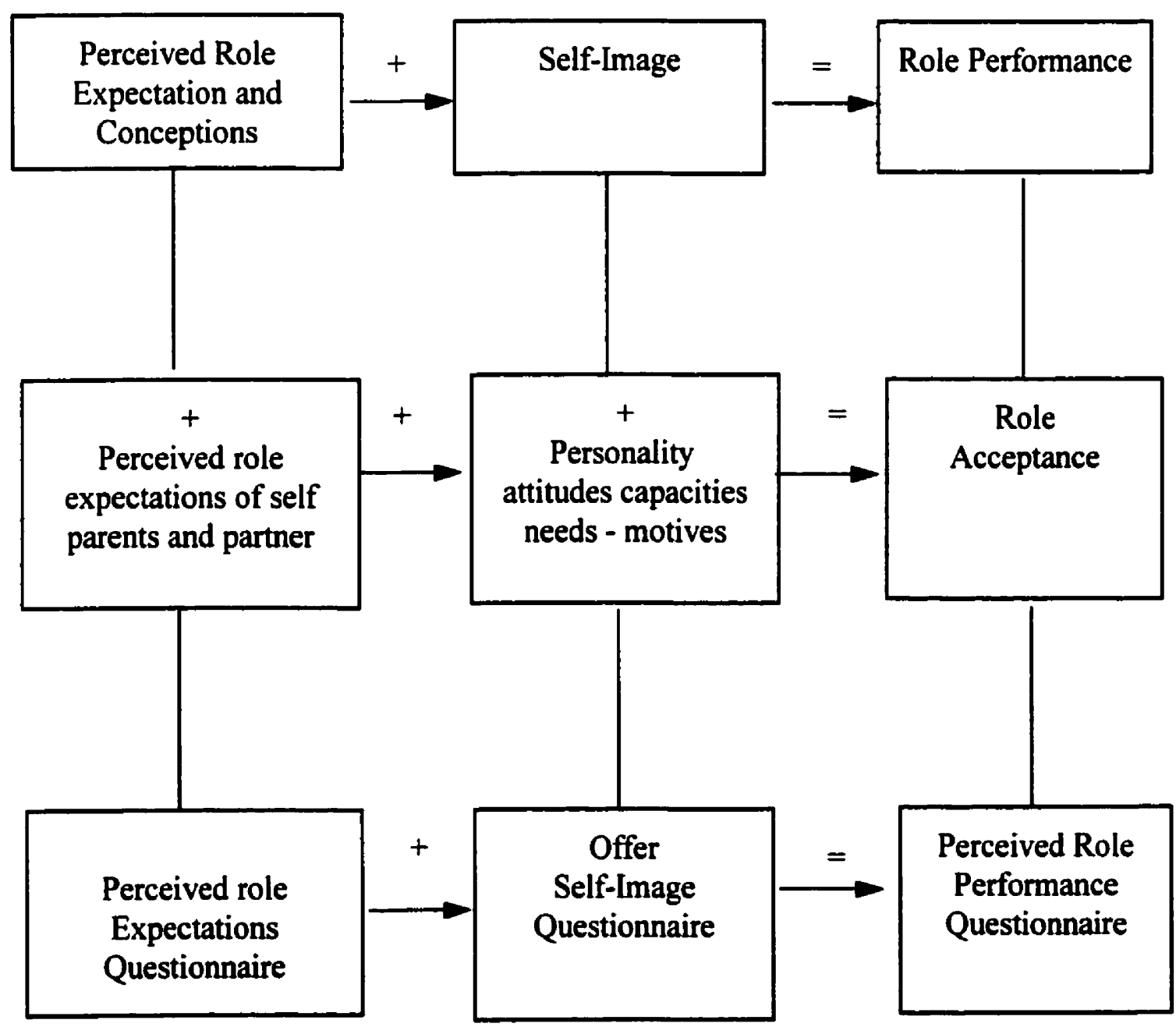

Figure III

three levels involved in operationalizing the concepts and their interrelationships as they relate to this study. The top row (horizontally) shows each concept: role expectations 
and conceptions, together with self-image will, if positive, lead to role performance. In the second horizontal row of boxes, the researcher's hypotheses are represented, that is, positive role perceptions of self and significant others (parents and partner) will, if combined with a positive self-image, result in role acceptance. Finally, the last row represents the operational level, that is, how the concepts are measured. Longitudinal lines between the boxes show the interrelationship of the three levels: conceptual, hypothetical, and operational. Plus signs located above the arrows indicate the influence of the variables which, if positive, will result in (the adolescent father's) high perceived role performance, role acceptance and ultimately role performance related to parental responsibilities. Equal $(=)$ signs above the arrows indicate the sum total of the influence of the variables at each level of the model in Figure III. However, as a result of extraneous factors, role acceptance and performance may not always follow this pattern.

\section{Summary}

This study will be guided by a conceptual framework grounded in family role theory. Role expectations of society and role expectations of significant others (parents and partners) merge with self conceptions and collectively influence role performance, specifically how the adolescent father executes the duties associated with his parental role. This chapter has presented a schematic illustration of the framework, as well as an operational model guiding this study. Highlights of the literature surrounding the formation of self-image, and results of previous studies related to adolescent fathers' involvement in parenting will be presented in the following chapter. 


\section{CHAPTER III}

\section{Review Of The Literature}

\section{Introduction}

Early parenting has been associated with serious and far-reaching implications for young parents and their children, as weil as society. Yet, researchers and healthcare providers have, until recently, focused almost solely on the plight of the teen mother and her child (Tuttle, 1988). Young fathers, however, face multiple difficulties when confronted with impending fatherhood while coping with their own developmental needs (Sadler, 1983). Adolescent fathers have been portrayed by health professionals as uncaring, uninterested, and unwilling to accept their parenting responsibilities (Taucher, 1991). While this may be true for some adolescent fathers, a review of the literature indicates that not all teen fathers fit this stereotypical image.

Adolescence is a transitional developmental stage between childhood and adulthood (Papalia \& Wendkos-Olds, 1995). According to the Group for the Advancement of Psychiatry [GAP], (1986), a wide "...variety of temperamental styles and psychosocial circumstances characterize this group" (p. 25). It is, therefore, important to understand the psychosocial development of these fathers, so that young men can be assisted to cope with the dual challenges of adolescence and parenthood.

The purpose of this literature review is twofold. First, developmental factors and formation of self-image which influence adolescent male behaviour, and the relationship which these elements have to the parenting role, premature fatherhood and teen fathers' capacity to parent will be explored. Second, issues related to adolescent fatherhood will 
be explored. These will include a review of the research findings related to psychosocial effects of premature fatherhood, parental and partner's influence on teen fathers role performance as parents, and parenting role performance as reported by adolescent fathers. A summary and overview of the significance of this study will conclude the chapter.

\section{Factors Influencing Self-image}

\section{Psychosocial Development}

Erikson's theory of adolescent development is not only the most accepted, it is also the most comprehensive (Gallatin, 1976). Psychoanalytical models dictate that the focus of adolescent development is identity formation: Who am I? How do I feel? Where am I going? What meaning is there in life? These are questions for which adolescents are seeking answers in their search for identity . Erikson (1975) proposed that identity formation bridges the gap between the experiences of childhood and adulthood, by integrating personal goals, values, and decisions during adolescence. According to Erikson (1975), identity formation results through integration of biophysical and psychosocial characteristics from multiple sources, such as, earlier gender identity, parents, friends/peers, social class, ethnic and religious groups. To form identity, Papalia and Wendkos-Olds (1995), suggest that “...the ego organizes a person's ability, needs, and desires, and helps to adapt them to the demands of society" (p. 380).

More recently, James Marcia (1980) expanded Erikson's identity development theory. Marcia acknowledged differences among individuals and pursued the idea that the process of identity attainment must also be varied. He proposed four major identity statuses: achievement, foreclosure, diffusion, and moratorium. These were identified 
based on the presence or absence of crises and commitment, the two elements which Erikson believed to be vital for identity formation. Marcia's definition of identity correlates his four identity statuses with other personality characteristics. He defines identity as "an internal, self-constructed, dynamic organization of drives, abilities, beliefs, and individual history" $(1980$, p. 159). Marcia related the id status to other personality characteristics such as anxiety, self-esteem, moral reasoning, and patterns of behaviour. Crisis is defined as a conscious decision-making period, while commitment is a personal investment in an occupation or ideology - beliefs.

In Marcia's "identity achievement" an individual is capable of making choices, and following through with strong commitment to those choices. While in "identity foreclosure" individuals have a tendency to accept other people's plans for their lives. Marcia (1980), goes on to state that in "identity diffusion" individuals are unable to make commitments, for example, they may evaluate and consider various options but are unable to follow through with a commitment. Adolescents in identity diffusion are usually withdrawn from family, experience a moderate amount of anxiety, have low selfesteem, cannot make choices, and remain dependent. In Marcia's fourth identity status "moratorium," he describes an individual who is self-directed, but lacks commitment. Nevertheless, Marcia believes that identity moratorium will ultimately lead to "achievement".

Research has confirmed that many adolescents go through a period of foreclosure or diffusion, followed by moratorium before they commit themselves to a mature identity - achievement (Stassen-Berger, 1994). This has implications for adolescent fathers. 
Parenthood before a stable identity is developed may impair the teen father's ability to combine the tasks of adolescence with those of fatherhood (Papalia \& Wendkos- Olds, 1995). Adolescents whose identity growth is halted in foreclosure or diffusion may find themselves revisiting identity issues in later life (Shaw-Shuster, Cronk \& Reno, 1992).

Although adolescents may go through each identity type, they tend to settle in one. Thus, in the search for identity, the teen utilizes information while looking for supportive facts, considers various solutions to problems, applies present ideas to future goals, and organizes abstract thoughts into more practical forms. In some situations, however, added stress such as responsibilities of parenting, may force the adolescent to remain in a dependent role - without identity achievement (Stassen-Berger, 1994).

Although adolescence is a transition period, the search for identity is not fleeting. Identity formation is variable and may extend 10 years or more according to Papalia and Wendkos Olds, (1995). Psychological factors are not solely responsible for identity development. Stassen-Berger (1994), suggests that socializing agents, such as, family and peers, play an instrumental role in shaping an adolescent's identity.

\section{Family}

Family continues to be a source of major support to adolescents in their identity search (Shaw-Schuster, et al., 1992). The sense of closeness within a family promotes intimacy, trust and support. According to Shaw-Schuster et al., these feelings create an emotional bond, whereby the adolescent can safely identify with a primary group.

Shaw-Schuster et al. go on to say that the basic elements of family influence in identity formation are never fully replaced by other social institutions. 
Parenting style which promotes positive exploration, such as, trying new activities, making new friends, taking on new challenges, learning new skills, or withstanding peer pressure, provides adolescents with opportunities and challenges for identity growth and development of self-image (Papalia \& Wendkos-Olds, 1995). According to Steinberg (1990), warmth promotes the development of self-esteem and social skills, while behavioural checks assist in curbing impulses. Giving psychological independence helps to develop a sense of responsibility and competence in young people. Parents, however, must find a balance, since too much closeness may lead to the adolescent's enmeshment with his family, while too little closeness may produce feelings of alienation and rejection (Shaw-Schuster and Smith-Ashburn, 1992).

Parents serve as important role models in the psychosocial development of their children. Adolescents learn the dynamics of adaptability from their family. Norms and rationales related to behaviour, and the values of society are passed on to children by their chief socializing agent - their family. Shaw-Schuster and colleague (1992), propose that the family serves as a role model for demonstrating how power structure can change, how roles develop, and how new relationship norms are forged. This information and skill is valuable to adolescents in their interaction, not only within the family, but also in the outside world. Shaw-Schuster and Smith-Ashburn, (1992), go on to say that the interaction style of families influences the adolescents' interaction style within relationships. Parental involvement and interpersonal communication with adolescents are influential in promoting their involvement in parenting. For example, (GAP, 1986), suggests that a teen father who has not had the benefit of his father's involvement in 
parenting, is likely to have difficulties accepting his own parenting responsibilities.

Contrary to the belief that the "generation gap" between the old and young is widening, Stassen-Berger (1994), found that parents and adolescents have very similar values and aspirations. This view is supported by research findings which show that parents and children have similar political, religious and economic values, while disagreements centre around smaller issues, such as, school work, personal appearance, friends, dating, curfews, and chores (Smetana et al., 1994). However, parent-child relationships, which are marked by ongoing conflict throughout adolescence are vulnerable to problems such as teen pregnancy, substance abuse, and delinquence (Dryfoos, 1990; Offer, Ostrov \& Howard, 1989).

Thus, parents can either enhance or hinder their childrens' psychosocial development and growth by their parenting style. Offer et al. (1989), believe that "the family continues to serve as a first line of psychological defence for most teenagers" (p. 735). Families, however, are not the only influence in an adolescent's life. Peers and peer groups also have a great impact on a teen's identity development.

\section{Peers}

Peer relationships offer valuable support to developing adolescents. Additionally, peers pressure the developing teen to conform to group norms (Papalia \& WendkosOlds, 1995). These relationships influence adolescents' leisure activities, speech, and dress. Furthermore, Papalia and Wendkos-Olds state that peer groups provide a frame of reference where adolescents can test their developing social and interpersonal skills by comparing themselves with similar "others" and experimenting with a wide range of roles 
and behaviours. For example, teens can practice leadership roles, learn how to cope with social rejection and failure, learn about reciprocity, social support and esteem, and resolving interpersonal problems. Thus, peer groups offer a supportive environment where adolescents can pursue autonomy and independence from parents.

Although pressures to conform to peer group norms are tremendous, according to Papalia and Wendkos-Olds, (1995), adolescents are usually drawn to peer groups which hold similar values to those held by their parents. Papalia and Wendkos-Olds go on to say that parents' concern about conformity stems from knowledge that adolescents lack the capacity to project future consequences of their actions/behaviour. Conforming behaviour usuaily results from a need for social praise and recognition, and avoidance of peer disapproval and rejection. Papalia and colleague argue that a stressful, chaotic, and non-supportive home environment force adolescents to turn to peer groups for identity nurturing.

\section{Section Summary}

Identity formation is considered to be one of the most important tasks of adolescent development. Psychoanalysts, Erikson (1975) and Marcia (1980), take the view that identity formation is the result of integration and consolidation of past and present intrapersonal, as well as interpersonal experiences through psychosocial crises. Only identity achievement equips the adolescent to independently make a commitment and follow through with it. The psychological aspects of identity formation is interwoven with social elements of adolescent development. In their search for identity, adolescents turn to family who remain the chief socializing agents for children. Family 
and parents, in particular, instill society's values and offer emotional support. Peers offer a safe environment where adolescents can explore behaviour and intra - and inter personal skills.

\section{Self-Image}

In examining the role of adolescent fathers, it is essential to understand how teen fathers feel about themselves. Adolescent males bring their thoughts and ideas about themselves to the parenting role through feedback received from family and peers which can influence the teens' behaviour. An adolescent's psychosocial functioning, as well as the feelings he holds about himself, his self-image, will undoubtably influence his parenting behaviour.

Self-image is a critical component of adolescent psychological functioning. There is a significant correlation between self-image and elements of adolescence functioning, for example, personality, biophysical development, mood, coping abilities, and interpersonal relationships with family and friends (Offer, Ostrov, \& Howard, 1984, p. 59). How is self-image developed? Investigators agree that the development of "self" begins with infancy and continues to evolve throughout the life-span. These researchers, however, disagree about how the self is developed. There are two schools of thought on this issue. Psychoanalysts believe that the "self is basically an organization of feelings, some of which the individual is motivated not to consciously recognize" (Offer, Ostrov, \& Howard, 1981, p. 20). Those who take the cognitive view believe that the process begins "when an infant learns to differentiate himself from other people or objects in the environment" (Sideleau, 1992, p. 29). 
Sullivan (1953), a psychoanalyst, proposed that personification of self, the "good me", "bad me", and "not me", begins in early infancy and is integrated sometime in midinfancy. This symbolic perception of self develops from an integration of the good me, the bad me, and not me eliciting feelings of self-esteem and approval by significant others (Chapman \&Chapman, 1980, p. 18; Sideleau, 1992). According to Sideleau, perception and definition of self are conveyed through verbal and non-verbal communication.

Sullivan furthers the understanding of self with this explanation: when a mother is loving and meets the emotional and physical needs of the infant, these nurturing activities convey positive feelings and perceptions to the infant. The infant perceives himself as being a good person - good me. Sideleau (1992), believes that a positive view of self will continue to develop in an environment of love, recognition, praise, and acceptance from parents and significant others.

According to Sullivan's theory of self, (1953), feelings of rejection promote a negative perception of self or bad me. Negative self feelings develop in an environment of criticism, and labelling or belittling, for example, being called lazy, useless, bad, or no good. Lastly, the not me evolves from feelings of intense or extreme anxiety which remain images of confused, mixed-up feelings. These feelings of the not me, continue to operate at an unconscious level and remain unverbalized (Sullivan, 1953). 
Sullivan postulates that the three concepts of self -good me, bad me, and not me are merged into one at the end of infancy, that is, approximately 18 months of age. Sullivan goes on to say that an individual's perception of himself, his self-regard as an interpersonal being is determined by the relative strength or weakness of the three selves good me, bad me, and not me. Although this image of self which is established in early years remains relatively stable, it is however, subject to a certain degree of modification in response to social and environmental changes. According to Sideleau (1992), "becoming a social being is a life long process of comparison, assessment, reinterpretation, and internalization of perceived appraisals of others" (p. 30).

Following Sullivan's school of thought, Jacobson (1964), proposed his own theory of self-image. Jacobson proclaimed that self-image emerged from an awareness of our inner experience of sensations or emotions, and thought processes of our functional activity, as well as self-perception and introspection (p. 20-22). Self-image, therefore, evolves from early traces of happy and unhappy sensations which are experienced through bodily functions, such as, eating and elimination, and playful body exploration. In the initial stages of development, image of the self is hazy, and indistinguishable. This results in confusion and fusion of the self with other objects. Unpleasant and unhappy experiences are denied or repressed into the "unconscious", thus exerting significant influence on the development of self-image. For example, Jacobson (1964) reasons that an infant who is allowed to remain in wet and soiled diapers will suppress the memory of it, and instead will focus on more pleasurable experiences of infancy. In this manner, the infant will come to form an image of self or self-image. 
Piaget (1952), focused on the cognitive or intellectual development of self. Piaget noted that there was a close link between an infant's behaviour and perception. He believes that an awareness of self begins as the infant starts to differentiate himself from other objects. According to Piaget, the development of self progresses in stages which are facilitated through a process of internalization and limitation of others' behaviour. Development of self is consolidated through language in such a way that the distinction between self and non-self can be made. In his explanation of cognitive development, Piaget (1952), emphasized the child's own actions, explorations, and constructions of reality.

Both approaches, the psychodynamic and cognitive, are equally vital to the formation of self. Offer, Ostrov and Howard (1981), believe an integration of the two approaches leads to a greater understanding. They concluded that the self is made up of the sum total of perceptions, thoughts, and feelings that we hold of ourselves, although these may not be clearly identified or articulated into an ongoing self system. In essence, however, even if these feelings and thoughts are denied to ourselves or others, they continue to form part of self, and as a result influence who we are - our identity. The adolescent's ability to use abstract thoughts allows evaluation of every experience in relation to his self-worth - his self-image. People usually behave in a manner consistent with their self-image. A positive self-image is reflective of congruence between thought, experience, and behaviour, whereas experiences and feelings which are inconsistent and threatening may be denied and repressed, and remain in the unconscious (Sideleau, 1992). 
According to Sideleau, self-image remains flexible so that new experiences and ideas may be assimilated.

\section{Section Summary}

There are two approaches to defining the formation of self: psychodynamic and cognitive. Both the psychodynamic and the cognitive approach to formation of self stress the importance of early childhood experiences. The evaluation an individual has of himself, his self perception, forms his self-image. Self-image continues to evolve and affects the individual's behaviour through approval and criticism, success and failure, and interaction with others. Self-image combines with expectations to influence behaviour. This has implication for adolescent fathers.

\section{Impact Of Adolescent Development On Fatherhood}

An overview of some of the issues related to adolescent fathers' self-image and its impact on their ability to parent will be outlined in this section.

The adolescent father is suddenly faced with new, increased responsibilities, redefining social relationships, and incorporating a new family member (Auvenshine \& Enriquez, 1985). However, these tasks conflict with those of adolescence (Rivara, 1981). Premature parenting not only affects the infant's development, it also disrupts the teen father's development by impairing his ability to achieve his potential for full emotional and psychosocial growth (Smith, 1984). This in turn, leaves the adolescent in a dependent role due to his incomplete emotional and social growth, as well as inadequate financial resources (Taucher, 1991). 
Elkind, (1988), describes teens as egocentric. Erikson (1980), comments that adolescence is a time for experimenting with various roles before settling into a particular "niche". Feedback from others on their role performance is important to adolescents. Marcia (1980), contends that each role is mentally rehearsed before it is publicly performed. and, based on positive or negative feedback from their "audience," adolescents will adopt, reshape or discard a role. It is through this self-exploration that male adolescents develop a "sense of who they are" (Freidberg, 1992; Marcia, 1980). Adolescence, therefore, is a period of psychological moratorium when teens may believe that they are not fully accountable for behaviour to which they are not totally committed (Erikson, 1963; Marcia, 1980). As a result, adolescent fathers may not be sensitive to the needs of their partners and children. Although male adolescents may be sexually mature, their psychosocial capacity for intimacy and parenting is underdeveloped (GAP, 1986). The combination of psychosocial immaturity and the added stress of adolescent fatherhood distinguishes teen fathers from their adult counterparts, and jeopardizes the chances of adolescent fathers to parent their children successfully (Elster \& Lamb, 1982).

De Lissovoy (1973), investigated parenting knowledge and ability of teen fathers whose average age was 17 years. Fathers in de Lissovoy's study reported they felt confused about their expectations, and felt unprepared to assume parenting responsibilities when confronted with the pregnancy. These findings were supported by Dallas and Chen (1998). One father in Dallas and Chen's study described his initial reaction when confronted with the pregnancy with this response: "I was not ready! The first thing out of my mouth - that ain't mine! You better find you a sucker!" (p. 216). 
The strain of the sudden transition to a new role is compounded by the fathers' own developmental needs and immaturity.

Teen fathers' immaturity conflicts with the needs of their children and may lead to abuse of the infant or the mother (Dallas \& Chen 1998; Jacob 1994). Dallas and Chen reported that fathers worry about the harm they may inflict to their infants, for example, "crazy stuff like throwing it or hitting it" (p. 217). This indicates that teen fathers developmental immaturity and lack of knowledge related to child development may lead to impatience and unrealistic expectations of their children.

\section{Section Summary}

Psychological and cognitive immaturity may pose major barriers to adolescent males and render it impossible for them to provide the quality of parenting required for enhancing a child's psychological development, even though these fathers have good intentions. Young men are struggling to complete adolescent developmental tasks which include identity formation and securing a mature self-image.

\section{Premature Fatherhood: Psychosocial Issues}

Research in this area has focused on comparing teen fathers with non-teen fathers in an effort to seek out psychosocial variables which may differentiate these two populations. Investigators have examined locus of control and personality traits of both groups of teens - fathers and non-fathers. Findings from these studies were inconclusive. 
In assessing male adolescents involvement in parenting, it is not only necessary to examine psychological factors, but also social issues which affect the teen's perceptions of fatherhood. Social issues include the teen father's family background, his education, employment status, and his relationship with his partner. Whatever the psychosocial factors considered, each person brings a different self-image to the fatherhood role.

\section{Social Variables of Adolescent Fatherhood}

Hendricks (1983), compared 38 unmarried teen fathers with 35 teens who were not fathers or married. Subjects in both groups were less than 21 years of age, with a mean of 18.2 years, and resided within the same geographical area. Hendricks found very little difference between the two groups. The study, however, showed that adolescent fathers were more trusting, more likely to be employed and not attending school, and to be nonchurch goers. Hendricks concluded that greater social disparity rather than psychological differences exists between adolescent fathers and their non-father counterparts. Recent investigators have reported similar findings (Cady \& Schurman, 1991; Stouthamer-Loeber \& Wei, 1998; Tuttle, 1988).

Researchers have in the past speculated that boys who have experienced inter - and intra - personal difficulties, and behavioural problems at an earlier age have a greater tendency to become a teen father (Robinson \& Barrett, 1982). To prove this point, Pauker (1971) undertook a retrospective analysis of results from the Minnesota Multiphasic Personality Inventory (M.M.P.I.) which was taken by boys in the ninth grade. Pauker subdivided the group of boys into two groups: those who were now adolescent fathers and those who were non-fathers. Both groups were matched for socioeconomic status. 
The average age of the boys when they took the M.M.P.I. was 14.7 years. Results indicated that there was little difference between the two groups, except that the boys who later became adolescent fathers had a tendency to be "less controllable and more active". Pauker, therefore concluded that inter- and intra-personal difficulties and behavioural problems in earlier youth do not increase the likelihood of teenage fatherhood. Although Pauker's findings contradict the notion that teen fatherhood is related to problems of youth, this stereotype continues to thrive today.

Elster, Lamb and Tavare (1987), found that there is an association between behavioural and school problems, and premature fatherhood. These findings contradict Pauker's contention that behavioural problems and teen fatherhood are not associated. More recently Stouthamer-Loeber and Wei, (1998), reported that adolescent fathers were more likely to engage in early sexual intercourse, drug exposure, and sadistic activities. When compared to non-fathers, the teen fathers were reported to be more hyper-active, impulsive, and untrustworthy. Stouthamer-Loeber and Wei (1998), reported that social correlates of teen fatherhood to be: living in a bad neighbourhood and coming from a broken home. According to Stouthamer-Loeber and Wei, delinquent acts increased the year participants became fathers. Data analysis revealed that teen fathers were three times more likely to engage in acts of break and enter, car theft, and drug trafficking during their first year of parenthood. These activities may have yielded extra money for the teen fathers. However, it is unknown whether it resulted in an increase in child support, since 
Stouthamer-Loeber and Wei, (1998), did not include this variable as part of their investigation.

Stouthamer-Loeber and Wei's (1998), findings support those of Elster, Lamb and Tavare.(1987). Both these studies, contradict Pauker's earlier findings that delinquency is not correlated to teen fatherhood. However, Pauker's finding that teen fathers come from broken homes was supported by Stouthamer-Loeber and Wei. These results indicate that a single variable is inadequate to explain the relationship between delinquency and adolescent fatherhood.

\section{Psychosocial Variables of Adolescent Fatherhood}

Offer and Offer (1974), conducted a survey of a group of sexually active adolescent non-fathers from a middle class background. Their report indicated that these males had lower self-esteem, lower teacher and psychiatric ratings, and a poorer relationship with their mothers, compared to males who were less sexually active and more socially conforming. Offer and Offer concluded that if these findings were true for sexually active males, then it is probably true for adolescent fathers.

Another group of researchers, (Johnson \& Staples, 1979), conducted a study in an effort to develop a program which would promote sexual responsibility, by providing goaldirected support and assistance to adolescent fathers and a group of "potential adolescent fathers." Johnson and Staples (1979), interviewed three (almost equal) groups of unmarried adolescent fathers and non-fathers. The 118 subjects included Blacks, Chicanos and Asians living in the Los Angeles area. There was almost equal representation of each 
ethnic group previously mentioned included in the sample. No other demographic information was available.

Johnson and Staples (1979), concluded that minority males use their sexual relationships with women and resultant pregnancy to boost their own self-esteem and enhance their self-image. According to Johnson and Staples minority men are excluded from "mainstream" societal activities and as a result have no outlet for expressing conventional masculinity, such as, employment, and will therefore express it through sexual activity. Despite this conclusion, Johnson and Staples, failed to produce any concrete, objective evidence which would distinguish adolescents who are likely to become teen fathers.

Other investigators have suggested that there may not be any psychological predictors for premature fatherhood. From the male adolescent perspective, the pregnancy occurs accidentally and is unplanned or unintended, and is the result of successful "bargaining" with his partner (Earl \& Siegal, 1980). Participants in one study stated that they were surprised by the pregnancy, although none of the teen fathers reported using any type of contraceptives. One of these fathers stated that "When you are having sex, you aren't thinking about this (pregnancy), what's going to be the result" (Dallas \& Chen 1998, p. 215). This supports the theory that adolescent fatherhood is unplanned and unintended.

\section{Locus of Control and Adolescent Fatherhood}

Locus of control is another psychosocial variable which is thought to differentiate adolescent fathers from non-fathers. These investigations have occasionally produced 
contradictory results. Hendricks \& Fallilove (1983), compared the data from two groups of adolescents: 48 unmarried fathers and 50 non-fathers. Subjects were recruited from social service agencies in a non-random manner. The data were collected via face to face interviews with each subject. Questions focused on the demographic characteristics of subjects, as well as their sexual knowledge, attitudes and sexual behaviour. Subjects were also asked about problems they had encountered as adolescents. The demographic data revealed that the average age of the fathers at the time of their child's birth was 16.6 years. Additionally, the fathers were usually not in school and tended to be employed. Data analysis also revealed that participants doubted the efficacy of contraceptives, and as a result of this belief, they were unlikely to use birth control. Based on this finding, Hendricks and Fallilove concluded that Black adolescent fathers (since all their participants were Black) were more likely to be influenced by external locus of control. These findings suggest that adolescent males with an external locus of control are less likely to use contraceptives.

Robinson and Barrett (1983), also examined locus of control. These investigators recruited 40 male adolescents with a mean age of 17.5 years for their study. All the subjects were recruited through social agencies and were later divided into two groups: fathers and non-fathers. Robinson and Barrett concluded that there were no differences in locus of control between the two groups of adolescents, and that teen fathers believe they have as much control of their destiny as do non-fathers. These findings were obtained in spite of the fact that non-fathers were from intact, middle income, professional or blue collar families, while the group of fathers were not. This paradox in Robinson and 
Barrett's findings may well be characteristic of the adolescent fathers' developmental level, socio-economic status, or cultural attitudes. Premature fatherhood is known to disrupt education, reduce employment opportunities, and result in economic dependency (Cady \& Schurman, 1991; Papalia \& Wendkos-Olds, 1995), leaving most teen fathers with little control of their destiny. In spite of the negative consequences of premature fatherhood, some adolescents view paternity as a short cut to adulthood and independence from parents (GAP, 1986; Silber, 1982).

Other investigators explored locus of control, interpersonal trust, coping styles, and family history of parenting out of wedlock in two groups of adolescents: 24 unwed fathers and 27 unwed, non-fathers (Williams-McCoy \& Forrest, 1985). The investigators applied a competence/effectiveness model which showed no difference between the two groups on the major study variables. However, Williams-McCoy and Forrest conducted a multivariate analysis which revealed that fathers were not only older but were more likely to be born out of wedlock. Additionally, the investigators reported that adolescent fathers were "somewhat less trusting" than non fathers. Based on these findings, WilliamsMcCoy and Forrest concluded that adolescent fathers were slightly more external in their locus of control.

Although some degree of consensus exists between Hendriks and Fallilove's (1983), study and Williams-McCoy and his colleagues (1985), it is unknown whether the same tool was used to measure locus of control in these two studies. The Nowicki Strickland Scale for locus of control was used by Robinson and Barrett, while Hendriks and Fallilove's questionnaire contained just two questions pertaining to locus of control. 
The differences in the instrument utilized may, to some degree, explain the contradictory results between these two studies. Nevertheless, the findings illustrate the need for more research in this area, and with this population. This being said, GAP (1986), stated that there are wide variations of temperamental styles and psychosocial circumstances which characterize adolescent fathers. It may, therefore, be unrealistic to expect widespread consensus, since self evaluative instruments like locus of control may be limited because of "complex and contingent conditions associated with issues such as teen parenthood" (Giblin, Poland \& Ager, 1988, p. 9). The question, therefore, remains as to the nature of the relationship between locus of control and premature fatherhood.

\section{Psychosocial Consequences of Teen Fatherhood}

The long lasting psychosocial consequences of adolescent fatherhood are well documented in the literature. Card and Wise (1978), reported the findings of a large national study in the United States in which subjects were interviewed at four intervals over a period of eleven years. These investigators found that only $10 \%$ of the teen fathers completed college by age 29 , compared to 30 percent of the men who delayed parenthood beyond age 24 . The findings also showed that adolescent fathers usually marry at an earlier age than their non-parenting counterparts, and the incidence of separation and divorce is greater than in their non-parenting peers. These findings were supported by Cady and Schurman (1991), who stated that adolescent fathers also share some of the negative consequences of premature parenting which adolescent mothers face. Cady and Schurman observed that adolescent fathers were more likely to be poor, less educated, under-employed and to suffer long-term social and economic disadvantages than their 
non-parenting peers. However, it is debatable which came first, since others argue that fatherhood is used as a means of increasing self-esteem and masculinity when social circumstances are bleak (GAP, 1986; Johnson \& Staples, 1979).

\section{Section Summary}

In summary, psychosocial variables are important and relevant to investigations centred on adolescent fathers. Teen fathers bring "...a variety of temperamental styles and psycho-social circumstances" (GAP, 1986, p. 25), to the parenting role. The research findings in this area can best be described as inconclusive. Psychosocial is a complex, multi-dimensional concept and, therefore, it is not surprising that the studies cited sometimes yielded contradictory results. Despite this, investigators unanimously agree that teen fathers are ill prepared to combine their developmental tasks with those of parenting. It is, therefore, not surprising that investigators have included parents and partners of adolescent fathers in an effort to find correlates of involvement in parenting by teen fathers.

\section{Parental and Partner Influence}

There is very little in the literature related to the impact parent/s or partners have on adolescent fathers and their intentions to accept or reject their parental responsibility. Pannor (1971) contended that parental involvement is crucial in assisting male adolescents to provide adequate parenting to their children. Good communication between a boy an his parents must be established in order for the adolescent father to assume his parental role and execute his parental responsibilities. Furthermore, Pannor goes on to state that parents must clearly define what the unwed father can do to help the teen mother with 
childcare responsibilities. The family remains important to the male adolescent despite changing roles and relationships, the influence of peers, and the great desire to conform to peer group norms (Benson, Strommen, \& Gavin, 1987; Offer et al., 1988).

Fatherhood is viewed as an important role, which can only be fulfilled by a male (Dallas \& Chen, 1998). Although strong mothers are capable of performing many tasks related to fatherhood, mothers do not fully compensate for absent fathers, according to Dallas and Chen. One subject in Dallas and Chen's study stated that "A son really needs his father 'cause a mother can't show him certain things that a father can by being a man" (p. 215). This shows that parents do have an impact on children's lives and that fathers are especially crucial to the development of sons - a boy learns to be a father by learning to be a man.

Christmon (1990) investigated the influence of the teen father's perception of his parents' expectations of his parental behaviour. Results of Christmon's study revealed no correlation between the adolescent's perception of his parents expectations and his own parenting role performance. However, when his mother and father where considered independently, Christmon reported a "significant relationship" between the teen fathers" parenting and their mothers' expectations. Christmon attributed his findings to the teen father receiving "clearer expectations" from his mother. Interestingly, investigators have reported that many adolescent fathers have come from single parent families headed by females (Dallas \& Chen, 1998; GAP, 1986). As a result, teen fathers may have a closer relationship with their mothers. Dallas and Chen reported that subjects in their study identified their mothers as an important source of information (1998). Adolescent fathers 
reported that their mothers were their primary source of information, even when both parents were in the home. Single mothers encouraged their sons to take responsibility for their children by recounting their own emotional pain and distress caused by their experience of teen pregnancy. This supports the view that parents do influence adolescents and usually are their first source of information (Offer et al. 1988).

\section{Partners/Teen Mothers Infuence on Teen Fathers}

In many instances, the relationship between the adolescent father and his partner appear to be strong. However, investigators have devoted very little attention to the influence of teen mothers upon the parenting behaviour of their partners (Cady \& Schurman, 1991; Cervara, 1991; Hendricks, 1982; Pannor, 1971). Vaz and her colleagues investigated the influence of involving teen fathers in the pregnancy. Adolescent fathers suffered fewer symptoms of anxiety and depression when they were involved with their partners in the decision-making process and discussions related to the pregnancy outcome (Vaz, Smollen \& Miller, 1983). Christmon (1990), hypothesized that the teen mother does indeed exert some influence on her partner's behaviour. However, when Christmon later studied the issue of partner influence on teen fathers, data analysis revealed no relationship between the adolescent mothers' expectation and their partners' perceived expectation of parenting. According to Christmon (1990), a plausible explanation for this finding may have been the quality of the couples' relationship. Unfortunately, the quality of the couples' relationship was not one of the variables measured in Christmon's investigation. 
Teen mothers can "set the stage" for adolescent fathers' greater involvement in parenting by including the father's surname when naming the baby. (Furstenberg, 1980). One investigator reported that fathers of infants with their birth fathers' surname were more involved in parenting (Cervara, 1991). Although Cervara did not elaborate on the details of the involvement, he speculated that by giving the baby his surname, the adolescent mother endorses the father's importance in her life.

According to Cervara, (1991), an adolescent father's behaviour is influenced, not only by the duration and depth of his relationship with his partner, but also the perceived feelings toward him from her parents. Maternal grandparents, in Cervara's study, reported that teen fathers were unpredictable and immature. As a result, the maternal grandparents remained distant toward the teen fathers. Despite the fact that two-thirds of the teen fathers in this study continued involvement after the birth of the child, and 8 of the 15 babies had been given their father's surname, the maternal grandparents did not alter their negative opinions about the adolescent fathers. This may be an indication that a negative stereotype of adolescent fathers continues to prevail (Robinson \& Barrett, 1982). Furthermore, Comer et al.(1987), suggested that peoples' subjective perceptions of acceptance and belonging are much more important than reality in influencing behaviour. It is not surprising, therefore, that adolescent fathers were hesitant to become consistently involved in parenting when there was a perceived feeling of disapproval and/or rejection, conveyed by either his partner or her parents, as was the case in Cervara's study, (1991). 


\section{Section Summary}

In summary, these findings indicate that adolescent fathers' involvement in parenting can be influenced, to some degree, by their parents and partners. This has been supported by Offer, Ostrov and Howard (1981), who stated that the evaluations an individual has of himself in relation to others affects his behaviour. Nevertheless, there is much to be learned from further investigations related to the influence of the adolescent father's parents and his partner.

\section{Adolescent Fathers Role Performance}

What then, is the role performance of adolescent fathers? This question has been addressed by a few researchers. Most report that teen fathers do want to assume parenting responsibilities. However, the anticipated responsibilities of fatherhood compound the already challenging tasks adolescents face. As a result they may experience difficulties in assimilating their new role.

Adolescent pregnancy continues to receive public attention; however, most of the interest is centred around the mother and her baby. The fact that there are adolescent fathers who are involved in parenting is almost ignored (Christmon, 1990). Although a great deal is known about parenting behaviour of adolescent mothers, little is known about teen fathers' behaviour in this regard. Some fathers are described as "phantom fathers" (Cady \& Schurman, 1991), but many teen fathers have accepted their responsibilities and have tried to fulfill their parental obligations (Dallas and Chen, 1998; Taucher, 1991). In light of these reports, researchers have shifted their focus to include adolescent fathers in 
their investigations which have exposed strengths and weaknesses of teen fathers' parenting styles.

Christmon (1990), investigated the relationship of self-image and perceived willingness of adolescent fathers to assume parenting responsibility among 43 Black unwed fathers, age 15 to 21 . Findings reported by Christmon indicated that there is a positive relationship between the two variables, namely, self-image and perceived parenting behaviour. Thus, Christmon concluded that the adolescent's ability and willingness to take responsibility for parenting increases when his self-image and his parenting expectations increase. A teen father's interest in parenting may not always result in his becoming an effective parent. This scepticism about the ability of teen fathers to parent effectively is supported by investigators who found that the combination of adolescent developmental immaturity, and lack of knowledge and experience with children, sometimes have a deleterious outcome for the offspring of young parents. (Dallas \& Chen, 1998; de Lissovoy, 1973; Jacobs, 1994; Taucher, 1991).

Many adolescent fathers "drop out of school" and seek employment in order to provide financial support for their children (GAP, 1986). Others reported that fathers were "proud of their children," gave them gifts, visited frequently or shared living arrangements with the mother, and provided financial support for their children (Dallas and Chen 1998; Westney, Cole \& Munford, 1986). Evidence of financial support was also found by other investigators. A follow-up of adolescent fathers over a five year period, showed that $33 \%$ of these fathers continued to provide modest financial support. Furstenberg (1980) 
reported that teen fathers provided a median of $\$ 600.00$ per year for child support. Furstenberg concluded that teen fathers failure to provide for their children, was in part, due to the lack of inclusion by medical and social services, rather than the irresponsible attitudes of the fathers.

Since financial support is not the only activity involved in parenting, Panzarine and Elster (1983), asked 20 adolescent fathers how they perceived their parenting role. Adolescent fathers in this group equated a large part of the "fathering role" to being a "provider". The fathers in this study described their activities in preparing for the birth of the child. All the fathers stated that they were actively seeking opportunities which would improve their financial potential to provide support for mother and baby. Some of the fathers had left school to seek full time employment; others, who were already employed, sought better jobs or worked more overtime. The investigators also reported that 18 of the expectant fathers were involved in activities such as: fixing up a crib, decorating a room, purchasing infant clothing, toys, and other baby supplies. Fourteen fathers reported that they spoke with other new fathers of their own age so that they could find out their experiences and feelings on what it is like to be a father.

Other investigators have reported that adolescent fathers visit regularly and consistently with their children; however, the fathers' immaturity, combined with his lack of preparation for parenting, is very likely to jeopardize the quality of care that these fathers are able to give their children (Christmon, 1990). 
In an effort to investigate parenting knowledge and ability of fathers, as well asmarital stability and child development, de Lissovoy (1973), interviewed 48 married, adolescent couples. The couples were interviewed at five different intervals, over a period of three years. Average age of the girls was 16.5 years, while the boys had an average age of 17 years. Forty-six couples were expecting a child at the time of their marriage.

Results of de Lissovoy's study indicated that the fathers were generally unfamiliar with the developmental norms of infants and older children. De Lissovoy concluded that the fathers' lack of knowledge and experience with children, combined with their unawareness of child development norms and poor economic resources, as well as a general feeling of disappointment with their own lives, lead to unrealistic expectations of their children and marital instability, and lowered their threshold of tolerance, (1973). De Lissovoy failed to mention how many fathers remained involved and to what extent at the end of his three year follow up. Precocious parenting by ill-prepared adolescent parents who are themselves experiencing an identity transition, while trying to adapt to married life, places adolescent couples at higher risk for marital instability and parenting failure.

Elster and Panzarine (1981), argued that male adolescents are likely to be more emotionally vulnerable to the stresses surrounding the pregnancy than adult fathers. Additional turmoil may be partially attributed to the adolescents' premature role transition which is "out of step" with societal expectations. The psychological immaturity of adolescent fathers not only makes them more vulnerable to stress, but also reduces their 
ability to manage their stress. Elster and Panzarine (1981), interviewed 20 adolescent fathers from low socio-economic families, in an effort to assess the amount and source of stress associated with the pregnancy and fatherhood.

Four sources of stress were identified by the 20 fathers in Elster and Panzarine's study. Adolescent fathers were concerned about their economic status. The fathers worried about financial support for the child, quitting or continuing school, and finding a job and maintaining it. These fathers expressed concern about their partners' health, the course and outcome of labour and delivery, and the future health and welfare of the baby. The fathers' next area of concern revolved around parenting issues. This group of fathers were worried about their parenting skills and abilities, which included discipline and child care tasks. Finally, the impact of fatherhood upon their interpersonal relationships with their partners, friends, and parents was of concern to this group of subjects. Elster and Panzarine concluded that the nature of adolescent development is such that adolescent males have not yet developed the capacity and self-esteem to deal with the stresses which an unplanned pregnancy can create (1981).

Dallas and Chen (1998), conducted a study involving a small focus group of adolescent fathers to explore the "lived experience of adolescent fathers". A convenience sample of five teen fathers was recruited from a public high school, in a mid-western city in the United States. Ages of the fathers were not specified. However, the participants' children were between the ages of 10 to 36 months. Analysis of the data revealed that three of the five fathers responded negatively to the news of the pregnancy. Fathers in this study reported feeling confused about their own expectations of fatherhood, and feeling 
ill-prepared to assume their parenting role. When confronted with the pregnancy, one father summed up his reactions thus: "You don't really feel like a father during the pregnancy 'cause you don't see it, you don't really feel it. All you know is that in nine months you are going to have a son or a daughter" (Dallas \& Chen, 1998, p. 215). In spite of this initial negative feeling, all fathers reported "feeling like a father" at the time of participation in the focus group. Nevertheless, these young men continued to struggle with the burdens of premature fatherhood.

One young man describes the conflict he felt trying to assimilate the developmental tasks of adolescence with those of fatherhood: "I am not ready. I wasn't ready, you know, but now that I have a child, and now its here, I have to be ready. I have to! And I have to be there for him all the time. And I have to give up things like partying and hanging out with my friends." (Dallas \& Chen, 1998, p. 216). Fathers' participation in parenting consisted of provision of clothes, money, diapers, and baby equipment. However, these fathers remained economically dependent on their parents for their own personal needs. Additionally, fathers reported performing a wide array of child care activities, such as, accompanying sick children to medical appointments, comforting crying children, feeding, and changing diapers.

Dallas and Chen's study provided valuable insights into adolescent fathers' experiences in parenting, (1998). Clearly, teen fathers do not possess the psychosocial capacity to cope with the responsibilities of fatherhood, while still coping with the challenges of adolescent development (Papalia \& Wendkos-Olds, 1995). Adolescent 
fathers will therefore require assistance in the parenting role, so that they can simultaneously continue with their developmental tasks. Furthermore, these results illustrate teens' ambivalence when confronted with premature fatherhood. Additionally, results from Dallas and Chen's study reaffirmed findings of previous investigators - that teen fathers do want to be involved with their children but lack the maturity and resources to do so (Christmon, 1990; Smith 1984; Taucher, 1991).

\section{Impact of Teen Father's Involvement with Mother and Baby}

An adolescent father's parenting ability is not only important for his personal growth and development, but also that of his partner and child (Christmon, 1990). Researchers have begun to examine the impact of adolescent fathers' involvement upon their children and their partners. Elster and Lamb (1982), proclaim that service agencies, which include fathers, have an indirect positive influence on the mothers' self-confidence and competence. The positive outcomes associated with having adolescent fathers involved with teen mothers and their children have been summarized as:

1. Increased maternal sense of security

2. Increased maternal sense of confidence

3. Improved paternal self-esteem

4. Improved children's sense of trust, self-esteem, and socialization skills as compared with children whose fathers were not involved with parenting (Sander \& Rosen, 1989). 
Financial support from fathers has a positive influence upon teen mothers. This support not only helps to provide the necessities for the baby, but it also promotes the teen mother's feelings of security, thereby increasing her interaction with the child (Caddy \& Schurman, 1991; Christmon, 1990). Financial support increases the teen mothers' ability to provide for the material needs of her child, and increases her perception of being a competent and "good mother". Furthermore, the teen mother feels greater security in her relationship with the teen father when he provides some financial assistance. This results in greater mother - child interaction.

Adolescent fathers' emotional support is also important, especially in the light of societal disapproval which is still associated with teen pregnancy and usually directed at the teen mother. Cervara (1991), observed that the teen mother's relationship with her parents may become strained due to the pregnancy, and that emotional support from her partner is critical in assisting to alleviate that stress. Cervara points out that teen mothers often have to make a choice between their parents and the baby's father, since maternal grandparents do not always welcome teen fathers.

Teen fathers often face anger and hostility from the adolescent mother's family (Hendricks 1980; Robinson \& Barrett, 1986). Additionally, the teen mother's family often express anger and resentment about the possibility of having to assume primary responsibility for the child (Cervara 1989, Furstenberg 1980.) Adolescent fathers have not yet developed interpersonal and negotiation skills necessary to overcome the communication barriers and attitudes of maternal grandparents (Dallas \& Chen, 1998). 
As a result, teen father's interest in remaining involved with parenting may wane over time according to Furstenberg, (1980).

\section{Effects of Teen Fathers Involvement in Parenting: Baby}

In 1976, Furstenberg undertook one of the largest most indepth investigations which explored various aspects of teen pregnancy, including an interview with adolescent fathers. Four hundred and four, mostly Black adolescent mothers from lower class and blue collar families were interviewed at one , three and five year intervals after giving birth.

Fathers of these children were also included in the third interview. However, Furstenberg commented that it was a difficult task because of address changes, fathers' failure to maintain contact with the mothers and children, and fathers' refusal to participate in the study. Fathers who agreed to participate were interviewed alone, in their own homes. The final interview involved the children and their interview focused on their development, for which they completed a battery of small tests.

Analysis of the data in Furstenberg's study revealed a "slight association" between parental involvement and the number of behavioural problems reported by the mothers in their children. Behaviours exhibited by these children included frequent temper tantrums, taking things which belonged to others, and frequent fighting with peers. Performance in the Preschool Inventory Tests (P.S.I.), was positively correlated to fathers' continuous involvement with their children. Lower P.S.I. scores were reported in children whose fathers were absent from the home. This difference was noticeable, regardless of the 
economic status of the family. Children from two parent families consistently performed at a higher level in all the tests. Furstenberg concluded that fathers' involvement with their children may be responsible for increasing a child's cognitive abilities. It is unclear whether Furstenberg differentiated between fathers' "continuous involvement"and "two parent" families, or whether the performance of the children differed in these two groups.

A weak relationship between the children's social development and the magnitude of their continuous relationship with their fathers was also reported by Furstenberg (1976). Children were observed to have better scores in cognitive and social skills if they came from homes where parents were married and remained married. There were no differences in the children's scores whether fathers visited frequently, periodically or not at all. Furstenberg concluded that extraneous factors could have contributed to the cognitive and social development of the children whose fathers were uninvolved. These findings were later supported by Bozett (1985), who pointed out that fathers must be involved in caretaking activities, if a positive influence is to be realized. Bozett emphasized that caretaking must go beyond physical care such as feeding, and include other childcare activities such as reading to, and playing with children.

\section{Section Summary}

Most adolescent fathers do not fit the stereotype once applied to them. Teen fathers have shown that they are willing to accept the responsibilities, and challenges of premature fatherhood. Despite numerous barriers, most young fathers have made a valiant effort to provide financial support and participate in child care activities. Paternal support is important to the physical, social and intellectual development of the child 
(Sander \& Rosen, 1989). Responsibilities of premature fatherhood may, however, conflict with the developmental tasks of adolescence.

\section{Summary and Significance of Study}

This chapter presented an overview of self-image and its impact on male adolescents' behaviour during a developmental period in which young men make the physical, psychosocial and cognitive transition to adulthood. Self-image is an illusive term which is generally used to describe a psychological process involving an integration of the three "selves": "good me", "bad me", and "not me". Although, the groundwork for self-image is established in infancy, it is a life-long process which may be a source of intense emotions, conflicts, stress, and turmoil during the adolescent years. Researchers have linked volatile, impulsive, male adolescent behaviour to this developmental process, which may lead to unprotected sexual intercourse, resulting in pregnancy and fatherhood, for which he is ill-prepared.

Researchers and service providers have traditionally overlooked the role of fathers in parenting their children. This has been true for all fathers; however, it was especially true in the case of adolescent fathers. Fortunately, a new dawn is awakening and investigators have begun to pay attention to the role of all fathers (adolescents, adults, married, and unmarried). Results from these studies have clearly indicated that fathers are not only important to their childrens' physical growth, but also influence the psychological and social development of their children. Additionally, there is evidence that teen fathers are more involved in their childrens' care than investigators, service providers, and 
professionals were first aware. Despite his involvement with his child's care, the adolescent father is unfamiliar with the development norms of infancy and early childhood. Futhermore, the extent and quality of teen fathers' parenting remains uncertain, in light of their immaturity and lack of preparation, as well as their financial resources to support a family. The responsibilities of fatherhood conflict with the tasks of adolescence and place teen fathers at high risk for parenting failure.

Two approaches have been taken by researchers in their exploration of psychosocial issues surrounding adolescent fatherhood. First, they have examined the psychosocial consequences of premature fatherhood, and secondly, the investigators have explored the psychosocial differences between teen fathers and their non-father peers. However, the divergent designs, and findings from retrospective data derived from tests designed to measure different variables are extrapolated to issues related to teen fatherhood. Nevertheless, investigators have reached a consensus on some of the psychosocial consequences of adolescent fatherhood, such as: decreased earnings, lower education, and greater dependence on social assistance or parents for financial support.

The influence of parents and partners upon the parenting behaviour of teen fathers has not received a great deal of attention from researchers. However, there is some evidence that adolescent fathers tend to seek parental advice when confronted with difficulties in parenting. Teen fathers also identified their partner as a source of advice. Thus, by assessing and acknowledging adolescent fathers' vulnerability, healthcare and other service providers can assist and guide teen fathers to develop more realistic and 
appropriate parenting expectations.

The literature review identified several variables which may be influential on teen fathers' decision to become involved in parenting. These variables include self-image, the teen father's own expectations and perceptions about his role as a parent, as well as the possible influence of significant others (parents and partners). Thus, several testable hypotheses emerged from this literature review:

1. Perceived parenting role performance of the adolescent fathet/partner is positively related to his self- image.

2. Perceived parenting role performance of the adolescent father/partner is positively related to his parenting expectations.

3. Perceived parenting role performance of the adolescent father/partner is positively related to his perceptions of his parents expectations of him.

4. Perceived parenting role performance of the adolescent father/partner is positively related to his perception of his partner's expectations of him.

This researcher anticipates that findings from this study will assist nurses and allied care providers in making a more realistic assessment of adolescent fathers. Areas of intervention can be identified and the knowledge used to develop and implement programmes which may better meet the needs of teen fathers. It is also anticipated that this study will provide insight into a much forgotten neglected component of teen pregnancy in this Province - namely adolescent fathers. Finally, this study will add to the knowledge base of this complex problem - teen pregnancy and precocious fathers. 


\section{CHAPTER IV}

\section{Methodology}

This chapter will focus on design, method, and conduct of this study. A description of the instruments used in this study will also be included. Limitations of the study's design and summary will conclude this chapter.

Research Design

A descriptive correlational design was selected to explore the influence of selfimage and perceived role expectations of adolescent fathers on their perceived role performance. Specifically, this study was designed to address the following hypotheses:

1. Perceived parenting role performance of the adolescent father/partner is positively related to his self- image.

2. Perceived parenting role performance of the adolescent father/partner is positively related to his parenting expectations.

3. Perceived parenting role performance of the adolescent father/partner is positively related to his perceptions of his parents expectations.

4. Perceived parenting role performance of the adolescent father/partner is positively related to his perception of his partner/infant's mother expectations.

Polit and Hungler (1991), state that when the focus of a study is to explore the relationship between several variables rather than to imply causal relationships, a correlational design is most appropriate. A correlational design was therefore chosen for 
this study because of its ability to uncover relationships among variables as they exist within the population of interest, namely, adolescent fathers. Since the purpose of this study is congruent with a correlational design, it was selected to examine variables which are thought to promote parenting involvement of adolescent fathers. The design will also enable the researcher to determine if a relationship exists between the variables: selfimage, perceived role performance, perceived role expectations of self, parents and partners.

A quantitative approach was chosen since it facilitated collection of a large amount of data in a relatively economical manner. Additionally, a quantitative approach allowed subjects to remain relatively anonymous (Polit \& Hungler, 1991), since adolescent fathers are known to be reluctant to identify themselves (Dallas \& Chen, 1998; Robinson \& Barrett, 1982). Considering that little is known about teen fathers, a correlational design, using a quantitative data collection approach offered an efficient and effective means whereby a large amount of data could be collected over a short period of time. This meets the criteria of correlational research as described by Kerlinger (1986); Lobiondo-Woods and Haber (1990); and Polit and Hungler (1991).

\section{Sample}

This study relied on a convenience sample of 30 acknowledged (named) adolescent fathers/partners of expectant teen mothers recruited from a large urban hospital. An average of 22 adolescent mothers give birth each month at the above facility. Approximately $80 \%$ of these mothers had identified an involved male partner. 
Although partners were identified, they did not always accompany the mothers since some mothers were transported to this facility from distant locations. Another 10 to $15 \%$ of teen mothers identified partners who were beyond 21 years of age. Thus, the total possible sample population from which subjects could be recruited was reduced to $65 \%$ or approximately 14 teen fathers/partners per month. It was therefore, estimated that a recruitment rate of seven per month was feasible, since the projected rate of refusals was expected to be high. While a large sample is considered ideal for correlational design (Brink \& Woods 1990), and given the expected difficulties in recruiting subjects, this was an impossible task to achieve in the four months to which this study was limited. While convenience sampling is both economical and practical, it is the weakest form of subject recruitment because it increases the risk of bias, especially when used in heterogenous populations (Polit \& Hungler, 1991, p. 260). In order to reduce the influence of extraneous variables and to decrease the risk of bias, the researcher developed inclusion criteria for subject recruitment.

To increase the probability of recruiting 30 subjects, the age criteria for participation was raised to age 21 , since dating patterns of girls show that their male partners are usually two years older, and generally attain psychosocial maturity later (Papalia \& Wendkos-Olds 1995). Nakashima and Camp (1984) found that males who are beyond the age of 20 and involved with adolescent females, are less mature and more like adolescents. Rubenstein (1991) takes this further and states that adolescence actually extends to age 21 . Additionally, most of the research involving adolescent 
fathers/partners have included subjects beyond age 20 (Barrett \& Robinson, 1986; Cady \& Shurman, 1991; Christmon, 1990).

Males eligible to participate in this study were defined by the following criteria:

1. Acknowledged (named) partner/husband of an expectant mother who is age 19 or less.

2. Age 21 or less

3. Able to speak, read and write English.

4. Able to give informed, written consent.

\section{Setting}

The sample was recruited from two settings, an Adolescent Prenatal Clinic and Childbirth Classes, located in a large urban hospital in a mid-western Canadian prairie city. The facility is located in a socially and economically heterogenous neighbourhood, with ethnic and cultural diversity. While many of the hospital's clients reside within this area, a substantial number come from outside, since the facility is a major referral centre for physicians, not only within Manitoba, but also from Northwestern Ontario and Nunavut. Thus, the Adolescent Prenatal Clinic has a large geographic catchment area. Approximately 50 to $60 \%$ of the population served at this facility are Aboriginal. Staff in the Adolescent Prenatal Clinic estimated that the majority of the teen mothers are unmarried, but have identified a male partner as a "support" person. However, the male support person identified by the expectant mother is not necessarily the biological father of the expected baby. 
Both recruitment sites, the Adolescent Clinic and the Childbirth Classes, are located in the basement of the urban hospital. Participants in the Childbirth Classes are usually receiving prenatal care through the Adolescent Clinic. Additionally, the nurse educator who conducts these classes is part of the clinic's staff. The similarity between the two settings ends here.

The chief aim of the Adolescent Clinic is to provide comprehensive, age appropriate prenatal and postnatal care in a non-threatening environment for women less than age 18. A multi-disciplinary team including an obstetrician-gynaecologist, midwife, nurses, nurse-educator, social workers, and dietician staff the Adolescent Clinic. The focus of the clinic is to provide medical care and address on-going social concerns, whereas Childbirth Classes provide education related to pregnancy, labour and delivery, and care of the new born. Expectant fathers/partners are encouraged to participate in both the clinic and the classes. Clients in the Adolescent Clinic are restricted to age 18 or less. In contrast, the Childbirth Classes include adult couples. Adolescent males may be reluctant to identify themselves in the presence of adult couples due to guilt or embarrassment. The recruitment site was not expected to influence the study's outcome, since most of the teen participants in the Childbirth Classes come from the Adolescent Clinic.

\section{Conduct of the Study}

\section{InstitutionaV/Access and Subject Recruitment}

Approval to access clients at the hospital was granted by the Ethical Review Committee, Faculty of Nursing, University of Manitoba (Appendix G), and the Health 
Sciences Centre (Appendix H). Departmental access was granted by the Director of Patient Services. The Unit Manager (UM) and staff of the Adolescent Clinic were provided with an outline of the study and asked to identify prospective subjects [Appendices $F, F(I)$ ]. All patients have an extensive social and medical history taken during their first visit to the clinic. Patients who identified an involved partner were asked if it were possible for the researcher to speak with her. The researcher was given the name/s of the expectant mothers who agreed to their partners being approached by the investigator. Following this, the investigator met with these expectant mothers and obtained the names of their partners. If partners were present, they were invited to participate in the study (Appendix D). The expectant mothers were, therefore, "gate keepers" for accessing subjects.

Following agreement to participate in the study, a written consent was obtained from each subject (Appendix E), and each was given a copy of the agreement. Questionnaires were administered at this time. The researcher remained available during the completion of the questionnaires, in case subjects required help. If however, it was inconvenient for the teen father/partner to complete the questionnaires after consent was signed, arrangements were made for them to be completed at a mutually convenient time.

Expectant fathers/partners who met the study's inclusion criteria but were not accompanying their partners to either the Adolescent Clinic or Childbirth Classes were sent an invitation to participate in the study via the expectant mother [Appendix D (1)]. If a telephone was available, the investigator obtained the number from the expectant mother, who was informed that her partner would be contacted by the researcher in a few 
of days. Twenty-four invitations were sent out to the fathers/partners via the expectant mother, but none responded. After a waiting period of two days, the researcher telephoned each adolescent father/partner who had been sent a written invitation. Unfortunately, only two fathers/partners were successfully contacted. Both declined participation for unspecified reasons.

Expectant fathers/partners who were identified as being involved but did not have a telephone were also sent invitations to participate in the study via the expectant mother. Arrangements were made to meet the recipients of these invitations at the expectant mother's next prenatal visit [Appendix D (II)]. Eight invitations were sent out in this manner. Unfortunately, none of these expectant fathers/partners responded. Teen mothers were not asked the reason for their partner's absence on the subsequent visit. It is unknown how many of these invitations were actually given to the identified fathers/partners by the expectant mother.

Fifty-six teen fathers/partners who were identified through the expectant mother were approached by the investigator. Of these 56 people, 10 were beyond age 21 . One 17 year old withdrew because he felt "the questions were stupid." When asked to specify, this young man responded by reading statement five in the Offer Self-Image Questionnaire: "I would not hurt someone for the 'heck of it'." The other 15 (mean age 18.2 years) refused to participate for unknown reasons. The final sample size of 30 comprised 29 teen fathers and one partner, who was not the baby's biological father, but had now assumed the fatherhood role. Only 2 fathers were recruited from the Childbirth Classes. 
All subjects who participated in the study were reimbursed for travel with the sum of five dollars $(\$ 5.00)$. Subjects were given an opportunity for debriefing, following completion of the questionnaires. Polit and Hungler (1991), believe that debriefing facilitates open communication about events which may provoke stress and anxiety for some individuals. Debriefing assists individuals to put the experience in perspective, thereby reducing their stress and anxiety. Thus, the procedure was as follows:

1. Ethical and institutional approval

2. Approach for contact

3. Sign consents

4. Administer questionnaires

5. Debriefing/addressing participants' concerns

6. Complete data analysis

7. Distribute results to participants, if requested.

\section{Instrumentation/Questionnaires}

The design of this study involved the administration of the following questionnaires: Offer Self-Image Questionnaire - Revised [OSIQ-R], (Offer, Ostrov, Howard \& Dolan, 1992), Perceived Role Performance- Expectations of Self and Others (Christmon, 1987), and a demographic form (Appendices: A, B \& C). These questionnaires will be described in detail in the following sections.

\section{Offer Self-Image Questionnaire - Revised (O.S.I.Q. - R)}

The OSIQ-R is a self-report personality test which is generally used to measure the psychological development of adolescents - boys and girls (Appendix A). The 
questionnaire, first developed in 1962, contained 130 items which were clustered into "... eleven content areas considered important in the psychological world of teenagers" (Offer, Ostrov \& Howard, 1977, p. 1). Theories of adolescent development are incorporated with the authors' clinical experience in psychiatry. Two major assumptions governed the operational approach of Offer and his colleagues in the development of the OSIQ.

First, it is necessary to evaluate the adolescent's functioning in multiple areas, since he can master an aspect of his world while failing to adjust in another. Second, the psychological sensitivity of the adolescent is sufficiently acute to allow us to utilize self description as a basis for reliable selection of subgroups. Empirical work with the OSIQ has attended to validation of these assumptions (Offer, Ostrov, \& Howard, 1977, p. 1).

Three changes were made to the format of the OSIQ by Offer, Ostrov, Howard and Dolan, (1992). These changes which apply to the test administration and scoring procedures include: deletion of one item related to normalcy of sexual organ, renaming of scales but not the content, and introduction of the metric scaled scores, that is, the T-score (Offer et al., 1992, p. 16). Following these changes the OSIQ was renamed OSIQ-R. T-scores for the OSIQ-R are calculated by using a mean of 50 and standard deviation of 10. According to Offer et al., T-scores are widely used for reporting results of personality tests. Additionally, Offer et al. believe that the aforementioned changes in the OSIQ improved the instrument's clinical utility. Both the original OSIQ and the revised OSIQ- $R$ are self-report questionnaires which have been widely used to assess self-esteem and adjustment of adolescents, as well as young adults who may still be dealing with unresolved adolescent issues (Adams, 1986; Offer et al., 1992). 
The revised OSIQ-R (1992) contains 129 items which are inclusive of 12 scales measuring/assessing important areas of psychosocial functioning in adolescents.

The 12 content areas covered in the OSIQ - R are: Emotional Tone (ET), Impulse Control (IC), Emotional Health (EH), Social Functioning (SF), Family Functioning (FF), Vocational Attitudes (VA), Self-Confidence (SC), Self Reliance (SR), Body Image (BI), Sexuality (SX), Ethical Values (EV), and Idealism (I). According to Offer et al. (1992), these 12 content areas represent aspects of functioning which are thought to be important to adolescents (p.20).

Readability of the OSIQ-R has been assessed and determined to be at the mid-fifth grade level, thus making it suitable for older individuals with a lower than average reading skills (Offer et al., 1992). Responses to the statements in the questionnaire are based on a six-point scale, ranging from "describes me very well" to "does not describe me at all." (See Appendix A). According to Offer et al. (1992) the score from the 12 content areas provides a self report about adolescents' self-perceptions of the self, specifically, the self-image. T-scores below $\mathbf{4 0}$ are indicative of a negative self-image, whereas $\mathrm{T}$-scores above 40 indicate a positive self-image. Offer et al. believe the higher the $\mathrm{T}$-score, the more well adjusted the individual. This questionnaire was selected for use in the study because of qualities already mentioned and also its use in similar studies by Christmon (1990), and Elster and Panzarine (1980). Other studies which used the OSIQ are: Pletsch et al. (1991) with early adolescents age 11 to 14 years; Slap et al. (1994), with adolescent girls in Australia, and Sawyer et al. (1995), measuring self-image of 
adolescents with Cystic Fibrosis. Permission for use and purchase of the OSIQ-R was granted by the copyright owners.

\section{Reliability and Validity}

Reliability was assessed through Cronbach's alpha and has been reported to be within an acceptable range. The OSIQ-R was determined to be internally consistent with coefficients ranging from a low .60 to a high .90 . These figures translated to a median alpha coefficient greater than .70 (Offer et al., 1992). The design of the OSIQ-R is inclusive of the 12 scales which Offer et al. deem important to adolescent functioning. Although, the developers of the OSIQ-R anticipated intercorrelation of the 12 scales, Offer et al. were of the belief that the correlations should not be too great, since each scale measured different aspects of the same construct. Component scale correlations across 264 coefficients yielded a median correlation of .48 , which Offer et al. believe to be within their expected range of construct validity for the OSIQ-R. Two scales, Idealism and Sexuality, showed "very low" correlations with remaining measures. Offer et al. (1992) explained this phenomenon by pointing out that "Sexuality is a higher bipolar scale and extreme scores in either direction" indicate difficulty in adjustment (p. 20). On the other hand, Offer et al. state that "Idealism" is believed to reflect superior psychological functioning higher than the social and emotional dimensions of other scales. A moderate intercorrelation among the other scales ranges between .3 to .7 . Thus, Offer et al. believe that these results support the retention of the 12 scales. 
A factor analysis was performed to examine relationships between scales. Offer et al. (1992) report that over $58 \%$ of the variance is related to two factors. The first factor is considered a "general, inter-image factor," and includes these scales: IC, ET, BI, SF, FF, SC, EH, SR, SX, and VA. Offer et al. contend that the second factor is related to “... areas of self- image that are more influenced by societal image, morality, and social changes" (p. 22), which include: EV, I, SX, and VA. Construct stability of the OSIQ-R through test-re-test values over a two-year period produced a moderate reliability of .70 , in a sample size of 71 and $p$ less than .001 . An eight year follow-up of adolescent subjects by Offer et al. shows that "...the OSIQ accurately predicted future psychological functioning" (p. 25), thus, providing evidence of predictive validity.

Questionnaire: Perceived Role Expectations of Self and Others, and Perceived Role Performance.

This questionnaire was developed by Kenneth Christmon in 1987. Christmon used the contents of three books to guide the development of the four scales. These books were: 1) How to Parent (Dodson, 1970), 2) Child Behaviour (lig, Ames, and Baker, 1981), and 3) A Community of Caring (Joseph F. Kennedy Foundation, 1982). Two scales focused on the male adolescent's perceived role expectations and his perceived role performance, while two scales focused on the perceived role expectations of others, that is, parents and partners (Appendix B). 
The scale measuring the adolescent father's own role expectations is designed to elicit the male adolescent's preconceived ideas of parenting. This is done by asking him what he believes his responsibility is to his child. For example, "it is my responsibility to provide financial support for my child." Statements are presented in a Likert scale format and respondents are asked to choose the most appropriate answer which describe them. Choices range from "strongly agree" to "strongly disagree". This section of the questionnaire is made up of six questions. A low score is indicative of high expectations for fathers to be involved in parenting activities.

There are eight items on the next scale which assesses the amount of responsibility fathers perceive themselves to be taking for their children's care. Questions are presented to respondents in the same format as previously described, for example, how often do you think you will change your child's diapers? Choice of responses to the questions ranges from "total responsibility" to "no responsibility" (Appendix B). A low score indicates that the fathers "intended" to assume a great deal of responsibility for infant care. The last two scales follow the same format as previously outlined. These scales measure the teen fathers' perceived role expectations of others: partners and parents. A low score in these scales indicates that the father perceives "others" to have high parenting expectations of him.

Christmon (1987), utilized the split-half technique to determine reliability of the "Perceived Role Expectations and Role Performance Questionnaire." Cronbach's alpha showed inter-item reliability of the role performance scales to range from .49 to .91 , while 
the Cronbach's Alpha reliability coefficients for role performance, father's perceived expectations of himself, perceived expectations of partner, and perceived expectations of father's parents (mother and father) respectively were: $.71, .86, .49$, and .60 . Christmon acknowledged that the Cronbach's alpha coefficient was low for the scales which measured the adolescent father's own expectations and the perceived expectations of his partner. However, these were within an acceptable range. Therefore, no changes were made to the questionnaire.

Construct validity of the scales was determined by a panel of three experts who had worked with adolescent parents for a number or years. (Christmon, 1987). According to Christmon, no problems were encountered during the administration of the questionnaire which was used by the author in a study on Black adolescent fathers. Although this questionnaire has only been used in one study, the investigator was satisfied that the instrument measured the variables for which it was designed.

Permission for use of this tool was granted by the Catholic University of America, Department of Social Work, Washington.

\section{Demographic Data Sheet}

The demographic questionnaire contains items which were identified in the literature as being related to teen fathers and their involvement in parenting. Demographic characteristics such as age, education, and employment status provide a profile of the subjects. Additionally adolescent fathers' involvement in parenting and role performance may be influenced by the length of his relationship with the expectant mother, marital status of the couple or his living arrangements. Other factors affecting the adolescent's 
parenting performance include parental support and influence. Teen fathers are known to lack patience and knowledge of child development, consequently they risk parenting failure (Furstenberg, 1980). Additionally parenting style may be affected by the teen father's own experiences, for example, physical abuse and being born out of wedlock to young parents. Questions related to these factors were included in the demographic questionnaire.

A record of the number of subjects who declined participation in the study was kept. Although the record did not include the subjects' names, their characteristics and reason/s for declining, if given, were included.

\section{Ethical Considerations}

The conduct of the investigator was guided by the CNA's Code of Ethics for Nursing and the Tri-council Conduct for Research Involving Humans (1997). Permission to access subjects at the urban hospital was obtained. Written informed consent was obtained from all subjects who voluntarily agreed to participate in this study. The researcher acknowledged the difficulty of obtaining informed consent from minors However, to protect the prospective participants and their partners' privacy and confidentiality, parental consent was waived. Many parents have not yet been informed of the pregnancy. Therefore, minors who agreed to participate gave informed consent as "emancipated minors". A written explanation of the study's purpose and relevance was available to subjects. Benefits of participating in the study were outlined. These included an opportunity for the expectant father to talk to someone about "his feelings" and increase his sensitivity regarding his parenting skills which may contribute to his becoming a better 
father. Aside from these benefits, subjects were reassured they would not be penalized, should they decline participation. Additionally, subjects were reassured that they retained their right to withdraw from the study at any time, without obligation or penalty. Subjects were not exposed to any experimental conditions or treatment.

Privacy, confidentiality, and anonymity were protected - questionnaires did not contain any identification which connected them to subjects. All consent forms were stored in a separate, locked filing cabinet. Completed questionnaires and consent forms are secured and will be retained for ten years. There were no perceived negative or harmful physical effects on the participants; however, subjects were advised that they may experience some uncomfortable feelings when answering certain questions. Therefore, participants were advised that questions which aroused such feelings could be omitted. The risk of invasion of privacy, emotions, and space could result in inaccurate data or illicit responses which are sociaily desirable and thus not reflective of true values (May, 1991; Polit \& Hungler, 1991). The researcher tried to minimize these by developing a trusting relationship, and communicating openly about the arousal of such feelings. Protection of confidentiality and privacy were emphasized, for example, parental consent was waived if the subject was a minor. However, if the subjects revealed thoughts or ideas (suicide, homicide, physical and/or sexual abuse) which may be harmful to themselves or others, a referral was made to an appropriate resource. Three subjects were referred to social workers and/or Child and Family Services for a history of being involved in physical violence which resulted in time spent at a correctional institution. All data collected in the study were analyzed and reported as group results. Individual data may 
only be accessed by the thesis committee. A full explanation was provided in the invitation to participate [Appendices D, D (I), D (II)] and the consent form (Appendix E).

Deception or coercion was not involved. The researcher is not a frontline worker/ direct care-giver and had no contact with the subjects, either before or after the birth of the baby. Participants were reimbursed for parking or bus fare with the sum of five dollars (\$5.00) upon the completion of all questionnaires. All respondents were given an opportunity for debriefing, following completion of questionnaires. According to Polit and Hungler (1991) the opportunity to speak openly about an experience reduces anxiety, by assisting individuals to put the experience in perspective. Additionally, participants were offered a copy of the summary of the results upon the study's completion.

\section{Limitations and Strengths}

Limitations included method of sampling, the sample size, and the setting. Limited representation may occur because subjects were recruited from a pre-existing group and sampling was purposeful. Experiences of the participants may differ from those of other expectant adolescent fathers in the general population. Although a small sample size reduced generalizability of the findings, the study provided profiles of teen fathers and their perception of parenting, as well as a means for assessing the appropriateness of the tools for future use in this area. Additionally, the groundwork for future investigations in this area has been established. 


\section{Summary}

Details of the study's design, sample size, recruitment process, and setting have been outlined in this chapter. Actions to protect subjects were described. Additionally, a brief description of the instruments were included. Lastly, the advantages as well as some of the limitations of the study's design were summarized. The findings of the study will be presented in the next chapter. 


\section{CHAPTER V}

\section{Results}

This study explored the influence of self-image and perceived parenting role expectations of adolescent fathers' perceived role performance. The results of the data analyses for this descriptive correlational study are presented in this chapter.

Both descriptive and inferential statistics were analysed through the Statistical Package for the Social Sciences (SPSS). Descriptive statistics facilitated the synthesis and description of raw data, and consisted of the mean, median, range, and standard deviation. Pearson's product-moment correlation coefficients (Pearson's $r$ ) were computed to determine relationships between self-image and perceived role performance expectations of self and others (mother of baby/partner, and subjects' parents). Two-tailed analyses were performed using a significance level of $p<0.05$ for all correlational and t-tests. Exact $\mathrm{p}$ - values will be quoted throughout the chapter to facilitate reader interpretation.

\section{Sample Characteristics}

The multi-ethnic sample included 29 adolescent fathers and one partner (not the biological father of the baby, but who is now assuming the fatherhood role), who were recruited from a large urban, tertiary care facility. Eighteen subjects (60\%) were city 
residents, $9(30 \%)$ were rural residents (including Reserves), and the remainder (10\%) were residents of North Western Ontario. See Table I for ethnic distribution of sample.

Table 1

Ethnic background of sample $(\mathrm{N}=30)$

\begin{tabular}{|l|c|c|}
\hline \multicolumn{1}{|c|}{ Ethnic Group } & n & Percentage \\
\hline European & 10 & 33 \\
\hline Aboriginal/Metis & 17 & 57 \\
\hline Filipino & 2 & 7 \\
\hline Chinese & 1 & 3 \\
\hline
\end{tabular}

Age of respondents ranged from 14 to 21 years, with a mean of 18.5 years, median 18 years, and standard deviation of 1.8 years. See Table 2 for age distribution.

Table 2

Age distribution of subjects $(\mathrm{N}=30)$

\begin{tabular}{|c|c|c|}
\hline Age & $\mathbf{n}$ & Percentage \\
\hline 14 & 1 & 3 \\
\hline 15 & 1 & 3 \\
\hline 16 & 2 & 7 \\
\hline 17 & 4 & 13 \\
\hline 18 & 8 & 27 \\
\hline 19 & 4 & 13 \\
\hline 20 & 5 & 17 \\
\hline 21 & 5 & 17 \\
\hline
\end{tabular}


Education was measured as the last grade completed by subjects. Nineteen subjects $(63 \%)$ reported having completed either grade 11 or 12 . See Table 3 for frequency distribution.

Table 3

Education level of subjects $(\mathbb{N}=30)$
\begin{tabular}{|c|c|c|}
\hline Education Level & $\mathbf{n}$ & Percentage \\
\hline s grade 8 & 1 & 3 \\
\hline $9-10$ & 9 & 30 \\
\hline $11-12$ & 19 & 63 \\
\hline some college & 1 & 3 \\
\hline
\end{tabular}

Fifteen subjects reported being employed. However most of their employment was seasonal or casual in nature. Two respondents were employed part-time while still attending school. See Table 4 for details of employment status.

Table 4

Employment of status of sample. $(\mathrm{N}=30)$

\begin{tabular}{|l|c|c|}
\hline Employment Status & n & Percentage \\
\hline Student & 9 & 30 \\
\hline Labourer & 14 & 47 \\
\hline Retail & 1 & 3 \\
\hline Employment Benefit & 6 & 20 \\
\hline Social Assistance & 2 & 7 \\
\hline
\end{tabular}


Most of the respondents who lived with their partner/mother of infant stated that their relationship was "common-law". One respondent was married (7 months). The average length of the respondents' relationship with the mother of their child was 2.2 years. For 3 fathers/partners this was not their first child with their present partner/child's mother. The minimum age when respondents reported leaving parental home was 12 years, while the maximum was 18 years. See Table 5 of living arrangements of subjects.

\title{
Table 5
}

Subjects' living arrangements $(\mathbb{N}=30)$
\begin{tabular}{|l|c|c|}
\hline \multicolumn{1}{|c|}{ Living Arrangements } & n & Percentage \\
\hline Home with parents & 14 & 47 \\
\hline $\begin{array}{l}\text { Living with } \\
\text { partner/expectant mother }\end{array}$ & 12 & 40 \\
\hline Living alone & 3 & 10 \\
\hline $\begin{array}{l}\text { Living with extended family } \\
\text { (aunt) }\end{array}$ & 1 & 3 \\
\hline
\end{tabular}

\begin{abstract}
Abuse
Five respondents (17\%) reported that they have experienced physical and/or verbal abuse. A further 6 respondents (20\%) stated that they were unsure if abuse had taken place.
\end{abstract}

\section{Parental Living Arrangements}

Eight subjects stated that their parents are married, 10 stated that their parents were never married - 3 subjects in this group did not know their father's identity, while one 
knew his father's identity but did not have a relationship with him. See Table 6 for frequency distribution of marital status of parents.

Table 6

Marital status of subjects' parents. $(\mathrm{N}=30)$

\begin{tabular}{|l|c|c|}
\hline \multicolumn{1}{|c|}{ Marital Status } & $\mathbf{n}$ & Percentage \\
\hline Married & $\mathbf{8}$ & 27 \\
\hline Never Married & 10 & 33 \\
\hline Divorced/Separated & 7 & 23 \\
\hline Common-Law & 4 & 13 \\
\hline Widowed & 1 & 4 \\
\hline
\end{tabular}

\section{Self-Image}

In terms of self-image, raw scores ranged from 190 to 417 , with a mean of 313.7 . Each raw score was then converted to a $\mathrm{T}$-score. This was done by using the mean and standard deviation of the reference population referred to in the OSIQ- R Manual (1992). A T-score between 40 and 60 placed the teen fathers within the average range for selfimage, while a T-score $>60$ was considered high. Twenty subjects $(67 \%)$ scored within the average range set by Offer et al. (1992). A T-score $<40$ suggested a low self-image. Nine subjects (30\%) had a T-score $<40$. Fifteen subjects (50\%) had T-scores of $<45$, which suggests a relatively low self-image. Of these 15 subjects, $6(40 \%)$ had extremely low T-scores (<35). The confidence limits for the T-score was set at $68 \%$ (Offer et al., 1992). 
Details of frequency and distribution of scores are presented in Table 7 and 8.

Table 7

Self-Image: scores. $(\mathrm{N}=30)$

\begin{tabular}{|c|c|c|}
\hline T-Score & n & Percentage \\
\hline$<25$ & 2 & 7 \\
\hline $25-35$ & 4 & 13 \\
\hline $36-45$ & 9 & 30 \\
\hline $46-45$ & 12 & 40 \\
\hline $56-65$ & 2 & 7 \\
\hline$>66$ & 1 & 3 \\
\hline
\end{tabular}

Table 8

Self-Image score summary

\begin{tabular}{|l|c|c|c|c|c|}
\hline Self-Image & $\mathbf{N}$ & $\mathbf{M}$ & $\mathbf{S ~ D}$ & Minimum & Maximum \\
\hline Raw Score & 30 & 313.8 & 55.6 & 190 & 420 \\
\hline T-score & 30 & 43.8 & 10.2 & 66.6 & 24.3 \\
\hline
\end{tabular}

\section{Perceived Role Performance: Adolescent Fathers/Partners}

Teen fathers' expectations of role performance scores ranged from 10 to 29 , with a mean of 17.3 and standard deviation of 4.4. A low score indicates that teen fathers intended to assume a great deal of infant care, with a "reasonable amount of confidence and competency" (Christmon, 1987, p. 67). See Table 9 for details of role performance scores. 


\section{Perceived Expectations: Fathers/Partners}

Teen fathers/partners scored low on this scale. Scores ranged from 6 to 18 , with a mean of 12.9 and a standard deviation of 2.4 , which shows very little variability among the scores. The scores in this section measured the teen fathers/partners' expectations of what tasks and responsibilities they anticipated undertaking after the birth of the baby. See Table 9 for details of role expectation scores.

\section{Perceived Expectations of Fathers/Partners: Parents}

Scores in this section tended toward the lower end of the scale; however, 4 subjects did not identify/acknowledge a father or a father figure. Therefore, these subjects omitted completion of questions (15-19 in parenting role questionnaire). The cumulative summary scores on this scale are based on a sample size of $26(n=26)$. For clarity, scores from subjects' perceived expectations of their parents were combined. Additionally, the score related to each parent was presented individually, that is, mother's score and father's score. Test scores for subjects' perceived role expectations of parents ranged from 10 to 30 , with a mean of 18.1 and a standard deviation of 6 . Greater variability in the scores was reflected in this section, specifically of note is the variation in the adolescent 
father/partner's perception of his parents expectations. See Table 9 for summary of role expectation/role performance scores.

Table 9

Role performance/expectations summary scores $(\mathrm{N}=30$ )

\begin{tabular}{|c|c|c|c|c|c|}
\hline Variable & $\mathrm{n}$ & $\mathrm{M}$ & $\mathrm{SD}$ & Minimum & Maximum \\
\hline V1 & 30 & 17.3 & 4.3 & 10.0 & 29 \\
\hline V2 & 30 & 11.8 & 2.4 & 8.0 & 17 \\
\hline V3 & 30 & 9.2 & 3.3 & 5.0 & 17 \\
\hline V4 & 26 & 9.1 & 3.0 & 5.0 & 15 \\
\hline V5 & 26 & 18.1 & 6.0 & 10.0 & 30 \\
\hline V6 & 30 & 12.9 & 2.4 & 6.0 & 18 \\
\hline
\end{tabular}

Note. $\mathrm{Vl}=$ Father's own expectations of role performance;

V2 = Perceived role expectations of partner (child's mother);

V3 = Perceived role expectations of subject's mother;

V4 = Perceived role expectations of subject's father

V5 = Perceived role expectations of subject's parents;

V6 $=$ Father's own expectations.

A two tailed t-test was computed to examine the difference between the means of each variable measuring the subjects' parents expectations, (Appendix B, questions 1519). No significant differences were found in the variables which measured infant care, that is, preparing formula, changing diapers, and bathing. See Table 10 for summary of $t-$ scores. However, there was a significant difference between the subject's mother and father's expectation relating to financial support $(t=2.44, p=0.02)$. The $p$ - value was 
established at $p<.05$. The subjects perceived their fathers to have higher expectations of them to support their child financially.

Table 10

Perceived role expectation of parents, summary of $t$-values $(n=26)$

\begin{tabular}{|l|c|c|c|c|}
\hline \multicolumn{1}{|c|}{ Variables } & M & SD & t-score & $\mathbf{p}$ \\
\hline Financial Support & 0.19 & 0.40 & $2.44^{*}$ & 0.02 \\
\hline Formula Preparation & -0.08 & 0.27 & -1.44 & 0.16 \\
\hline Bathing Infant & -0.08 & 0.27 & -1.44 & 0.16 \\
\hline Changing Diapers & -0.04 & 0.20 & 1.00 & 0.33 \\
\hline Finishing School & -0.12 & 0.77 & -0.77 & 0.45 \\
\hline
\end{tabular}

Note. ${ }^{*} p<.05$

\section{Hypotheses}

A correlation matrix was constructed to examine the relationship betweer. the variables outlined in each hypothesis. Pearson's $\mathrm{r}$, with $\mathrm{p}<.05$, was used for computation of the scores.

Hypothesis one, perceived role expectations of the adolescent father/partner is related to his self-image. This was not confirmed. See Table 11 for a summary of Pearson's correlation coefficients. Next, hypothesis two stated that the adolescent father/partner's parenting role performance is positively related to his expectations. This hypothesis was also rejected. Perceived parenting role expectations of teen fathers/partners was not related to adolescent fathers' participation in parenting. This is also true for self-image. However, there was a significant negative correlation between 
self-image and teen fathers/partners parenting expectations $(r=-0.35, \mathrm{p}<.05)$. This suggests that fathers/partners with low self-image are more likely to have high parenting expectations of themselves.

Hypothesis three stated that perceived parenting role performance of adolescent fathers/partners is positively related to their parents expectations. No relationship was found. When the subjects' parents' scores were considered individually, the results remain unchanged.

Hypothesis four addressed the influence of the expectant mother on the parenting involvement of her partner/infant's father, specifically, that the perceived parenting role performance of adolescent father/partner is positively related to the expectations of his partner/infant's mother. This hypothesis was not confirmed. It is interesting to note, Table 11

Pearson's Correlation Coefficients: Hypotheses 1-4 $(N=30)$

\begin{tabular}{|l|c|c|}
\hline \multicolumn{1}{|c|}{ Variables } & $\begin{array}{c}\text { Role } \\
\text { Performance }\end{array}$ & $\mathbf{p}$ \\
\hline Self-Image & -0.17 & 0.36 \\
\hline Role Expectation & 0.34 & 0.06 \\
\hline Parents ( $=26)$ & 0.08 & 0.08 \\
\hline Mother $(\mathbf{n}=\mathbf{3 0})$ & 0.21 & 0.26 \\
\hline Father $(\mathbf{n}=\mathbf{2 6})$ & 0.04 & 0.84 \\
\hline Partner $(\mathbf{n}=\mathbf{3 0})$ & 0.11 & 0.57 \\
\hline
\end{tabular}

Note. $\mathrm{p}=<0.05^{*}$

$H_{1}=$ Father's perceived expectations of role performance is positively related to self-image

$\mathrm{H}_{2}=$ Fathers perceived expectations are positively related to his perceived role performance

$\mathrm{H}_{3}=$ Perceived role performance of adolescent father is positively related to parents expectation

$\mathrm{H}_{4}=$ Perceived role performance of adolescent father is positively related to partner's expectation 
that there is a significant positive correlation between the perceived expectations of teen fathers/partners and his parents expectations $(r=0.55, p=0.004)$. Teen fathers' perceive their parents to have high expectations of the teenagers' ability to parent.

\section{Summary}

This chapter reported the analysis and findings of data collected in this study. First, a brief description of a demographic profile of the respondents, including age, ethnic background, education, marital status and living arrangements, was presented. Second, results of inferential data analysis was summarized. Analysis of inferential data was facilitated through Pearson's $r$ and two-tailed t-tests. Pearson's correlation coefficient results failed to validate any of the four hypotheses in this study. Significance level was established at $\mathrm{p}=<.05$, and tables were tabulated for clarity in data reporting. 


\section{CHAPTER VI}

\section{Discussion}

A discussion of the findings related to adolescent fathers/partners' psychosocial development and perceived parenting role performance, specifically, self-image, perceived expectations of the teen father/partner, his parents and partner/infant's mother and their influence on the adolescent father/partner's perceived role performance will be presented in this chapter. Strengths and limitations of this study will be outlined. Implications for nurses and allied health care providers, as well as those for future research, and a summary will conclude this chapter.

\section{Characteristics of Adolescent Fathers/Partners}

Adolescent fathers/partners in this study had a mean age of 18.5 years. This was consistent with the age of the subjects in other studies of teen fathers (Stouthamer-Loeber \& Wei,1998; Christmon, 1990). Teen fathers in this study who were less than age 18, continued with their education. Only one of these fathers believed it was more important to find a job than continue with his education. This finding disputes those of other small studies, where most of the subjects believed finding a job was more important than school (Cady \& Schurman, 1991; Taucher, 1991; Christmon, 1990; Barth et al, 1987). Teen fathers/partners, over age 18, did not continue their education beyond grade 12 . This did not appear to be related to teen fatherhood, since the majority of these young men had already been out of school for at least one to two years when the pregnancy occurred. This finding raises questions regarding lower education attainment among adolescent 
fathers and its relationship to premature fatherhood or the sequel of a larger, more complex issue.

Teen fathers in this study described their family as predominantly blue-collar workers. Four ethnic groups were represented. Over half the respondents in this study were Aboriginal or Metis. This is representative of the ethnic mix of teen fathers/partners whose partners give birth at the urban facility where this study took place. This study's population differs from similar small studies of teen fathers who were predominantly Black American adolescents.

Attendance with their partner/infant's mother at the Adolescent Prenatal Clinic can best be described as "inconsistent". Most fathers were left sitting in the waiting area, while their partners/infants' mothers were channelled through various services provided by this Clinic. Fathers were only included when the teen mother/partner indicated to staff that she would like her "boyfriend" to accompany her. This may have been one of the reasons why the teen father/partner does not accompany the teen mother/partner to her prenatal check-ups. Other researchers have made similar observations (Cady \& Schurman, 1991; Taucher, 1991; Tuttle, 1988). However, reasons for non-attendance was not one of the variables included in this study.

Slightly over one third of the respondents stated that they shared living arrangements with their partners/teen mothers, and one teen father reported being married. These teen fathers/partners described their relationship with their partner as stable, with an average duration of 2.2 years. Other researchers have observed that stresses of parenting, combined with the parent's immaturity and lack of resources 
usually resulted in high rates of separation and divorce (Card \& Wise, 1978; Cervara, 1990). Three fathers pointed out that this was not their first child with their present partner/teen mother. This, plus the average length of the relationship, suggests that these teen fathers/partners are deeply committed to their parenting responsibilities. Longevity of teen parents' relationships has been confirmed by Cervara (1990) and Furstenberg (1980). The rest of the teen fathers/partners described their relationships with their partners as "good". Despite this positive perception of their relationship, this investigator overheard teen mothers/partners, on several occasions, telling staff that their relationship with the adolescent father/partner "was off". This type of volatility in teen partners' relationship is consistent with reports from similar studies (Cervara, 1990; Dallas \& Chen, 1998; Furstenberg, 1980). This instability in the teen parents' relationship may be related to their emotional and developmental immaturity and reaffirms support for Marcia's (1980) theory that teens lack the maturity to formulate and/or follow-through with long-term commitments. That said, other researchers point to teen fathers' lack of negotiating skills which are often necessary to overcome barriers to their relationships with the teen mothers (Cervara, 1990; Dallas \& Chen, 1998). In spite of their immaturity, this group of teen fathers/partners appeared eager to face the challenges of parenting and fatherhood and indicated good relationships with their partners.

It should be noted that half the respondents came from single parent families headed by females, who were either never married or separated/divorced. This is consistent with the social background of respondents in other studies (Christmon, 1990; 
Dallas \& Chen, 1998; Pauker, 1971; Stouthamer-Loeber \& Wei, 1998). Despite the marital status of these respondents' parents, most of the teen fathers reported having a relationship with their biological father. This may well have some impact on these teen fathers'partners' intention to be involved with their own children, since families transmit values to their own children (Papalia \& Wendkos-Olds, 1995). These findings, combined with the fact that almost all the parents of the teen fathers/partners were themselves teen parents, support the notion of intergenerational cycle of adolescent pregnancy (Dallas \& Chen, 1998).

\section{Employment Status of Teen Fathers/Partners}

Only $50 \%$ of the fathers were employed. However, they described their jobs as seasonal or casual, which may imply employment instability. Furthermore, these jobs required little or no skill, and were at the low end of the pay scale. The other $50 \%$ of respondents were either attending school or receiving some kind of government assistance, such as employment benefit or social assistance. These findings are consistent with those of other investigators (Sander \& Rosen, 1989; Smith, 1984; Spivak \& Weitzman, 1987; Taucher, 1991). These characteristics suggest financial instability and economic dependency, yet these fathers/partners overwhelmingly expected to provide financial support for their children. Teen fathers'/partners' developmental immaturity prevents them from making a realistic evaluation of their own capabilities (Marcia, 1980; Papalia \& Wendkos-Olds, 1995). The fact that over $90 \%$ of the teen fathers/partners believed that they had an obligation to provide financial support for their children further indicates that these fathers took their fatherhood role seriously. 


\section{Support}

Generally the parents of teen fathers/partners were aware of their son's involvement in the pregnancy, and most were supportive of him. When support was examined in terms of mother and father, mothers were generally more supportive than fathers. Non-supportive parents may result in teen fathers/partners abandoning their parental responsibilities (Cervara, 1990; Furstenberg, 1980). Stronger maternal support may stem from her recollection of her own pregnancy experience during her teens (Dallas $\&$ Chen, 1998). Adolescent fathers need support and encouragement if they are to remain involved in parenting (Hendricks, 1983; Jacobs, 1994). Teen fathers are sometimes overwhelmed by the responsibilities of fatherhood, and as a result they may well take flight and abandon their parenting role (Dallas \& Chen, 1998; Shaw-Schuster \& SmithAshburn, 1992). Therefore, supportive parents are essential to ongoing involvement of teen fathers in parenting. Through clear communication of what fathers can do to help, parents, with their knowledge and experience, can guide teen fathers. This reaffirms the continuing importance of family in the face of changing roles and relationships (Benson et al, 1987; Offer et al, 1988).

\section{Adolescent Father: Abuse}

A relatively large number of the teen fathers/partners in this study reported that they had either been victims of abuse or that they were uncertain about being abused. Respondents in most instances did not identify what type of abuse (sexual, physical and/or verbal) they had experienced. They were advised, prior to completing questionnaires, that information or behavior which may have a negative influence on the 
ability to parent will be shared with a social worker or possibly Child and Family Services (CFS). Surprisingly, none of the fathers withdrew from the study and all but one responded to the abuse question. Social workers and CFS were notified of three fathers who were involved in physical violence which resulted in time spent at a correctional institution.

Personal experience of abuse has been linked to behavior such as physical aggression and explosive conduct with poor impulse control (Stouthamer-Loeber \& Wei, 1998). The fact that teen fathers, due to their developmental immaturity and lack of child care knowledge, are more likely to use inappropriate methods to discipline their children makes them high risk parents. However, parenting becomes even more hazardous/risky if the teen father has been a victim of abuse or a perpetrator of abuse. In some instances, both the social worker and CFS workers had to be notified of potentially high risk situations. Intergenerational abuse has been linked to child abuse; therefore, this variable warrants further investigation in view of the large number of reported or suspected cases in this study. Despite their history, the teen fathers/partners did not waiver in their determination to be "good fathers" to their children. It is, however, questionable whether the teen fathers/partners goal of becoming good fathers would be realized, without adequate supports and resources.

\section{Self-Image}

Teen fathers/partners had relatively low scores for self-image. Four subjects had "very low" T-scores, that is, below 30. This is suggestive of "deeper psychological problems" which warrant further follow-up (Offer et al, 1992). Five respondents scored 
in the low self-image range, which is a T-score of less than 40 . Low self-image scores suggest that resolution of age-specific developmental tasks have not yet occurred in this group of young fathers/partners. As a result they are more likely to experience difficulties in meeting the needs of their partners and infants. Findings similar to these were reported by Elster and Lamb (1982), in a group of Black American teen fathers, and Robinson and Frank (1994), in a group of "predominantly white" teen fathers. However, Christmon (1990) also used the OSIQ in a small sampie of Black American teen fathers, and reported "higher than average" self- image scores. These differences in self-image scores are not surprising because teen fathers bring a ". . variety of temperamental styles and psychosocial circumstances" (GAP, 1986, p. 25) to the parenting role. Offer et al. (1992) recommends psychiatric counselling for individuals who have T-scores which are considered low. These individuals may experience coping difficulties with normal dayto-day functioning; therefore, they are high risk for parenting difficulties. Infants may be especially at risk if placed in care of these fathers since they may have low impulse control (Dallas \& Chen, 1998; Stouthamer-Loeber \& Wei, 1998).

Low self-image scores were not isolated to the younger respondents who were expected to have more unresolved developmental issues than teen fathers/partners, who were on the threshold of young adulthood, that is, age 20 to 21 . This finding lends some support to the notion that men beyond 20 who are involved with adolescent females have more problems associated with responsibilities of fatherhood (Hendricks et al, 1983; Nakashima \& Camp, 1984). These findings support the conclusion that teen fathers are 
at high risk for parenting failure, which may result in physical harm to the mother and infant (Dallas \& Chen, 1998; Jacob, 1994).

This raises the question asked by numerous investigators, "Is fatherhood an attempt to boost self-image?" Reports have indicated that this may be the case for some teen fathers (GAP, 1986). However, most pregnancies among teen parents, are unplanned (Castiglia, 1990). Findings of this study indicate that teen fathers despite their eagerness to become involved in parenting need appropriate support and guidance, if they are to succeed. Strategies to improve self-image, if indicated, may be necessary. It is, therefore, important to assess not only the mothers, but also the teen fathers during the prenatal period so that remedial strategies can be implemented with both young parents. Feelings held by adolescents about themselves, and their self-image, will have an impact on their parenting behavior, thereby influencing their abilities to parent.

\section{Perceived Role Expectations and Role Performance}

Teen fathers/partners had high parenting expectations of themselves.

Respondents believed themselves to be competent and able to perform their parenting role with a moderate to high level of confidence. Furthermore, they perceived themselves to have adequate parenting skills. These findings are consistent with those of Christmon (1990), who developed and used this questionnaire to assess teen fathers' involvement in parenting. However, these findings contradict those of Dallas and Chen (1998). Teen fathers in their study reported feeling very confused and ill-prepared to parent. These contradictory findings may be related to the different stages of fatherhood between the two groups. Fathers in Dallas and Chen's study were already parenting; whereas, teen 
fathers in this study were still awaiting the birth of their baby. Adolescents lack the capacity to project future consequences of their actions/behaviour (Papalia \& WendkosOlds, 1995).

Respondents in this study felt strongly about their financial responsibility to provide for their children. However, when asked whether this expectation was going to be translated to actual role performance, almost half the teen fathers/partners had second thoughts about their ability to provide financial support. It is possible to speculate that the teen fathers in this study were merely reflecting their parents' values that fathers should provide financial support for their children. Parents usually transmit their values to their children (Papalia \& Wendkos-Olds, 1995; Stassen-Berger, 1994). Most fathers view their role as "provider" to be an integral part of fatherhood (Panzarine \& Elster, 1983). To a large extent, society also dictates that a father is financially responsible for his child (Rotundo, 1985). Therefore, teen fathers/partners may just be reflecting societal views in their responses.

Since most of the fathers in this study were attending school or unemployed, their perception of providing financial support is unrealistic. Fathers also displayed unrealistic expectations of themselves in other areas involving childcare, for example, some expected to "change all diapers" or "spend all their time with the baby." This overenthusiasm to parent is consistent with an immature development as identified by Marcia (1980) in his description of the various identity types. Teens lack the ability to follow through with commitments if they have not yet reached "identity achievement" (Marcia, 1980). Thus, teen fathers/partners clearly need their parenting expectations assessed early 
in the pregnancy, so that nurses and allied care providers can assist young fathers to develop more realistic expectations. This may assist teen fathers/partners to achieve their parenting goal, which would indirectly benefit the adolescent and improve his self-image.

\section{Perceived Expectations of Parents and Partners/Teen Mothers}

Respondents in this study perceived both parents and partners to have high expectations of them. Positive expectations were also confirmed by Christmon (1990), in his investigations of Black American adolescent fathers. It is impossible to predict teen fathers' involvement in parenting from this finding. Nevertheless, one can speculate that if teen fathers perceive their parents' support and confidence in their ability to parent, then these fathers are more likely to be involved in parenting their children. Perceptions are thought to be much more important than reality in influencing behavior (Comer et al, 1987). The alternative is also true. If a person perceives negative feedback about a role, he may well abandon that role (Erickson, 1980).

Parental scores were for the most part, similar. This suggests that parents were not transmitting mixed messages to their sons. However, fathers were perceived as having higher expectations than mothers of their sons obligations to provide financial support for their children $(t=2.44, p<.05)$. This lends further support to the view that the fatherhood role is equated to that of provider (Panzarine \& Elster, 1983). Conversely, this may also indicate that fathers have a stronger influence on their son's behaviour.

Mothers may have been more empathetic to the predicament of the teen mother, because of their own experience of teen motherhood. Mothers tend to use their own teen 
experience with pregnancy to encourage their sons to remain involved in parenting (Dallas \& Chen, 1998). However, mothers may have focused more on non-financial assistance, that is, expecting their sons to participate in childcare activities.

Although scores relating to partner's/teen mother's expectations were relatively high, it is impossible to draw a full conclusion. Teen mothers/partners may be conveying messages which are more positive, since they may be feeling very vulnerable and are dependent on the teen fathers/partners for support (Cervara, 1990). The positive perceptions may also serve to satisfy the teen fathers/partners' dependency needs since they are also experiencing increased stress and anxiety related to premature fatherhood. Teen mothers can, and in many instances "set the stage" for greater paternal involvement (Furstenberg, 1980).

Positive feedback, such as high expectations, may instill greater confidence in young fathers. However, without adequate supports and resources these teen fathers/partners will be unable to transform their high expectations into reality. Teen fathers/partners lack knowledge of child development and care. This often leads to impatience and intolerance, which may jeopardize the health of the infant (Jacob, 1994). Young fathers have reported being afraid of harming their children (Dallas \& Chen, 1998).

\section{Hypotheses}

The first hypothesis stating that perceived parenting role performance of adolescent father/partner is positively related to his self-image was not supported. This contradicts Christmon's (1990) finding, which reported a "slight correlation" between 
self-image and perceived role performance of Black American teen fathers. Family role theory dictates that internal factors, such as, feelings an individual has of himself -- his self-image, affect behavior or role performance (Friedman, 1992). Teen fathers/partners in this study had fairly low self-image scores, suggesting that this group of young men were still coping with issues related to their development and were, therefore, unlikely to cope with the stressors and responsibilities of premature fatherhood. But these low selfimage scores contradict the extremely positive perception these fathers/partners felt about their ability to parent. It is plausible that these unrealistic expectations and overconfidence fathers' felt about their capacity to parent stemmed from their immaturity and an "invincibility fable", that is, "nothing is impossible".

Hypothesis two proposed that perceived parenting role performance is positively related to perceived expectations of teen fathers/partners was also rejected. This contradicts Christmon's (1990) findings that these two variables, namely role expectations and role performance are related. Results of this study also contradict the assertions of family role theory, which state that a person's behavior is dictated by selfexpectations (Atkinson et al, 1983; Field \& Radin, 1982: Friedman, 1992). Fathers in this study tended to have lower role performance scores. One possible explanation is that respondents may believe it is socially acceptable to hold high expectations of one's self because you are still doing "okay" if you fall a little beneath your expectations. This type of reasoning is consistent with developmental immaturity and results in the teen's inability to project the consequences of his behavior (Papalia \& Wendkos-Olds, 1995; Stassen-Berger, 1994). Another plausible explanation may be the respondents' desire to 
give "the right answer" because society expects a father to be responsible for his child.

An interesting correlation was noted between two variables not stated in the hypotheses. A moderately significant negative correlation was observed between role expectations of the adolescent father/partner and self-image. This indicates that teen fathers/partners with lower self-image are more likely to hold high expectations. This further disputes the ideas presented in family role theory, which contend that role expectations an individual has of himself are congruent with his feelings about himself (self-image). A negative correlation is also indicative of more serious problems associated with teen fathers/partners unrealistic expectations. Additionally, a low selfimage is associated with impatience, lack of emotional control, and possibly aggressive physical behaviour (Stouthamer-Loeber \& Wei, 1998). Thus, when these two are combined, it makes for hazardous parenting, which could jeopardize the safety of the infant. Nurses and other allied care givers need to raise their awareness to the issues related to low self-image among teen fathers, and that low self-image may increase the risk of parenting failure in this population.

Finally, hypotheses three and four state that role performance of teen fathers/partners is positively related to parents' and partners' expectations; both hypotheses were rejected. This is inconsistent with family role theory, which states that role performance is influenced by an individual's expectations of what a role should be (Friedman, 1992). This inconsistency suggests that these respondents lack the ability to accurately assess anothers' perception or misinterpret their own perception so that selfimage may be elevated. If this explanation is correct, it calls into question the teen 
fathers' ability to assess his own capabilities in relation to those required for parenting. Since teen mothers/partners are at a similar developmental stage, it is possible that these mothers share some of the same maturational shortcomings of their partners. It is, therefore, essential for nurses and allied care providers to accurately assess both teen parents so that interventions can be initiated to correct any shortcomings which may interfere with their parenting abilities.

Of note, there is a significant correlation between the teen fathers'/partners' expectations and those of their parents and partners/teen mothers. This is not surprising given that adolescent fathers/partners in this study have lower than average self-image. In perceiving high expectations of parents/partners, teen fathers may be serving their own self- interests and indirectly boosting their self-image. However, it may merely be reflective of teen fathers' inability to make accurate, objective assessment of self and others.

\section{Implications for Role Theory}

The fact that none of the hypotheses were supported within a family role model may indicate that this model may not be sensitive enough to cultural differences. The core concepts of family role theory were established, based on the average mature, white, middle class American family. This study's population was mostly Aboriginal, and it is known that family values within a sub-culture may vary from that of the dominant culture. Additionally, respondents in this study were adolescents, whose role conflicted with those of fatherhood. Family role theory states that individuals must have the capacity to imagine themselves in a role in order to gain a better understanding of their 
own role behaviour (Freidman, 1992). However, it is known that teens lack the developmental maturity to project future behaviour. (Erikson, 1980; Marcia, 1980; Papalia \& Wendkos-Olds, 1995; Stassen-Berger, 1994). Teens are therefore receiving contradictory messages about their role when they become a father, for example, on the one hand they are expected to be carefree, exploring ideas and dependent, while on the other they are expected to assume the responsibilities of fatherhood. Family role theory does not address how these changes can be accommodated within its present framework and as a result may not be applicable in all situations.

Furthermore, the scope of this investigation did not include variables which are salient to the dominant group in this study, namely, Aboriginals. Nevertheless, family role theory remains important and is well suited to guide researchers and practitioners who are working with families.

\section{Strengths and Limitations}

This study explored teen fathers/partners' involvement in parenting from the fathers' perspective. It is the first study of its kind in this Province, which also has one of the highest teen pregnancy rates in Canada. Furthermore, this study provided an opportunity for teen fathers to talk to someone about their experiences and the impact of fatherhood on their lives. This may have raised the teen fathers' awareness of their parental responsibilities. It is hoped that findings from this study will serve to dispel some of the negative stereotypical images which shroud this population. In the absence of probability studies with large random samples, consistencies between studies which employ small samples provide valuable information related to teen fathers and factors 
which may or may not influence involvement in parenting (Westney et al, 1986).

The ability to generalize the findings of this study is limited because of the use of a convenience sample, which was predominantly Aboriginal. The small sample size and single recruitment site further restrict the ability to generalize the findings beyond the recruitment facility. Questions relating to role performance/role expectations only measured a narrow range of parenting activities. Furthermore, the wording of questions and the restrictive range of responses may have prompted socially acceptable answers.

\section{Implications for Practice}

Based on the findings of this study, it is recommended that a paternal data base be developed which assess the immediate and long term plans teen fathers may have for child care and their parenting responsibilities. Additionally, nurses can assess teen fathers developmental maturity as well as their need for assistance in coping with issues, for example, education, employment, financial resources, and in some cases anger and hostility from their partner's parents. Following the comprehensive assessment, teen fathers who want to be involved can be referred to appropriate resources and programmes so that they can be assisted to realize their parenting goals. Nurses who are "in tune" with the adolescent fathers' desires, weaknesses and strengths can make a difference in the outcome of the lives of the young family. Nurses are in a unique position to assist teen fathers in making the transition from adolescence to parenthood. Institutions and community programmes that provide health care for teen mothers and their children must pay more than "lip service" to their philosophy of family centered care, that is, the inclusion of teen fathers as recipients of their services. 
Health and allied care-givers can include teen fathers who want to be involved in parenting, in all aspects of prenatal, labour and delivery and postpartum care. During the prenatal period teen fathers can be invited to listen to the baby's heart beat, touch their partner's abdomen and feel the movements of the baby. The various stages of growth and development can be explained during each prenatal visit as the pregnancy progresses. Teen fathers experience difficulties in perceiving the reality of fatherhood prenatally since the baby is not a tangible being (Dallas \& Chen, 1998). Nurses can encourage teen fathers to actively participate during labour and delivery by offering full, understandable explanations of procedures. Nurses can demonstrate ways in which the teen father can offer comfort and support to his labouring partner, for example, back rubs, touching and verbal encouragement. The teen father should be encouraged to touch and hold his baby as soon as possible after birth, since this is known to promote parent- infant bonding. In the postpartum period, the teen father could be encouraged to participate in infant care activities, for example, cuddling, comforting, feeding, (if formula feeding), changing diapers and bathing baby. Fathers who actively participate in all stages of the pregnancy experience a sense of belonging which may enhance commitment to parenting (Taucher, 1991).

Community resources that provide services to adolescents can assist teen fathers to fulfill their parenting responsibilities and experience the compelling commitments and pleasures of fatherhood (Taucher, 1991). Community outreach programs to assist young parents' coping with the burdens of parenting can access those fathers who do not utilize 
these resources. Efforts to include teen fathers/partners who want to be involved must continue: "Fathers have a right to be involved with their children, and children have the right to enjoy the benefits of interacting with their fathers" (Barth et al, 1988, p. 284).

\section{Implications for Research}

A number of possible directions for future research have arisen from this study. First, the need to find an appropriate instrument which not only measures the teen father's perceived role performance, but also his knowledge and readiness to perform childcare tasks. Additionally, a less costly and more accessible instrument to measure selfimage/self-esteem is recommended. Although, the OSIQ-R is an established, widely used instrument for measuring adolescents' self-image, it is quite lengthy (129 items) and the language used in the tool is not reflective of the ' 90 's. Incorporating a qualitative component to any investigations with teen fathers would allow respondents to share their thoughts and feelings about teen fatherhood. This component would provide additional insights on the complex issue of teen pregnancy, which is not possible to obtain in questionnaires. A recommendation to replicate this study using a sample with less ethnic and cultural diversity, while incorporating the aforementioned changes may clarify some of the questions raised by this study, namely, the appropriateness of family role theory for guiding investigations involving teen fathers.

Second, further investigations related to the correlates of teen pregnancy among Aboriginal teens are indicated, since over $50 \%$ of the respondents in this study belong to this ethnic group. Specifically, the correlates of teen pregnancy among Aboriginal adolescents warrants further exploration within their cultural, social and economic 
context. This may require an analysis of the lived experience of Aboriginal teens.

Knowledge from such studies will be useful in developing programmes to reduce the teen pregnancy rate in this Province.

Since it is known that teen fathers involvement in parenting wanes over time (Furstenberg, 1980), this is yet another area which warrants a longitudinal study possibly over a number of years. This subject has never been investigated beyond five years. Teen mothers and their infants could also be included in such an investigation. Findings from such studies would "shed some light" on the depth of the teen father's involvement, and the effects of this on mother and infant. Such investigations will provide further insight into the future outcome for not only the father, but also the teen mother and baby. Father involvement has been reported to promote emotional well-being and psychological growth of teen parents and their children (Sander \& Rosen, 1989). Barriers to the teen fathers' ongoing involvement may also be identified through such studies.

Other issues also warrant further investigation. These include the incidence of intergenerational abuse among teen fathers and their children, given the high rate of abuse reported among the respondents in this study. Additionally, research is needed to learn why male teens are not sharing the responsibility of pregnancy prevention. Answers to these questions will assist care providers and programme planners in gaining insights into the needs of teen fathers. It is anticipated that greater understanding of teen fathers will assist in dispelling the negative stereotype which presently exists among care providers and result in increased efforts to meet the needs of both adolescent parents. 


\section{Summary}

The purpose of this study was to investigate the influence of self-image and perceived role expectations of self, parents and partners on perceived role performance of teen fathers. Results of this study demonstrated no support for the variables - self-image, perceived expectations of self, partners and parents, and perceived role performance of teen fathers. However, findings indicated a moderate negative correlation between low self-image and high role expectations in this group of fathers. These results indicate that teen fathers want to be involved in parenting their children. However, teen fathers' unrealistic expectations combined with their developmental immaturity, lack of child care knowledge and skills prevent them from realizing their parenting goal. Findings in this study support those of similar studies; the teen fathers are a "high needs" group requiring additional support and education before and after the birth of their children. This study provided a much needed insight of teen fathers and the complex issue of teen pregnancy. In light of the findings there are implications for health care practitioners and future research. 


\section{REFERENCES}

Adams, G.R. (1986). Offer self-image Questionnaire for adolescents. In Daniel J.Keyser and Richard C. Sweetland (Eds.), Test critiques vol V. Kansas City, Missouri: Test Corporation of America.

Archer, S.L. \& Waterman, A. (1990). Varieties of identity diffusions and foreclosures: An exploration of the sub-categories of the identity of statuses. Joumal of Adolescent Research. 5: 96-111.

Atkinson, R.L. Atkinson, R.C., \& Hilgard, E.R., (1983). Introduction to Psychology $\left(8^{\text {th }}\right.$ ed). New York: Harcourt Brace Jovanovich, Publishers.

Auvenshine, M., \& Enriquez, M. (1985). Maternity Nursing: Dimensions of change. Monterey, Ca.: Wadsworth.

Barret, R.L. \& Robinson, B.E. (1986). Adolescent fathers: Often forgotten parents. Pediatric Nursing 12 (4), 273-280.

Barret, R.L. \& Robinson, B.E. (1985). The Adolescent father. In S.Hanson and F. Barret (Eds.) Dimensions of fatherhood (p353-368). Beverly Hills, CA: Sage.

Barret, R.L. \& Robinson, B.E. (1982). A descriptive study of teenage expectant fathers. Eamily Relations, 31, 349-352

Barth, R.P., Claycoomb, M. \& Loomis, A. (1988). Services to adolescent fathers. Health and Social Work. 13 (4): 277-287.

Benson, P., Strommen, M.P. \& Gavin, E. (1987). The Quicksilver years: The hope and fears of early adolescence. San Francisco: Harper \& Row. 255-256, 276.

Berland, A. (1987). Young fathers support group. Pediatric Nursing 13 (4),

Biddle, B. (1979). Role theory: explanation, identities and behaviours. New York: Academic Press.

Bowen, S., \& Miller, B. (1980). Parental attachment behaviour. Nursing Research, 29 (5): 307-311.

Bozett, F. (1985). Male development and fathering throughout the life cycle. American Behavioural Scientist,29 (1): $41-51$ 
Brink, P., \& Woods, M.J. (1989). Advanced design in nursing research. London: Sage.

Cady, J. \& Schurman, J. (1991). Adolescent males: The fogotten half. Clinical Issues in Perinatal and Women's Health Nursing, 2 (2), 255-261.

Canadian Nurses Association (1997). Code of ethics. Ottawa: Author.

Caparulo, F. \& London, K. (1981). Adolescent fathers: adolescent first, fathers second. Issues in Health Care of Women, 23-33.

Card, J. \& Wise, L. (1978). Teenage mothers and fathers: the impact of early childbearing on the parents' personal and professional lives. Eamily Planning Perspectives, 10: 199-205

Castiglia, P.T. (1990). Adolescent fathers. Joumal of Pediatric Health Care, 4 (6): 311-313.

Cervara, N. (1991). Unwed teenage pregnancy: family relationships with the father of the baby. Families in Society: Journal of Contemporary Human Services, 1 (72): 29-37.

Cervara, N. (1989). Unwed teenage pregnancy: the transition to unexpected grandparenthood. Social Work with Groups: Special Edition, 12: 71-93.

Chapman, A. \& Chapman, M. (1980). Harry Stack Sullivan's concepts of development and psychiatric illness. New York: Brunner/Mazel.

Christmon, K. (1990). Prenatal responsibility of African-American unwed adolescent fathers. Adolescence, 25 (99), 645-653.

Christmon, K. (1987). The impact of self-image and perceived role expectations on perceived role performance among unwed adolescent fathers. Ann Arbor, Michigan: UMI Dissertation Services.

Chubb, N. \& Fertman, C. (1992). Adolescents' perceptions of belonging in their families. Eamilies in Societv: The Journal of Contemporary Human Services, $Z$ (73): 387-394. 
Comer, J., Haynes, N., Hamilton-Lee, M., Boger, J. \& Rollock, D. (1987). Dimensions of children's self-concept as predictors of social competence. Joumal of Social Psychology, 127: 321-329.

Connelly, L. (1978). Boy Fathers. Human Behaviour, 40-43.

Cox, J. \& Bithoney, W. (1995). Fathers of children born to adolescent mothers. Archives of Pediatric Adolescent Medicine, 149: 962-966.

Cronenwett, L. \& Kunst-Wilson, W. (1981). Stress, support, and the transition to fatherhood. Nursing Research, $\underline{30}$ (4): 196-201

Cronenwett, L. \& Newmark, L. (1974). Fathers responses to childbirth Nursing Research, 23, 210-217.

Dallas, C. \& Chen, S. (1998). Experiences of African adolescent fathers. Western Journal of Nursing Research, 20 (20): 210-222 $22-25$

de Lissovoy, V. (1973). Childcare by adolescent parents. Children Today, 2:

Dryfoos, J. (1990). Adolescents at risk: prevalence and prevention: New York: Oxford University Press.

Earls, F. \& Siegal, B. (1980). Precocious fathers. American Journal of Orthopsychiatry, 50: 469-480.

Elkind, D. (1988). The hurried child: Growing up too fast, too soon. Reading, Mass: Addison-Wesley.

Elster, A. \& Lamb, M. (1982). Adolescent fathers: a group potentially at risk for parenting failure. Infant Mental Health Journal, 3 (3): 148-155.

Elster, A.B., Lamb, M.B., \& Kimmerly, N. (1989). Perceptions of fatherhood among adolescent fathers. Pediatrics, $\underline{83}$ (5): 758-765.

Elster A; Lamb, M. \& Tavare, J. (1987). Association between behavioural and school problems and fatherhood in a national sample of adolescent youths. Journal of Pediatrics, 111: 932-936

Elster, A. \& Panzarine, S. (1983). Teenage fathers: stresses during gestation and early parenthood. Clinical Pediatrics. 
Elster, A. \& Panzarine, S. (1989). Perceptions of Parenthood among adolescent fathers. Pediatrics. 83, 758-765.

Erikson, E. H. (1980). The life cycle completed. New York: Norton.

Erikson, E. H. (1975). Life history and the historical moment. New York: Norton.

Erikson, E. H. (1973). The wider identity. In K. Erikson (Ed.). In search of common ground: conversations with Erik $H$. Erikson and Huey P. Newton. New York: Norton.

Erikson, E. H. (1968). Identity youth and crisis. New York: Norton.

Erikson, E. H. (1964). Insight and responsibility. New York: Norton

Erikson, E. H. (1963). Childhood and society (2nd ed.). New York: Norton.

Fein, R. (1978). Research of fathering: social policy and emergent perspective. Journal of Social Issues, 34 (1): 122-135.

Felson, R. (1985). Reflected appraisal and the development of self. Social Psychology Quarterly, 48: 71-78.

Field, S. \& Radin, N. (1983). Social psychology for social work and the mental health professionals. New York: Columbia University.

Field, T; Widmayer, S; Stringer, S. \& Ignatoff, E. (1980). Teenage lower-class Black mothers and their pre-term infants: an intervention and development follow-up. Child Development, 51: 426-436.

Friedman, M. (1992). Family nursing theory and practice (3rd ed.). Norwalk, CT: Appleton \& Lange.

Furstenburg, F. F. (1976). Unplanned parenthood: The social consequences of teenage childbearing. New York: Free Press.

Furstenburg, F. \& Talvite, K (1980). Children;s name and paternal claims: bonds between unmarried fathers and their children. Journal of Family Issues, 1: 31-57.

Gallatin, J. (1976). Theories of adolescence. In J.F. Adams (Ed.). Understanding Adolescence. (3rd ed.). Boston: Allyn \& Bacon Inc. 
Garett, W. R. (1982). Seasons of marriage and the family life. New York: Holt, Rinehart \& Winston.

Gecas, V. \& Schwabe, M. (1986). Parental behaviour and adolescent selfesteem. Journal of Marriage and the Family, 48: 37-46.

Gibbs, J. (1972) City girls: psychosocial adjustment of urban Black adolescent females. Journal of Early Adolescence, 2 (2): 28-36.

Giblin, P; Poland, M. \& Ager, J. (1988). Clinical applications of self-esteem and locus of control to adolescent health. Journal of Adolescent Health Care, 9: 1-14. 461-464.

Grant, L. (1993). The pregnant teenager. Medicine North America (June):

Greenberg, M; Siegel, J. \& Leitch, C. (1983). The nature and importance of attachment relationships to parents and peers during adolescence. Journal of Youth and Adolescence, 12 (5): 373-386.

Group for the Advancement of Psychiatry [GAP], (1986). Crïis of Adolescence. New York: Brunner/Mazel Publishers.

Hanson, S. L., Morrison, D. L., \& Ginsburg, A. L. (1989). The antecedents of teenage fatherhood. Demography, 26 (4): 579-596.

Haskins, W. (1984). What about teenage fathers? Essence (Dec.): 160.

Health and Welfare Canada (1990). Report on adolescent reproduction health. Ottawa: Author.

Henderson, James (1980). On fathering (The nature and functions of the role). Part I: Aquiring an understanding of the father role. Canadian Journal of Psychiatry, 25 (5), 403-412.

Henderson, James (1980). On fathering: (The nature and functions of the father role). Part II: Conceptualization of fathering. Canadian Joumal of Psychiatry, 25, 413-429. 
Hendricks, L. (1983). Unmarried Black adolescent fathers and their controls: the Washington DC sample. Washington DC: Institute for Urban Affairs and Research.

Hendricks, L. (1982). Unmarried Black adolescent fathers' attitudes toward abortion, contraception, and sexuality: a preliminary report. Journal of Adolescent Health Care, 2: 199-203.

Hendricks, L. (1980). Unwed adolescents: problems they face and their source of social support. Adolescence, 15: 862-869.

Hendricks, L. \& Fallilove, R. (1983). Locus of control and the use of contraceptives among unmarried Black adolescent fathers and their controls: a preliminary report. Joumal of Youth and Adolescence, 12 (3): 225-233.

Hendricks, L; Howard, C. \& Caesar, P. (1981). Black unwed adolescent fathers: a comparative study of their problems and help-seeking behaviour. Journal of National Medical Association, 73 (9): 863-868.

Hendricks, L.E. \& Montgomery, T. (1983). A limited population of unmarried adolescent fathers: A preliminary report of their views on fatherhood and relationship with mothers of their children. Adolescence 28 (69), 201-210.

Hurlock, E. B. (1980). Developmental psychology: A life-span approach (5th ed.). New York: McCraw-Hill Book Company.

Jacobson, E. (1964). The self and the object world. New York: International Universities Press.

Johnson, L. \& Staples, R. (1979). Family planning and young minority male: a pilot study. Family Coordinator, 28 (535-546).

Kerlinger, F. (1986). Eoundation of behavioural research ( $3^{\text {rd }}$ ed.). New York: Holt, Rhinehard \& Winston.

Kinard, E. \& Klerman, L. (1980). Teenage parenting and child abuse: Are they related? American Joumal of Orthopsychiatry, 50: 481-488.

Klein, R., Gist, N., Nicholson, J., \& Stanley, K. (1981). A study of father-nurse support during labour. Birth and the Family Journal, 8 (3): 161-164. 
Lamb, M. E. (1976). The role of the father: An overview. In M. E. Lamb (Ed.) The role of the father in child development. New York: John Wiley \& Sons.

Leashore, B. (1979). Human Services and the unmarried father: the "forgotten half". Eamily Coordinator, 28: 529-534.

Lobiondo-Wood, G. \& Haber, J. (1990). Non-experimental designs. In G.Lobiondo-Wood and J.Haber (Eds.) Nursing research: methods, critical appraisal and utilization $\left(2^{\text {nd }}\right.$ ed.). Toronto: C. V. Mosby Co.

Marcia, J. (1980). Identity in adolescence. In Joseph Adelson (Ed.) Handbook of adolescent psychology. New York: Wiley.

May, K. (1991). Interview techniques in qualitative research: Concerns and challenges. In J. Morse (Ed.) Qualitative Nursing Research (2 $\left.{ }^{\text {nd }} E d.\right)$ pl 88-201. Newburg Park, London: Sage.

May, K. (1982). Three phases of father involvement in pregnancy. Nursing Research, 31 (6): $337-342$

May, K. (1978). Active involvement of expectant fathers in pregnancy: Some further considerations. JOGNN I (2): 7-12. Lippincott.

Meleis, A. (1985). Theoretical nursing: development and progress. New York:

Meyer, V. F. (1991). A critique of adolescent pregnancy prevention research: The invisible white male. Adolescence, 26 (101): 217-222.

Morris, M. (1991). Adolescent pregnancy. Journal of Societv of Obstetricians and Gynecologists, April: 15-20 absent homes.

Mott, F. (1990). When is a father really gone? Paternal-child contact in father-

Nakashima, I \& Camp, B. (1984). Fathers of infants born to adolescent mothers: a study of paternal characteristics. American Journal of Diseases in Children, 138: 452454. 
Nye, F. (1976). Role structure and analysis of the family (Vol.24). Beverly Hills, Ca: Sage Publications.

Offer, D. \& Offer, J. (1974). Normal adolescent males: the high school and college years. Journal of American College Health Association, 22 (2): 209-215.

Offer, D. Ostrov, E., \& Howard, K. \& Dolan, S. (1992). Offer Self-Image questionnaire revised: manual. Los Angeles, Ca: Western Psychological Services.

Offer, D. Ostrov, E., \& Howard, K. (1989). Adolescence: What is normal? American Journal of Diseases in Children, 143: 731-736.

Offer, D. Ostrov, E., \& Howard, K. (1984). Body image, self-perception and chronic illness in adolescence. In Robert Blum (Ed.). Chronic illness and disabilities in childhood and adolescence. Orlando, Fl.: Grune \& Stratton.

Offer, D. Ostrov, E., \& Howard, K. (1977). The self-image of adolescents: A study of four cultures. Journal of Youth and Adolescence, 6 (3): 265-280.

Offer, D. Ostrov, E., \& Howard, K.I. (1981). The adolescent: A psychological self-portrait. New York: Basic Books.

Offer, D. Ostrov, E., Howard, K.I. \& Atkinson, R. (1988). The teenage world: The adolescent's self-image in ten countries. New York: Plenum Medical Book Company.

Offer, D. Ostrov, E., Howard, K.I. \& Dolan, S. (1992). Offer self-image questionnaire - revised. Los Angeles, Ca: Western Psychological Services.

Palkovitz, R. (1982). Fathers birth attendance, early contact, and father interaction at 5 months postpartum. Birth, 2 (3): 173-177

Pannor, R. (1971). The teenage unwed father. Obsterics and Gynecology, 14 (2): 466-472.

Pannor, R; Massarik, F. \& Evans, B. (1971). The unmarried father. New York: Springer Publishing.

Panzarine, S. \& Elster, a. (1983). Coping in a group of expectant adolescent fathers: an exploratory study. Journal of Adolescent Health Care, 4: 117-120. 
Papalia, D \& Wendkos-Olds, S, (1995). The developing person through the life span ( $3^{\text {rd }}$ ed.). New York: Worth Publishers.

Parke, R. D. (1979). Perspectives on father-infant interaction. In J. D. Osofsky (Ed.) Handbook of infant development. New York: Wiley.

Platt, H.K. (1968). A public adoption agency's approach to natural fathers. Child Welfare, 47, 530-553.

Pletsh, P.K.; Johnson, M.K.; Tosi, C.B.; Thurston, C.A. \& Riesch, S.K. (1991). Self-image among early adolescents: Revisited. Journal of Community Health Nursing, $\underline{8}(4), 215-231$.

Polit, D.F. \& Hungler, B.P. (1991). Principles and methods (4th ed.), New York: J.B. Lippincott Co.

Redmond, M.A. (1985). Attitudes of adolescent pregnancy and fatherhood. Eamily Relations. 34, 337-342.

Rivara, F. P. (1981). Teenage pregnancy: The forgotten father Developmental Behavioural Pediatrics, 2: 142-145.

Rivara, F; Sweeney, P. \& Henderson, B. (1986). Black teenage fathers: What happens when the child is born? Pediatrics, 78: 151-158.

Robins, M. \& Lynn, D. (1973). The unwed fathers: generation recidivism and attitudes about intercourse in California Youth Authority wards. Journal of Sex Research, 2: 334-341.

Robinson, B. (1988). Teenage pregnancy from the father's perspective. American Journal of Orthopsychiatry, 58: (1): 46-51.

Robinson, B. (1987). Teenage fathers. Lexington MA: Lexington Books.

Robinson, B. \& Barret, R. (1983). Locus of control of unwed adolescent fathers versus adolescent non-fathers. Perceptual and Motor Skills, 56: 397-398.

Robinson, B. \& Barret, R. (1982). Issues and problems related to the research on teenage fathers: a critical analysis. Journal of School Health, 52 , (10), 596-600.

Robinson, B. \& Frank, D. (1994). The relation between self-esteem, sexual activity, and pregnancy. Adolescence, 113: 27-35. 
Rosenberg, M. (1985). Self-concept and psychological well-being in adolescence. In R.Leahy (Ed.), The development of self. (p.205-242). New York: Academic Press.

Rotundo, A. (1985). American fatherhood: a historical perspective - American Behavioural Scientist, 29 (1):

Rubenstein, E. (1991). Families in society: An overview of adolescent development, behaviour and clinical intervention. Joumal of Contemporary Family Services 4, (72), 220-225.

Ryan, G. M., \& Sweeney, P.J. (1980). Attitudes of adolescents towards pregnncy and contraception. American Journal of Obstetrics and Gynaecology 137: 358-366.

Sandor, J. \& Rosen, J. (1989). Teenage fathers: Working with the neglected partner in adolescent childbearing. Family Planning Perspective, 21 (6).

Sarbin, T. \& Allen, V. (1968). Role theory. In L.Gardener and E. Aronson (Eds.). Handbook of social psychology, Vol.1. Reading, Ma: Addison Wesley.

Sarrel, P. (1967). The University Hospital and the unwed mother. American Journal of Public Health, 57: 1308-1313.

Sawyer, S; Rosier, M; Pheln, P. \& Bowes, G. (1995). The self-image of adolescents with cystic fibrosis. Journal of Adolescent Health, 16 (3): 204-208.

Shaw-Schuster, C; Cronk, R. \& Reno, fF. (1992). Psychological development during adolescence. In C. Shaw-Schuster (Ed.). A process of human development ( $3^{\text {rd }}$ ed.). Philadelphia: J.B. Lippincott Company.

Shaw-Schuster, C. \& Smith-Ashburn, S. (1992). A process of human development $\left(3^{\text {rd }}\right.$ ed.). Philadelphia: J.B. Lippincott Company.

Sherline, D. M. \& Davidson, R. A. (1987). Adolescent pregnancy: The Jackson Mississippi experience. American Journal of Obstetrics and Gynaecology. 132: 245-255.

Shrauger, J.S. \& Schoeneman, T.J. (1979). Symbolic interactionist view of self-concept; Through the looking-glass darkly. Psychological Bulletin, 48: 459-473.

Sideleau, B. (1992). The person. In J.Haber, A. Leach-McMahon, P.PriceHoskins and B. Sideleau (Eds.). Comprehensive Psychiatric Nursing ( $4^{\text {th }}$ ed.). .Toronto: Mosby Year Book. 
Silber, J. (1982). Adolescent sexuality: a developmental viewpoint. Journal of Youth and Adolescence, 1: 205-214.

Slap, G; Khalid, N; Paikoff, R; Brooks-Gunn, J. \& Warren, M. (1994). Evolving self-image, pubertal manifestations, and pubertal hormones: preliminary findings in young adolescent girls. Journal of Adolescent Health, 15 (4): 327-335.

Smetana, J; Yaw, J; Restrepo, A. \& Braeges, J. (1991). Adolescent-parent conflict in married and divorced families. Developmental Psychology, 27 (6): 10001010.

Smith, D.L. (1984). Meeting the needs of teenage mothers and fathers. Nursing Clinics of North America 19, (2), 369-379.

Spivak, H. \& Weitzman, M. (1987). Social barriers faced by adolescent parents and their children. HAMA, 258, (11), 1500-1504.

Stack. C. (1974). All our kin: strategies for survival in an African American community New York: Harper \& Row.

Stassen-Berger, K. (1994). The developing person through the life span ( $3^{\text {rd }}$ ed.). New York: Worth Publishers.

Statistics Canada (1997). Births and deaths, 1995. Ottawa: Author.

Steinberg, L. (1990). Autonomy, conflict and harmony in the family relationship. In S. Feldman \& G. Elliott (Eds.). At the thresehold: The developing adolescent. Cambridge, MA: Harvard University Press.

Stouthamer-Loeber, M. \& Wei, E. (1998). The precursors of young fatherhood and its effect on delinquency of teenage males. Journal of Adolescent Health, 22 (1): 56-65. W.W.Norton.

Sullivan, H.S., (1953). The interpersonal theory of psychiatry New York:

Taucher, P. (1991). Support for adolescent fathers. Nursing Forum, 26, (1), 22-26.

Tri-Council Working Group (1997). Code of ethical conduct for research involving humans. Unpublished. 
Tuttle, J. (1988). Adolescent pregnancy: factoring in the father of the baby. Journal of Pediatric Health Care, 2: 240-244.

Unger, D.\& Cooley, M. (1992). Partner and grandmother contact in Black and White teen parents families. Journal of Adolescent Health, 13: 546-552.

Vaz, R. Smolen, P. \& Miller, C. (1983). Adolescent pregnancy: involvement of the male partner. Joumal of Adolescent Health Care 4, (4), 246-250.

Waltz, C. \& Bausell, R. (1981). Nursing research: design. statistics and computer analysis. Philadelphia: F.A. Davis.

Westney, O.E., Cole, O.J. \& Munford, T.L. (1986). Adolescent unwed prospective fathers: Readiness for fatherhood and behaviours toward the mother and expected infant. Adolescence, 21, (84), 901-911.

Williams-McCoy, J. \& Forrest, T. (1985). Selected psychosocial characteristics of Black unwed adolescent fathers. Joumal of Adolescent Health Care, 6: 12-16.

Yoos, L. (1989). Adolescent cognitive and contraception behaviours. Pediatric Nursing, 13 (4): 247-250. 
Appendix A

Offer Self-Image Questionnaire - Revised

(OSIQ - R) 
DEPARTMENT OF OBSTETRICS, GYNECOLOCY, AND REPRODUCTIVE SCIENCES

May 13, 1997

Women's Hospital

735 Norre Dame Avenue

Winnipeg, Manitoba

Canada R3E OLS

Tel.: (204) 787 .

FAX: (204) 78726832

Northwestern Psychiatric Institute

12031 Wilshire Boulevard

Los Angeles, CA 90025

Attention: Purchasing Department

Dear Dr. Offer:

Further to our telephone conversation, I have decided to purchase the manual related to the Offer Self-Image Questionnaire for Adolescents (O.S.I.Q.) for more in-depth information. If the use of this questionnaire meets with the approval of my thesis committee, I would be purchasing the complete package(s).

I am a Graduate student in the Faculty of Nursing, University of Manitoba. My proposed research topic is: "What is the influence of self-image and role models on adolescent fathers' involvement in the pregnancy?" The thesis committee that will be supervising the research and use of the O.S.I.Q. is made up of: Dr. Janet Beaton, Dean of the Faculty of Nursing [(204) 474-9201]; Dr. Annette Gupton, Associate Professor in the Faculty of Nursing [(204) 474-6220], both at the University of Manitoba; and Dr. Lorna Grant, ObstetricianGynecologist at Women's Hospital, Health Sciences Centre, Associate Professor in the Faculty of Medicine, also at the University of Manitoba [(204) 787-2832].

In accordance with the requirement to purchase any material related to the O.S.I.Q., Dr. Grant's signature on this letter indicates her consent to supervise the proposed use of the aforementioned tool.

Thank you for your good wishes towards my proposed research. I look forward to reviewing the O.S.I.Q. manual in greater detail, and the use of the questionnaire.

Sincerely,

intrace.

Merle Jones, R.N., B.N.

27 Roberts Crescent

Winnipeg, MB R2P 1 A4

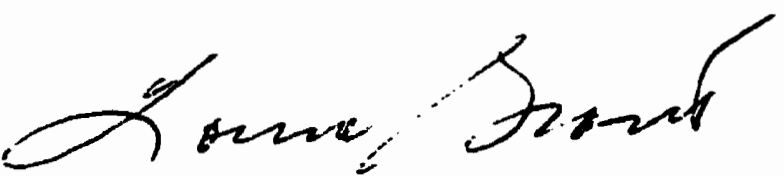

Lorna J. Grant, M.D., FRCSC

External Thesis Committee Member

Ph: (H) (204) 697-1960

(W) (204) 787-1593

FAX: (204) 787-1375

\section{My/bes}




\section{APPENDIX A}

\section{OFFER SELF-IMAGE QUESTIONNAIRE - REVISED}

Your answers to the following questions will help me to learn more about how you think and feel about yourself. There are no right or wrong answers, and only you can choose for yourself. After you read each of the following statements, choose the answer which best describes you for numbers 1-6. (eg., I am a male Answer: 1)

1. Describes me very well.

2. Describes me well.

3. Describes me fairly well.
4. Does not quite describe me.

5. Does not really describe me.

6. Does not describe me at all.

1. I carry many grudges

1.

2. When I am with people, I am afraid that someone will make fun of me.

2.

3. Most of the time I think that the world is an exciting place to live in.

3.

4. I think that I will be a source of pride to my parents in the future.

4.

5. I would not hurt someone just for the "heck of it."

5.

6. The recent changes in my body have given me some satisfaction.

6.

7. I am going to devote my life to help others.

7.

8. I "lose my head" easily.

8. 

1. Describes me very well.
4. Does not quite describe me.
2. Describes me well.
5. Does not really describe me.
3. Describes me fairly well.
6. Does not describe me at all.

9. My parents are almost always on the side of someone else, such as my brother or sister.

9.

10.

10. The opposite sex finds me a bore.

11. If I would be separated from all the people I know, I feel that I would not be able to make a go of if.

11.

12.

13

14.

15.

15. My parents will be disappointed in me in the future.

16. It is very hard for a teenager to know how to handle sex in a right way.

16.

17. At times I have fits of crying and/or laughing that I seem unable to control.

17.

18. I am going to devote my life to making as much money as I can.

18.

19. If I put my mind to it, I can learn almost anything.

19.

20. Only stupid people work.

20.

21. Very often I feel that my father is no good.

21.

22. I am confused most of the time.
22. 
1. Describes me very well. 4. Does not quite describe me.

2. Describes me well. 5. Does not really describe me.

3. Describes me fairly well. 6. Does not describe me at all.

23. I feel inferior to most people I know.

23.

24. Understanding my parents is beyond me.

24.

25. I do not like putting things in order and make sense of them.

25.

26. I can count on my parents most of the time.

26.

27. In the past year I have been very worried about my health.

27.

28. Dirty jokes are fun at times.

28.

29. I often blame myself even when I am not at fault.

29.

30. I would not stop at anything if I felt I was done wrong.

30.

31. Most of the time I am happy.

31.

32. I am going to devote myself to making the world a better place to live in.32.

33. I can take criticism without resentment.

33.

34. My work, in general, is at least as good as the work of the girl/boy next to me.

34.

35. Sometimes I feel so ashamed of myself that I just want to hide in a corner and cry.

35.

36. I am sure that I would be proud of my future profession.

36.

37. My feelings are easily hurt.

37. 
1. Describes me very well. 4. Does not quite describe me.

2. Describes me well. 5. Does not really describe me.

3. Describes me fairly well. 6. Does not describe me at all.

38. When a tragedy occurs to one of my friends, I feel sad, too.

38.

39. I blame others even when I know that I am at fault, too.

39.

40. When I want something, I just sit around wishing I could have it.

40.

41. The pictures I have of myself in the future satisfies me.

41.

42. I am a superior student in school.

42.

43. I feel relaxed under normal circumstances.

43.

44. I feel empty emotionally most of the time.

44.

45. I would rather sit around and loaf off then work.

45.

46. Even if it was dangerous, I would help someone who is in trouble.

46.

47. Telling the truth means nothing to me.

47.

48. Our society is a competitive one and I am not afraid of it.

48.

49. I get violent if I don't get my way.

49.

50. Most of the time my parents get along well with each other.

50.

51. I think that other people just don't like me.

51.

52. I find it very difficult to establish new friendships.

52.

53. I am so very anxious.

53. 

1. Describes me very well.
4. Does not quite describe me.
2. Describes me well.
5. Does not really describe me.
3. Describes me fairly well.
6. Does not describe me at all.

54. When my parents are strict I feel that they are right even if I get angry. 54.

55. Working closely with another boy/girl never gives me pleasure.

55.

56. I am proud of my body.

56.

57. At times I think about what kind of work I will do in the future.

57.

58. Even under pressure I manage to remain caim.

58.

59. When I grow up and have a family it will be in at least a few ways similar to my own.

59.

60. I often feel that I would rather die than go on living.

60.

61. I find it extremely hard to make friends.

61.

62. I would rather be supported for the rest of my life than work.

62.

63. I feel that I have a part in making family decisions.

63.

64. I do not mind being corrected, since I can learn from it.

64.

65. I feel so very lonely.

65.

66. I do not care how my actions affect others, as long as I gain something.

66.

67. I enjoy life.

67.

68. I keep an even temper most of the time.

68.

69. A job well done gives me pleasure.

69. 
1. Describes me very well.

2. Describes me well.

3. Describes me fairly well.
4. Does not quite describe me.

5. Does not really describe me.

6. Does not describe me at all.

70. My parents are usually patient with me.

70.

71. I seem to be forced to imitate the people I like.

71.

72. Very often parents don't understand a person because they had an unhappy childhood.

72.

73. For me good sportsmanship is as important as winning the game.

73.

74. I prefer being alone with people my own age.

74.

75. When I decide to do something, I do it.

75.

76. I think that girls find me attractive.

76.

77. Other people are not after me to take advantage of me.

77.

78. I feel that there is plenty I can learn from others.

78.

79. I do not attend sexy shows.

79.

80. I fear something constantly.

80.

81. Very often I think I am not at all the person I would like to be.

81.

82. I like to help a friend whenever I can.

82.

83. When I know I will be facing a new situation, I try in advance to find out as much as possible about it.

83.

84. Usually I feel that I am a bother at home.

84. 

1. Describes me very well.
4. Does not quite describe me.
2 .Describes me well.
5. Does not really describe me.
3. Describes me fairly well.
6. Does not describe me at all.

85. If others disapprove of me I get terribly upset.

85.

86. I like one of parents much better than the other.

86.

87. Being together with older people gives me a good feeling

87.

88. Whenever I fail at something, I try to find out what I can do in order to avoid another failure.

88.

89. I frequently feel ugly and unattractive.

89.

90. Sexually I am way behind.

90.

91. If you confide in others you ask for trouble.

91.

92. Even though I am continuously on the go, I seem unable to get things done.92.

93. When others look at me they must think I am poorly developed.

93.

94. My parents are ashamed of me.

94.

95. I believe I can tell the real from fantasy.

95.

96. Thinking or talking about sex frightens me.

96.

97. I am against giving so much money to the poor.

97.

98. I feel strong and healthy.

98.

99. Even when I am sad I can enjoy a good joke.

99. 
1. Describes me very well. 4. Does not quite describe me.

2. Describes me well. 5. Does not really describe me.

3. Describes me fairly well. 6. Does not describe me at all.

100. There is nothing wrong with putting oneself before others. 100 .

101. I try to stay away from home most of the time. 101.

102. I find life an endless series of problems - without any solutions insight. 102 .

103. At times, I feel like a leader and feel that other kids can learn something from me.

103.

104. I feel that $I$ am able to make decisions. 104.

105. I have been carrying a grudge against my parents for years. 105.

106. I am certain I will not be able to assume responsibilities for myself in the future.

106.

107. When I enter a new room I have a strange and funny feeling. 107.

108. I feel I have no talent whatsoever. 108.

109. I do not rehearse how I might deal with a real coming event. 109.

110. When I am with people, I am bothered by hearing strange noises. 110.

111. Most of the time my parents are satisfied with me. 111.

112. I do not have a particularly difficult time in making friends. 112.

113. I do not enjoy solving difficult problems. 113. 


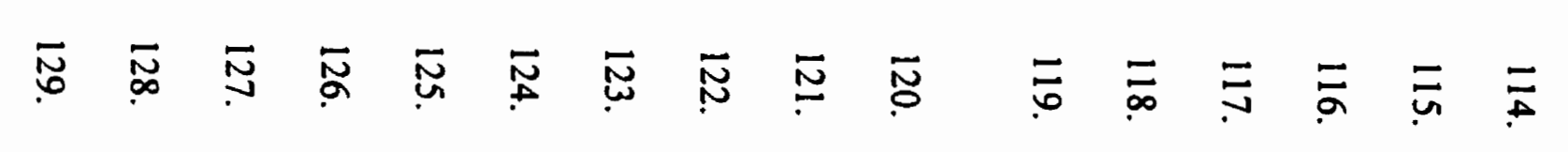
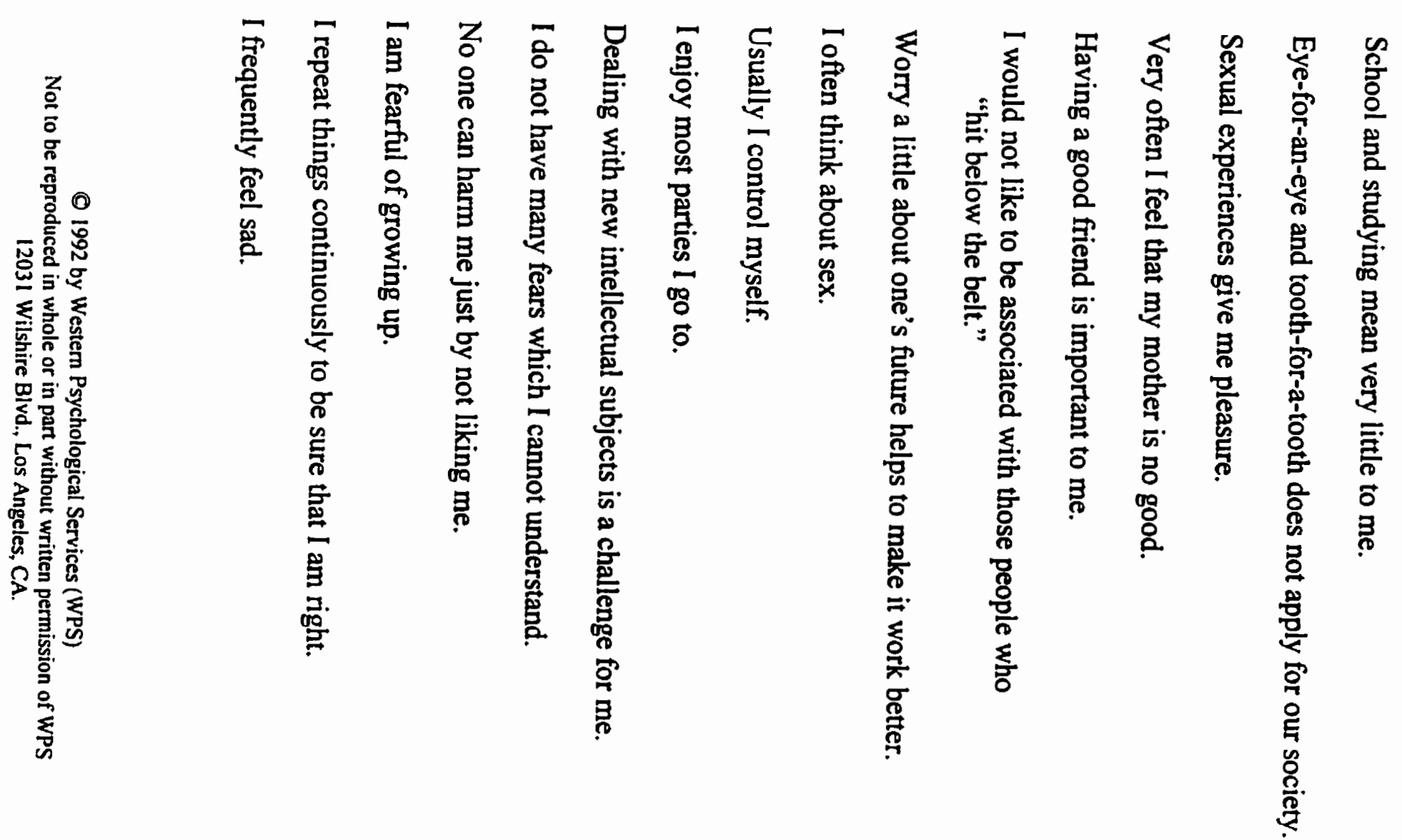

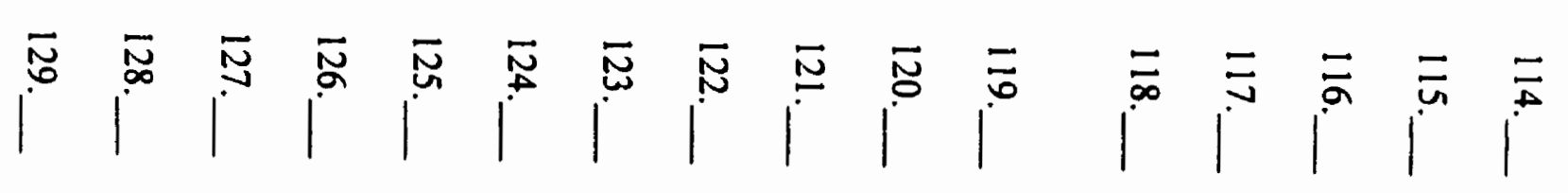

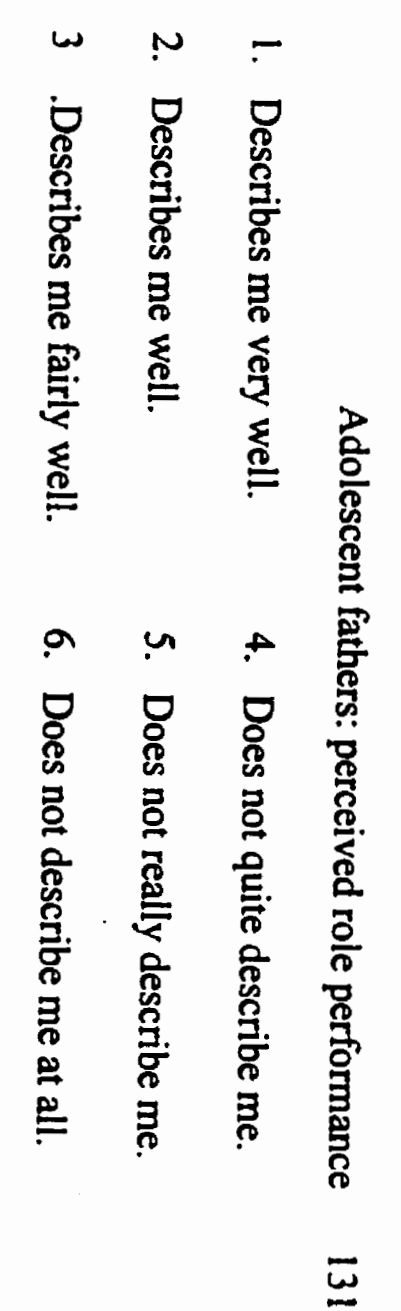


Appendix B

Role Performance Questionnaire 


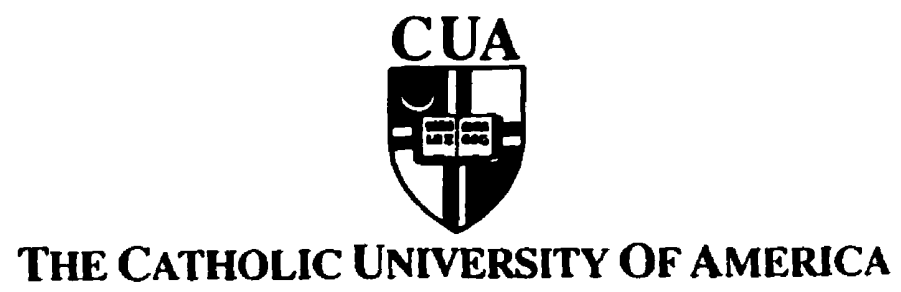

National Catholic School of Social Service

Shaluan Hall

Wushingron. D.C. 2006

$202-319-5458$

Fis. $202 \cdot 3 / 9-504.3$

March 12, 1998

Ms. Merle Jones

27 Roberts Crescent

Winnipes, Manitoba R2PIA4

Dear Ms. Jones:

Per your request, enclosed are chapters from Dr. Kenneth Ontwon Christmon's Dissertation, entitled "The Impact of Self-Image and Perceived Role Expectations on Perceived Role Performance Among Unwed Adolescent Fathers". You indicated you were interested in the chapter on Methodology. As I reviewed the dissertation, I thought perhaps the questionnaire might also be helpful to you.

Please let me know if there is further information you may need.

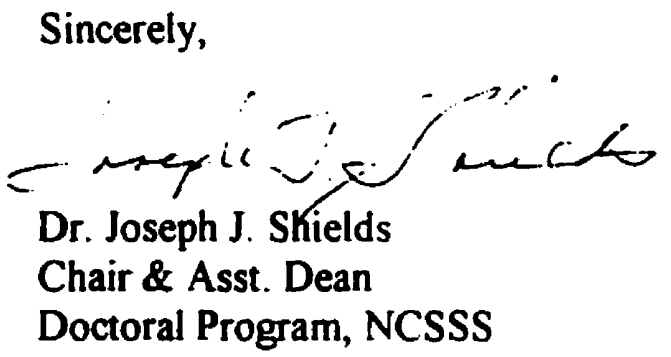




\section{APPENDIX B}

\section{ROLE PERFORMANCE: PERCEIVED}

The following questions are on young fathers and how they feel about parenting. Some questions are on what you think others might think about you being a parents. First, you will be asked questions about yourself and your parents. Secondly, you will be asked questions about your partner's thoughts on your parenting skills. After you read the questions, the answer that best describes you. Remember, there are no right or wrong answers - only you know how you feel and what you think.Fathers Own Expectations Of Role Performance 1. How much of baby's expenses will you provide? Expenses include material goods, for example: food, diapers, clothes, etc.

1. All

2. More than half

3. Half

4. Less than half

5. None

2. How often will you feed or prepare formula/food for the baby? Would you say you will have:

1. Total responsibility

2. Most of the responsibility

3. About half of the responsibility

4. Less than half the responsibility

5. Little or no responsibility 
3. How often will you bathe the baby? Would you say you will have:

1. Total responsibility

2. Most of the responsibility

3. About half of the responsibility

4. Less than half of the responsibility

5. Little or no responsibility

4. How often will you play with your baby/child? Play includes holding, cuddling, hugging, talking, etc.

1. Frequently

2. Often

3. Sometimes

4. Seldom

5. Never

5. How often will you discipline the baby/child? Would you say you will have:

1. Total responsibility

2. Most of the responsibility

3. About half of the responsibility

4. Less than half of the responsibility

5. Little or no responsibility

6. How often will you change your child's diapers? Would you say you will have:

1. Total responsibility

2. Most of the responsibility

3. About half the responsibility 
4. Less than half the responsibility

5. Little or no responsibility $\square$

7. How much time will you spend with your child per week?

1. 25 hours or more

2. 2l-24 hours

3. $16-20$ hours

4. 11-15 hours

5. 5-10 hours

6. 0 hours

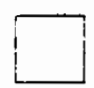

8. How often will you take or accompany your child to the clinic or doctor? Would you say you will have:

1. Total responsibility

2. Most of the responsibility

3. About half of the responsibility

4. Less than half the responsibility

5. Little or no responsibility

In this section you will be asked some questions about what you think your partner feels you should do for the child. Remember, choose the answer that best describes what you think she feels 


\section{Perceived Role Expectations of Partner (Child's Mother)}

9. My partner expects me to support my child financially.

1. Strongly agree

2. Agree

3. Uncertain

4. Disagree

5. Strongly disagree

10. My partner expects me to feed or prepare formula/food for my child.

1. Strongly agree

2. Agree

3. Uncertain

4. Disagree

5. Strongly disagree

11. My partner expects to bathe or help with my child's bath.

1. Strongly agree

2. Agree

3. Uncertain

4. Disagree

5. Strongly disagree

12. My partner expects me to change my child's diapers.

1. Strongly agree

2. Agree

3. Uncertain 


\section{Disagree}

5. Strongly disagree

13. My partner wants me or did want me to finish school instead of working to take care of my child.

1. Strongly agree

2. Agree

3. Uncertain

4. Disagree

5. Strongly disagree

14. My partner believes that it is just as important for me to spend time with my friends as with my child.

I. Strongly agree

2. Agree

3. Uncertain

4. Disagree

5. Strongly disagree 
Now, you will be asked questions about what your parents think. This section is similar to the last section. Choose the answer which best describes what you believe they feel. You will be asked about your mother, first, and then, your father.

Perceived Role Expectations of Parents.

15. My expects me to support my child financially.

\section{Mother}

1. Strongly agree

2. Agree

3. Uncertain

4. Disagree

5. Strongly disagree

16. My baby.

Mother

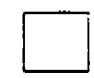

5. Strongly disagree
Father

1. Strongly agree

2. Agree

3. Uncertain

4. Disagree

5. Strongly disagree expects me to feed or prepare formula/food for my

1. Strongly agree

2. Agree

3. Uncertain

4. Disagree

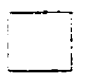

Mother

1. Strongly agree

2. Agree

17. My

\section{Father}

1. Strongly agree

2. Agree

3. Uncertain

4. Disagree

5. Strongly disagree expects me to bathe or help with my child's bath

\section{Father}

1. Strongly agree

2. Agree 
3. Uncertain

4. Disagree

5. Strongly disagree

18. My expects me to change my child's diapers.

Mother

1. Strongly agree

2. Agree

3. Uncertain

4. Disagree

5. Strongly disagree
3. Uncertain

4. Disagree

5. Strongly disagree

19. $\mathrm{My}$

\section{Father}

1. Strongly agree

2. Agree

3. Uncertain

4. Disagree

5. Strongly disagree

working to take care of my child.

Mother

1. Strongly agree

2. Agree

3. Uncertain

4. Disagree

5. Strongly disagree
Father

1. Strongly agree

2. Agree

3. Uncertain

4. Disagree

5. Strongly disagree 
In this last section you will be asked questions about what you think a father's responsibility is to his child. Remember, choose the answer that best describes what you think.

\section{Father's Own Expectations}

20. It is my responsibility to financially support my child. For example, to provide money to the mother, food, clothes, diapers, etc.

1. Strongly agree

2. Agree

3. Uncertain

4. Disagree

5. Strongly disagree

21. It is my responsibility to prepare meals for my child.

l. Strongly agree

2. Agree

3. Uncertain

4. Disagree

5. Strongly disagree

22. It is my responsibility to bathe or help my child to take a bath.

1. Strongly agree

2. Agree

3. Uncertain 
4. Disagree

5. Strongly disagree

23. It is my responsibility to change my child's diapers.

1. Strongly agree

2. Agree

3. Uncertain

4. Disagree

5. Strongly disagree

24. It is or was more important for me to finish school than to get a job to take care of my child.

1. Strongly agree

2. Agree

3. Uncertain

4. Disagree

5. Strongly disagree

25. Spending time with my friends is more important to me than spending time with my child.

1. Strongly agree

2. Agree

3. Uncertain

4. Disagree

5. Strongly disagree 
Appendix C

Demographic Data 


\section{APPENDIX C}

\section{Demographic Data}

I.D.\#:

Date:

This final questionnaire will provide some background information about you and your parents. Remember, only choose one answer from each of the following statements or questions.

Please $(\checkmark)$ one in each of the following:

1. How old were you on your last birthday? years

2. Education: highest level of education completed.

Grade 6 or less

Grade 7 - 8

Grade $9-10$

Grade $11-12$

Some College

Some University

3. Occupation:

Student

Clerical

Labourer 
Retail

Unemployed (EI)

Social Assistance

4. Ethnic Background

European

Aboriginal/Metis

Other

$\square$ (Please specify)

5. Marital status of parents:

Married

Never married

Divorced/Separated

Common-Law

Widowed 
6. Parental occupation:

Mother

Homemaker

Clerical

Retail

Management

Professional

Other

(Please specify)
Father

Clerical

Retail

Labourer

Management

Professional

Other

(Please specify)

7. Have you experienced abuse, example: physical, verbal or sexual? Please omit this question if it provokes anxiety.

Yes

No

Not sure 
8. What are your present living arrangements:
Home with parents
Live alone
Age when you left home
Live with partner

9. How long have you been in this relationship with your present partner?

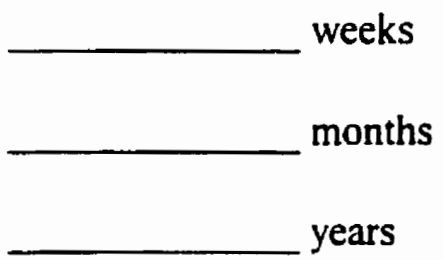

If married, please specify: months.

10. Do your parents know that your partner is pregnant?

Yes

No.

Not sure

11. What was your parent/s reaction to the pregnancy?

Mother

Supportive

Unsupportive

Not sure
Father

Supportive

Unsupportive

Not sure 
Appendix D, D (I) and D (II)

Explanation of Study 


\section{APPENDIX D}

\section{EXPLANATION OF STUDY}

Hello, my name is . I am a Master of Nursing student at

the University of Manitoba, Faculty of Nursing. As a nurse, I have a special interest in teenage pregnancy. I would therefore, like to learn more about the factors which help young men to care for their children.

If you agree to participate in this study, it will involve filling out three questionnaires, which will help me to learn more about you and your thoughts or ideas of parenting. You will also be asked about your parents and partner's expectations regarding your parenting responsibilities. There are no right or wrong answers. Other questions will provide information about your background such as: age, education, number of brothers and sisters, as well as number of friends and family members who are young parents. Some questions will provide an insight into your present relationship, and living arrangements. All questionnaires will be completed in my presence, at a mutually agreed upon time in the Women's Hospital.

All the information you provide will be kept in strict confidence, and only I will have your name and information which may identify you. Your name will not appear on any of the questionnaires. All questionnaires will be kept in a locked filing cabinet and will only be available to me and my research supervisors: Dr. Janet Beaton, and 
Dr. Annette Gupton, Professors in the Faculty of Nursing - University of Manitoba; and Dr. Lorna Grant, Obstetrician - Gynecologist, Clinical Director, Maternal Child Health, St. Boniface Hospital.

Remember, your name will not be on the questionnaires. The result will be based on group information, this will insure that no one will ever know how you filled out the questionnaires. Results will be published as a master's thesis and possibly in a journal article.

I do not believe that there is risk to you, since you can choose not to answer any question/s which may cause you discomfort. However, you may experience a minor inconvenience of having to come to Women's Hospital for about one and a half hours. All information will be kept confidential, if however, thoughts of, or plans to harm yourself and/or others are revealed, I will help you find appropriate help and/or refer you to an appropriate resource. Following the completion of the questionnaires you may discuss any concerns you might have with me, or should you prefer another source, I will make an appropriate referral. After the questionnaires are filled out, you will be given the sum of $\$ 5.00$ to cover parking or bus fare.

Your participation in this study is voluntary and you may choose to withdraw at any time during the study without penalty or risks to your partner and unborn child. You may benefit from the study which may increase your sensitivity regarding your parenting 
skills and the reality of becoming a parent. The knowledge gained from this study may help health professionals and allied workers to provide appropriate and relevant support and education which may result in helping future young parents to develop good, more effective parenting skills. This may result in young parents feeling better about themselves, as well as dealing more sensitively to the needs of their children.

You may contact me at (204) $787-1593$ or write to me at: 735 Notre Dame Avenue, c/o Women's Hospital, WR329, Winnipeg, Manitoba, R3E 0L8. You may ask me questions about the study at any time and receive answers.

Thank you for your time and cooperation, they are greatly appreciated. 
APPENDIX D (I)

\section{EXPLANATION OF STUDY}

Hello, my name is I am a Master of Nursing student at the University of Manitoba, Facuity of Nursing. As a nurse, I have a special interest in teenage pregnancy. I would therefore, like to learn more about the factors which help young men to care for their children.

If you agree to participate in this study, it will involve filling out three questionnaires, which will help me to learn more about you and your thoughts or ideas of parenting. You will also be asked about your parents and partner's expectations regarding your parenting responsibilities. There are no right or wrong answers. Other questions will provide information about your background such as: age, education, number of brothers and sisters, as well as number of friends and family members who are young parents. Some questions will provide an insight into your present relationship, and living arrangements. All questionnaires will be completed in my presence, at a mutually agreed upon time in the Women's Hospital.

All the information you provide will be kept in strict confidence, and only I will have your name and information which may identify you. Your name will not appear on any of the questionnaires. All questionnaires will be kept in a locked filing cabinet and will only be available to me and my research supervisors: Dr. Janet Beaton, and 
Dr. Annette Gupton, Professors in the Faculty of Nursing - University of Manitoba; and

Dr. Lorna Grant, Obstetrician - Gynecologist, Clinical Director, Maternal Child Health,

St. Boniface Hospital.

Remember, your name will not be on the questionnaires. The result will be based on group information, this will insure that no one will ever know how you filled out the questionnaires. Results will be published as a master's thesis and possibly in a journal article.

I do not believe that there is risk to you, since you can choose not to answer any question/s which may cause you discomfort. However, you may experience a minor inconvenience of having to come to Women's Hospital for about one and a half hours. All information will be kept confidential, if however, thoughts of, or plans to harm yourself and/or others are revealed, I will help you find appropriate help and/or refer you to an appropriate resource. Following the completion of the questionnaires you may discuss any concerns you might have with me, or should you prefer another source, I will make an appropriate referral. After the questionnaires are filled out, you will be given the sum of $\$ 5.00$ to cover parking or bus fare.

Your participation in this study is voluntary and you may choose to withdraw at any time during the study without penalty or risks to your partner and unborn child. You may benefit from the study which may increase your sensitivity regarding your parenting 
skills and the reality of becoming a parent. The knowledge gained from this study may help health professionals and allied workers to provide appropriate and relevant support and education which may result in helping future young parents to develop good, more effective parenting skills. This may result in young parents feeling better about themselves, as well as dealing more sensitively to the needs of their children.

You may contact me at (204) $787-1593$ or write to me at: 735 Notre Dame Avenue, c/o Women's Hospital, WR329, Winnipeg, Manitoba, R3E 0L8. You may ask me questions about the study at any time and receive answers.

If you have received this invitation to participate in this study through your partner, I will be contacting you by phone, and I will only speak with you about this matter. This will ensure your confidentiality is maintained. I will answer any questions you may have. Should you decide not to participate this time, you will not be phone again.

Thank you for your time and cooperation, they are greatly appreciated. 
APPENDIX D(II)

\section{EXPLANATION OF STUDY}

Hello, my name is . I am a Master of Nursing student at

the University of Manitoba, Faculty of Nursing. As a nurse, I have a special interest in teenage pregnancy. I would therefore, like to learn more about the factors which help young men to care for their children.

If you agree to participate in this study, it will involve filling out three questionnaires, which will help me to learn more about you and your thoughts or ideas of parenting. You will also be asked about your parents and partner's expectations regarding your parenting responsibilities. There are no right or wrong answers. Other questions will provide information about your background such as: age, education, number of brothers and sisters, as well as number of friends and family members who are young parents. Some questions will provide an insight into your present relationship, and living arrangements. All questionnaires will be completed in my presence, at a mutually agreed upon time in the Women's Hospital.

All the information you provide will be kept in strict confidence, and only I will have your name and information which may identify you. Your name will not appear on any of the questionnaires. All questionnaires will be kept in a locked filing cabinet and will only be available to me and my research supervisors: Dr. Janet Beaton, and 
Dr. Annette Gupton, Professors in the Faculty of Nursing - University of Manitoba; and Dr. Lorna Grant, Obstetrician - Gynecologist, Clinical Director, Maternal Child Health, St. Boniface Hospital.

Remember, your name will not be on the questionnaires. The result will be based on group information, this will insure that no one will ever know how you filled out the questionnaires. Results will be published as a master's thesis and possibly in a journal article.

I do not believe that there is risk to you, since you can choose not to answer any question/s which may cause you discomfort. However, you may experience a minor inconvenience of having to come to Women's Hospital for about one and a half hours. All information will be kept confidential, if however, thoughts of, or plans to harm yourself and/or others are revealed, I will help you find appropriate help and/or refer you to an appropriate resource. Following the completion of the questionnaires you may discuss any concerns you might have with me, or should you prefer another source, I will make an appropriate referral. After the questionnaires are filled out, you will be given the sum of $\$ 5.00$ to cover parking or bus fare.

Your participation in this study is voluntary and you may choose to withdraw at any time during the study without penalty or risks to your partner and unborn child. You may benefit from the study which may increase your sensitivity regarding your parenting 
skills and the reality of becoming a parent. The knowledge gained from this study may help health professionals and allied workers to provide appropriate and relevant support and education which may result in helping future young parents to develop good, more effective parenting skills. This may result in young parents feeling better about themselves, as well as dealing more sensitively to the needs of their children.

You may contact me at (204) $787-1593$ or write to me at: 735 Notre Dame Avenue, c/o Women's Hospital, WR329, Winnipeg, Manitoba, R3E 0L8. You may ask me questions about the study at any time and receive answers.

If you have received this invitation to participate in this study through your partner, I would like to meet with you at your partner's next prenatal appointment, which is on: date at

I look forward to meeting you. Your questions will be answered at that time. Thank you for your time and cooperation, they are greatly appreciated. 


\section{Appendix E}

Consent Form 


\section{APPENDIX E \\ CONSENT TO BE A RESEARCH PARTICIPANT}

\section{Purpose}

I agree to participate in a project by Merle Jones, a Master of Nursing student at the University of Manitoba, to learn more about the factors which help young men to be good parents. My answers to the questions are valuable and will promote greater understanding of the young men's thoughts, feelings and expectations related to parenting.

\section{Procedure}

I will be asked to complete three questionnaires which will take one hour to fill out. I understand that I will be asked specific questions about how I think and feel about myself as well as my parenting skills. Other questions relate to my partner and my parents expectations regarding my parenting skills. The questionnaires will be filled out in the researcher's presence, in the Women's Hospital at a mutually convenient time. After the completion of the questionnaires I will be given an opportunity to discuss any concerns.

\section{Risks/Disadvantages}

I do not believe that there is any risk to me. However, there may be an minor inconvenience of having to come to the Women's Hospital. I understand that if I am uncomfortable with any question. I may choose not to answer it. My name will not be written on the questionnaires, and will only be known to the investigator. All completed questionnaires will be analyzed collectively and stored in a locked drawer, so that my 
identity/confidentiality will be protected. If, however, I reveal plans and/or thoughts of harm to myself and/or others, I will be referred to an appropriate resource for help. The data will be secured for 10 years.

This study is being supervised by: Dr. Janet Beaton, and Dr. Annette Gupton, (474-6220) Professors in the Faculty of Nursing, University of Manitoba, and Dr. Loma Grant, Obstetrician-Gynecologist Clinical Director, Maternal Child Health, St. Boniface Hospital and Associate Professor in Faculty of Medicine, University of Manitoba (237-2548). These three people will have access to the data, which will not have my name or any identifying information.

\section{Benefits}

I understand that the study may benefit me by increasing my sensitivity regarding my parenting skills and as a result, it may help me to become a better father. The information and insights from this study will help those who work with young parents, specifically young fathers, to identity what can be done to help young men (parents) to be good and effective parents. I am aware that information from the data analysis will be used in presentations to health care workers and/or publications. I understand that my travel expense (parking or bus fare) will be reimbursed to a maximum of $\$ 5.00$, after I have completed all the questionnaires. 


\section{Questions}

I have received a copy of the written explanation of the study. However, if I have other questions, Merle Jones may be contacted at: (204) 787-1593 or 735 Notre Dame Avenue, c/o Women's Hospital, WR329, Winnipeg, R3E 0L8, at any point in the study. Rights

I have read the description of the study and my questions have been satisfactorily answered. My signature on this form indicates that I am informed and that I agree to participate as a volunteer subject in this study. I understand that my decision to participate is voluntary and that I may choose to withdraw at any time during the study without penalty or risks to my partner and unborn child.

Participant's Signature

Researcher's Signature

\begin{tabular}{c}
\hline Date \\
\hline Date
\end{tabular}

Date

I would like a summary of the results of this study: Yes $\square$ No $\square$ If 'yes,' please mail to:

Name:

Address: 
Appendix F, F (I)

Unit Manager's Approach for

Participation 


\section{APPENDIX F}

\section{Unit Manager/s Approach for Participation in St!ndy}

There is a Master of Nursing Student from the University of Manitoba, her name is Merle Jones. She is interested in finding out what factors influence young mens' behaviour related to parenting skills. Merle would like to speak with you about your partner's participation in a research study. Would you like to speak to her? If you should speak with her, you are not obligated to participate in her project. 


\section{APPENDIX F (I)}

\section{Unit Manager/s Approach for Participation in Study}

There is a Master of Nursing Student from the University of Manitoba, her name is Merle Jones. She is interested in finding out what factors influence young mens' behaviour related to parenting skills. Merle would like to speak with you about your partner's participation in a research study. Would you like to speak to her? If you should speak with her, you partner is not obligated to participate in her project. 
Appendix G

Ethical Approval 
The University of Manitoba

FACULTY OF NURSING

ETHICAL REVIEW COMMITTEE

\section{APPROVAL FORM}

Proposal Number \#98/41

Proposal Tille: $\quad$ "What is The Influence of Self-Image and Perceived Parenting Role Expectations on Adolescent Fathers' Perceived Role Performance?"

Name and Title of

Researcher(s): $\quad$ Merle Jones

Date of Review: $\quad$ September 21,1998

APPROVED BY THE COMMITTEE: $\quad$ October 5, 1998

Comments: With changes and clarifications outlined in your letters of September 29, and October 2,1998.

Date: act $5 / 98$

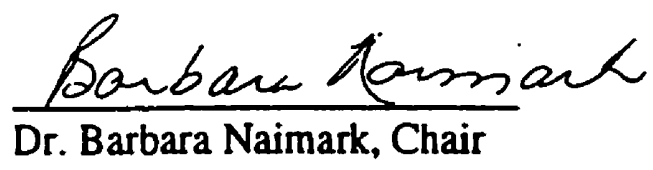

NOTE:

Any significant changes in the proposal should be reported to the Chairperson for the Ethical Review Committee's consideration, in advance of implementation of such changes. 


\section{Heallh Sciences Centre}

MST 7 B 20 SHEREROOK STREET WINNIPEG. MANTIOBA R3A IRO DIAL DIRECT

(204) 787-4587

OFFICE OF THE DIRECTOR OF RESEARCH

October 13, 1998

Ms M. Jones

Principal Investigator

WR329

Dear Ms Jones:

RE: WHAT IS THE INFLUENCE OF SELF-IMAGE AND PERCEIVED PARENTING ROLE EXPECTATIONS ON ADOLESCENT FATHERS PERCEIVED ROLE PERFORMANCE.

\section{ETHICS \#: N\#98/41}

RIC \#: RI98:137

The above-named protocol, has been evaluated and approved by the H.S.C. Research Impact Committee.

If your study is receiving funds and H.S.C. Finance Division will be administering the moneys, please contact the H.S.C. Finance Department for a "Specific Purposes Account Application Form". It is imperative that you submit a copy of this letter along with your application 10: Supervisor, Ancillary Services, Finance Division, so she is aware this has been approved by the H.S.C. Research Department.

PLEASE NOTE: THIS SPECIFIC RESEARCH ACCOUNT NUMBER CAN ONLY BE USED FOR THIS PARTICULAR STUDY.

My sincere best wishes for much success in your study.

Sincerely,

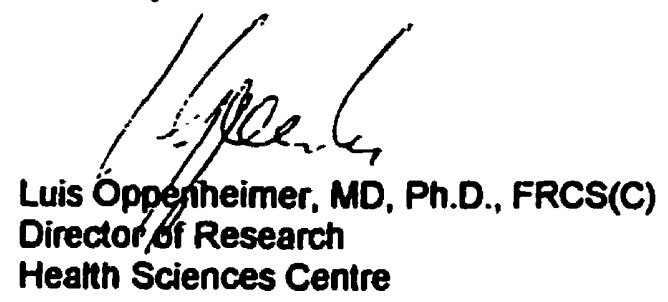

cc: Ms G. Dutchuk, Finance

Department Head 